\title{
Virtuous Victims
}

\author{
Jillian J. Jordan ${ }^{1 *}$, Maryam Kouchaki
}

Forthcoming, Science Advances

\author{
${ }^{1}$ Harvard Business School, Soldiers Field Road, Boston, MA 02163. \\ ${ }^{2}$ Kellogg School of Management, Northwestern University, 2211 Campus Dr, Evanston, IL \\ 60208.
}

*Corresponding author: Jillian J. Jordan

Email: jillianjordan@hbs.edu

\begin{abstract}
:
How do people perceive the moral character of victims? We find, across a range of transgressions, that people frequently see victims of wrongdoing as more moral than non-victims who have behaved identically. Across 17 experiments (total $n=9,676$ ), we document this Virtuous Victim effect and explore the mechanisms underlying it. We also find support for the Justice Restoration Hypothesis, which proposes that people see victims as moral because this perception serves to motivate punishment of perpetrators and helping of victims - and people frequently face incentives to enact or encourage these "justice-restorative" actions. Our results validate predictions of this hypothesis, and suggest that the Virtuous Victim effect does not merely reflect (i) that victims look good in contrast to perpetrators, (ii) that people are generally inclined to positively evaluate those who have suffered, or (iii) that people hold a genuine belief that victims tend to be people who behave morally.
\end{abstract}




\section{Introduction}

People ubiquitously encounter narratives about immoral acts and their victims. We are exposed to victim narratives in our personal and working lives, in the news, and in online and social media - and it has been proposed that victim narratives are in fact an increasingly prevalent staple of contemporary discourse $(1,2)$. How do these narratives influence our perceptions of victims?

The answer to this question has important societal implications. Perceptions of victims may shape the policy and legal responses that follow wrongdoing toward victims, the ways that victims are treated by members of their social networks, the decisions that victims make about whether to share their stories with others, and the ways that society frames and evaluates moral debates surrounding allegations of victimization.

Research from psychology provides some insight into the ways that people perceive victims of wrongdoing. Research on "victim blaming" has demonstrated that people sometimes see victims as to blame for causing their own victimization (3-6). Furthermore, a body of research on "moral typecasting" has provided evidence that people can see moral "patients" (i.e., the recipients of moral action), including victims, as less agentic and more passive (7-9). Here, we investigate a different question surrounding perceptions of victims. In particular, we ask: how do people perceive the moral character of victims?

Moral character is a predominant dimension on which people evaluate others, and plays an enormous role in shaping whom we form positive impressions of, choose to affiliate with, and behave prosocially towards (10-14). Furthermore, asking whether victims are seen as having good or bad moral character is theoretically distinct from asking whether victims are seen as passive (an attribution that is not morally valanced) or receive causal blame (given that it is theoretically possible, for example, to see a victim as morally good while also believing that they contributed, causally, to their victimization). Yet at first blush, it may seem strange to hypothesize that one's status as a victim might influence their perceived moral character. After all, both good and bad people can be mistreated: victims are defined as the recipients of bad treatment, not as actors who behave morally or immorally.

Indeed, previous research has established, unsurprisingly, that one's own moral action is a key determinant of perceived moral character: people who behave morally are seen as morally good, while people who behave immorally are seen as morally bad (12-15). We also know that other direct attributes of an individual — such as their social group membership (e.g., their race, nationality, religious identity, or political party) (16-20) or physical attractiveness $(21,22)$ - may influence their perceived moral character. In contrast, previous research does not provide much direct basis to expect an individual's perceived moral character to be shaped by the way they are treated by others - and in particular, their status as a victim of others' immoral action.

Yet in this paper, we provide evidence that victim narratives can meaningfully shape the perceived morality of victims. We find, across a range of moral transgressions, that people frequently see victims as having elevated moral character-not because of anything that they have done, but because others have mistreated them.

Here, we document this "Virtuous Victim effect" and explore the mechanisms underlying it. We investigate its robustness across potential boundary conditions-considering, for example, which narrative features give rise to the Virtuous Victim effect, and whether the effect is moderated by the victim's race or gender. We also ask whether the Virtuous Victim effect is specific to victims of immorality (or does it extend to victims of accidental misfortune?) and to moral virtue (or does it 
extend to positive but nonmoral traits?). And we investigate whether the effect extends beyond perceptions of victims' moral character to predictions about victims' moral behavior.

Our paper also evaluates several potential explanations for the Virtuous Victim effect. Ultimately, we find support for a proposal that we term the "Justice Restoration Hypothesis". According to the Justice Restoration Hypothesis, people see victims as moral because this perception serves to motivate punishment of perpetrators and helping of victims - and people frequently face incentives to enact or encourage these "justice-restorative" actions.

If you see the victim of a transgression as morally good, you might feel especially motivated to help her and to punish on her behalf. And there is reason to believe that these are often adaptive responses to wrongdoing (23-28). Punishment serves to deter future transgressions, and thus can be supported by processes like reciprocity (29), reputation (30-36), institutions $(37,38)$, and cultural group selection (39-42). For example, in the domain of reputation, punishment can serve as a signal of moral character $(29-32,36,43)$ or be supported by social norms $(34,35)$. Relative to punishment, there has been less research investigating the processes that incentivize victim compensation. However, the same mechanisms that encourage punishment (e.g., reciprocity, reputation) can also encourage prosocial helping (44). And there is some evidence that these mechanisms can encourage helping of victims specifically; for example, helping victims can confer even larger reputational benefits than punishing perpetrators (45-47). Thus, people might benefit from seeing victims as virtuous, insofar as this perception motivates them to punish perpetrators and/or help victims.

Furthermore, people sometimes face incentives not just to personally enact these justice-restorative actions, but also to encourage others to do the same. Groups often enact collective punishment of norm violators (48-50), because coordinating can reduce the costs of punishing (40). And when moral disputes occur, people stand to benefit from forming coalitions around their preferred side (51). Thus, when wrongdoing occurs, people may face incentives to persuade others that justice-restorative action is merited. And these incentives could provide another reason to elevate the morality of victims. If you see a victim as moral, you might be more persuasive at recruiting others to help her and/or punish the perpetrator who harmed her.

In sum, then, people frequently face incentives to enact or encourage justice-restorative action-and it may therefore be beneficial to see victims as virtuous. Moreover, a body of psychological research suggests that self-interest can color our moral judgements $(43,52-54)$. Thus, despite the fact that an individual's victim status merely reflects how they have been treated by others (and does not provide information about their own moral behavior), we hypothesize that incentives for justice-restorative action might cause people to see victims of wrongdoing as morally good.

As noted above, we also consider other potential explanations for the Virtuous Victim effect. First, victims might benefit from standing in narrative contrast to (morally bad) perpetrators (a "moral contrast effect" (7)). Second, people might feel sympathy for victims and therefore be inclined to evaluate them positively. And finally, people might see victims as moral because of a genuine (and perhaps accurate) evaluation that victims tend to be people who behave morally. For example, people might believe, based on their personal experiences, that people who behave morally are easier to exploit and thus more likely to be victimized, or that people who have been victimized are typically disinclined to do the same unto others. Yet our results ultimately validate predictions of the Justice Restoration Hypothesis and provide evidence against these alternatives. 
In this paper, we begin by documenting the Virtuous Victim effect and exploring its potential boundaries. Next, we provide support for the Justice Restoration Hypothesis. And finally, we provide evidence against the aforementioned alternative explanations - and, in doing so, further elucidate the effect's underlying mechanisms.

To these ends, we report analyses from 17 experiments (total $n=9,676$ ). In all experiments, subjects were recruited online via Amazon Turk, with the exception of one laboratory experiment. We individually pre-registered 15 of our experiments; for each of these experiments, we adhered to our pre-registered sample size and exclusion criteria. However, given our large number of experiments, we do not sequentially present results for each individual experiment. Rather, we structure our paper around a series of claims and support each claim by analyzing all relevant experiments (including by pooling data across experiments when many are relevant); this approach both facilitates brevity and allows us to provide statistical estimates that are less noisy and more precise. The analyses we report generally test the same questions as our primary pre-registered analyses, with some exceptions. See Table 1 for a design overview of each experiment, Supplementary Materials Sections 1 and 5 for more information about our samples and designs, and Supplementary Materials Section 3 for a discussion of pre-registered predictions.

\section{The Virtuous Victim effect}

\section{Results}

We begin by documenting the Virtuous Victim effect and exploring its potential boundaries. To do so, we present results from experiments in which subjects read narratives about target characters who were or were not victimized by others.

To start, we report results from experiments employing our "basic design" (Fig. 1). These experiments manipulated, between-subjects, whether subjects were assigned to a "neutral" or "victim" condition. In both conditions, we presented narratives containing identical information about a target character's behavior. However, in the victim condition, we also informed subjects that another character treated the target immorally. After reading their assigned narratives, subjects evaluated the target's moral character. Specifically, subjects rated the target's morality ("How moral of a person is [target]?") and trustworthiness ("How trustworthy of a person is [target]?") on 1-9 Likert scales ( $1=$ "Not at all", $3=$ "A little bit", 5 = "Moderately", $7=$ ="Quite a lot", $9=$ "Extremely"). Throughout this paper, we treat these questions as two measures of the same underlying construct (i.e., moral character).

In experiments featuring this basic design, subjects did not face or imagine facing any specific incentives to engage in justice-restorative action by punishing the perpetrator or helping the victim. However, we hypothesize that because people frequently face incentives for justice-restorative action in their lives outside of our experiments, they behave by default as if such incentives are present-and thus are inclined to elevate the moral character of victims.

We applied our basic design to six vignettes featuring six distinct moral transgressions. Below, for each vignette, we use linear regression to compare the neutral and victim conditions $(0=$ neutral, $1=$ victim) of all experiments featuring our basic design and the relevant vignette. (Some of these experiments also included other conditions, not included in these analyses; we note that when introducing each experiment for the first time and reporting its sample size, we report the full $n$ across all experimental conditions.) Throughout this paper, for all analyses that aggregate data across multiple experiments, we include experiment dummies in our models. We also note that for all results, we report both unstandardized coefficients $(b)$ with their standard errors, as well as standardized coefficients $(B)$. 
Our first vignette, which we applied our basic design to in Experiments $1(n=802), 2(n=207), 3(n=$ $803), 4(n=510)$, and $5(n=803)$ (all pre-registered), described the theft of an iPad. In both conditions, subjects learned that the target (e.g., "Sarah") was a college student, and had classmates over to study for an exam. While they were studying, one classmate (e.g., "Gabrielle") looked something up on Sarah's iPad. In the neutral condition, the vignette then ended; Sarah was thus a neutral target. In the victim condition, however, the vignette continued to explain that Gabrielle subsequently broke in and stole Sarah's iPad; Sarah was thus a victim.

Within the "basic design" conditions across Experiments 1-5, subjects who read that Sarah's iPad was stolen perceived Sarah as having elevated moral character. Specifically, relative to neutral targets, theft victims were seen as more moral, $b=.52[.39, .65], t=7.96, B=.18, p<.001$, and trustworthy, $b=.50$ $[.36, .63], t=7.26, B=.16, p<.001, n=1,917$. We also note that in Experiment 2, which (unlike all other experiments in this paper) was conducted in the physical laboratory with a university subject pool, we found a significant effect of victim status on morality, $b=.52[.19, .85], t=3.15, B=.21, p=$ .002 , but not trustworthiness, $b=.31[-.06, .68], t=1.64, B=.11, p=.102, n=207$.

Our second vignette, which we applied our basic design to in Experiment 6 ( $n=802$; pre-registered), described the theft of an idea. In both conditions, the target worked at an advertising agency and had a good idea for a slogan. In the victim condition only, the target's manager took undue credit for this idea. Within the "basic design" conditions of Experiment 6, relative to neutral targets, idea theft victims were seen as more moral, $b=.40[.13, .66], t=2.93, B=.14, p=.004$, and trustworthy, $b=.48$ $[.22, .75], t=3.58, B=.18, p<.001, n=403$.

Our third vignette, which we applied our basic design to in Experiment 7 ( $n=401$, pre-registered), described a corrupt doctor. In both conditions, the target discussed a medical condition with a doctor. In the victim condition only, in order to profit, the doctor recommended a drug that he anticipated would (and ultimately did) have adverse effects. Additionally, we used our corrupt doctor vignette to investigate whether the Virtuous Victim effect can occur even when subjects have relatively rich background information about the target. Thus, our corrupt doctor vignette (i) described the target's occupation, marital status, political affiliation, religious background, and hobbies, and (ii) provided information relevant to the target's moral character (e.g., subjects read that the target can "be a bit selffocused" and "get defensive when criticized", but also "usually comes through when you need a favor"). Relative to neutral targets, victims of the corrupt doctor were seen as significantly more moral, $b=.30[.02, .59], t=2.12, B=.11, p=.034$, although not significantly more trustworthy, $b=.20[-.06$, .46], $t=1.49, B=.07, p=.138, n=401$.

Our fourth vignette described a verbal attack. We applied our basic design to this vignette in Experiment 4 (in which all subjects evaluated three distinct vignettes). In both conditions, the target attended a party and was approached by a classmate who brought up the fact that he was a gun owner. In the victim condition only, the classmate aggressively verbally attacked the target for his gun ownership. Relative to neutral targets, verbal attack victims were seen as more moral, $b=.52[.26$, .79], $t=3.86, B=.17, p<.001$, and trustworthy, $b=.47[.19, .76], t=3.32, B=.15, p=.001, n=510$.

Our fifth vignette, which we likewise applied our basic design to in Experiment 4, described sexual aggression. In both conditions, the target, a college student, attended a party, began engaging sexually with a man, and then asked him to stop. In the victim condition only, the man nonetheless continued making advances. The vignette did not specify, however, the specific nature of these further advances or whether a sexual assault occurred. We did not find a significant Virtuous Victim effect for this 
vignette. Relative to neutral targets, victims were not seen as significantly more moral, $b=.19$ [-.13, $.51], t=1.16, B=.05, p=.245$, or trustworthy, $b=.18[-.13, .48], t=1.14, B=.05, p=.256, n=510$.

Our final vignette, which we applied our basic design to in Experiment 8 ( $n=437$; pre-registered), described rape. In both conditions, the target was walking home from the grocery store when a male acquaintance offered to help carry her groceries inside, and she accepted. In the victim condition only, once in the target's apartment, this man locked the door and then raped the target, covering her mouth and threatening her when she tried to scream. The victim condition of this vignette was sourced from Niemi \& Young, 2016 (5), and we adapted the vignette to create a neutral condition. We found a strong Virtuous Victim effect for this vignette. Relative to neutral targets, victims were seen as significantly more moral, $b=.99[.71,1.27], t=6.98, B=.32, p<.001$, and trustworthy, $b=1.10[.82$, $1.38], t=7.64, B=.34, p<.001, n=437$.

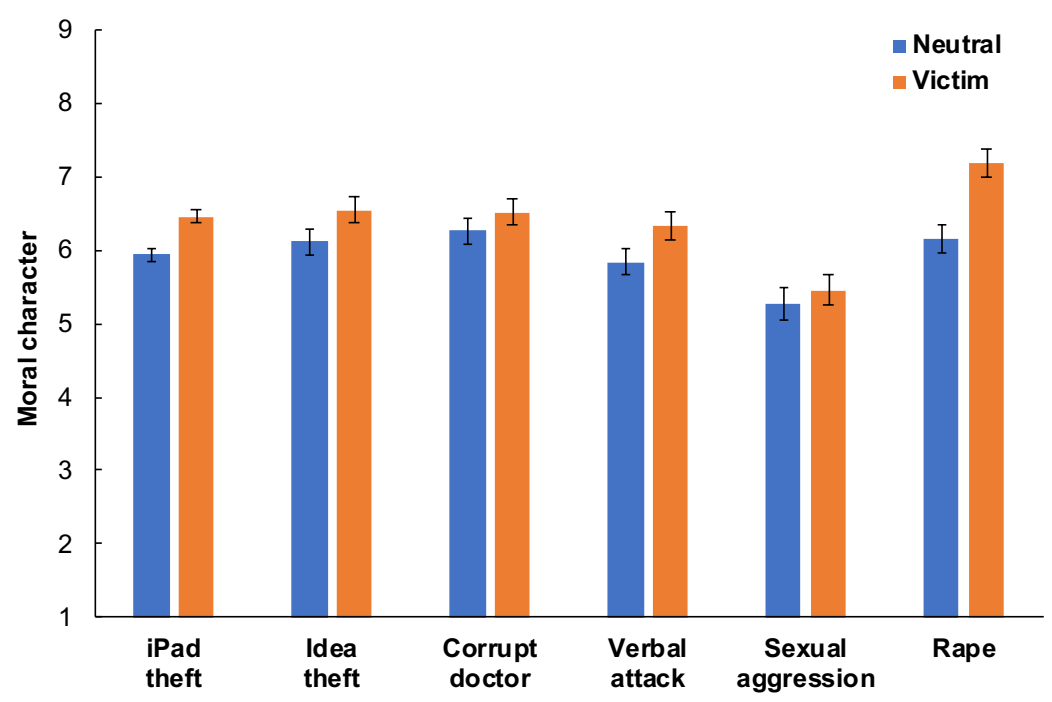

Fig. 1. The Virtuous Victim effect across vignettes. We plot the effect of our victim manipulation on ratings of moral character (computed by averaging ratings of morality and trustworthiness) in experiments employing our "basic design" for our iPad (Experiments 1-5; $n=1,917$ ), idea theft (Experiment 6; $n=403$ ), corrupt doctor (Experiment 7; $n=401$ ), verbal attack (Experiment 4; $n=$ 510), sexual aggression (Experiment $4 ; n=510$ ), and rape (Experiment $8, n=437$ ) vignettes. We find evidence that victims are seen as more virtuous than neutral targets (who took the same actions as victims, but were not mistreated). Error bars are 95\% CIs.

Thus, in five of our six vignettes, subjects saw victims as more moral than non-victims who behaved identically. We therefore find evidence that victims can be seen as virtuous - not because of actions that they have taken, but simply because others have wronged them.

But does this Virtuous Victim effect reflect an inference about actions that victims have not taken? In particular, might the effect reflect that subjects are impressed that the victims in our vignettes are not described as lashing out at the perpetrators who wronged them? Importantly, this explanation struggles to account for the Virtuous Victim effect in (i) our iPad theft vignette (in which the perpetrator is not present when the victim discovers that their iPad is missing, (ii) our corrupt doctor vignette (in which the victim never learns that the doctor was corrupt), and (iii) our rape vignette (in which the victim tries to resist her attacker but is physically overpowered). 
We also note that when aggregating across all of our "basic design" experiments (i.e., all data included in Fig. 1), we very robustly find a positive effect of victim status on both perceived morality, $b=.50$ $[.39, .60], t=9.50, B=.16, p<.001$, and trustworthiness, $b=.49[.39, .59], t=9.28, B=.15, p<.001$ ( $n=4,178$ observations across 3,158 unique subjects; standard errors are clustered to account for repeated measures across some subjects). Furthermore, in Supplementary Materials Section 2.1, we report and plot the Virtuous Victim effect (i.e., the comparison of our neutral and standard victim conditions) within each individual experiment in this paper that featured these conditions, and overall in aggregate analyses (see Table S3 and Fig. S1). We report effects for our morality and trustworthiness dependent variables, and also evaluate, for each experiment and in aggregate analyses, whether the magnitude of the effect differed across these two dependent variables. These analyses suggest that the Virtuous Victim effect is robust, and comparable in magnitude, for both morality and trustworthiness.

Next, we turn to exploring a few potential boundaries of the Virtuous Victim effect.

\section{Which narrative features give rise to the Virtuous Victim effect?}

First, we shine the spotlight on two interesting features of the victim narratives featured in our "basic design" experiments. In these experiments, subjects always read victim narratives that (i) described the perpetrator of the transgression and (ii) were presented in third person (by a presumptively objective narrator). Are these narrative features necessary to produce the Virtuous Victim effect?

Experiment 1 investigated whether the Virtuous Victim effect relies on narrative detail about the perpetrator. To this end, in Experiment 1 (which featured our iPad theft vignette), we included an additional condition in which subjects learned that the target's iPad was stolen, but not who stole it or how the theft occurred. Relative to the neutral condition, subjects in this "minimal victim narrative" condition (which is not included in our above analyses or Fig. 1) saw the target as significantly more moral, $b=.37[.10, .63], t=2.71, B=.13, p=.007$, but not significantly more trustworthy, $b=.09[-$ $.17, .36], t=.67, B=.03, p=.500, n=403$. Furthermore, relative to minimal narrative victims, standard "full narrative" victims were seen as more moral, $b=.38[.11, .66], t=2.72, B=.14, p=$ .007 , and trustworthy, $b=.52[.21, .82], t=3.35, B=.17, p=.001, n=398$. Thus, we find some evidence that the Virtuous Victim effect may occur in the absence of information about the perpetrator-but such detail seems to enhance the effect.

Experiments 5 and 6 investigated whether the Virtuous Victim effect extends to first-person narratives. To this end, we crossed our victim manipulation with a third- vs. first-person manipulation, both in Experiment 5 (using our iPad vignette) and Experiment 6 (using our idea theft vignette). The firstperson conditions of these experiments (which, unlike the third-person conditions, are not included in our above "basic design" analyses or Fig. 1) presented the same information as the third-person conditions, but in the form of the target speaking in first person to a friend. Interestingly, within the first-person conditions, we observed a significant Virtuous Victim effect for our idea theft vignette, but not our iPad theft vignette (whereas the third-person conditions produced a significant effect for both vignettes). For full results, see Supplementary Materials Section 2.3.

Thus, victims who share their stories can be seen as morally virtuous - but they are not always. We also note that in our iPad theft (but not idea theft) vignette, the victim was not present when the theft occurred - which may have caused subjects to question the credulity of her first-person narrative. As such, our results might reflect that first-person narratives are less likely to inspire the Virtuous Victim effect when there is more room to doubt them. 
Together, these analyses suggest that the Virtuous Victim effect may be especially likely to flow from victim narratives that describe a transgression's perpetrator, and are presented by a third-person narrator (or perhaps, more generally, a narrator who is unlikely to be doubted).

\section{Is the Virtuous Victim effect moderated by target race or gender?}

Next, we investigate whether the Virtuous Victim effect is moderated by target race and/or gender. To this end, in Experiment 9 ( $n=904$, pre-registered) we manipulated victim status via our iPad theft vignette, but modified our basic design by providing a photograph of the target in all conditions. We used these photographs, selected from the Chicago Face Database (55) to manipulate target race (in particular, by contrasting White vs. Black targets) and gender.

Using effect coding for each of our three independent variables, we predicted target morality as a function of victim status $(-.5=$ neutral, $.5=$ victim $)$, target race $(-.5=$ White, $.5=$ Black $)$, target gender $(-.5=$ male, $.5=$ female $)$, all two-way interactions, and the three-way interaction. We found a main effect of victim status $(b=.44[.25, .64], t=4.45, B=.15, p<.001)$, and no significant interaction between victim status and target race $(b=.14[-.25, .53], t=.72, B=.02, p=.475)$, victim status and target gender $(b=-.06[-.45, .33], t=-.29, B=-.01, p=.774)$, or victim status, target race, and target gender $(b=-.47[-1.25, .30], t=-1.20, B=-.04, p=.232)$. Similarly, when using this same approach to predict trustworthiness, we found a main effect of victim status $(b=.43[.23, .63], t=4.20, B=.14, p$ $<.001)$ that did not significantly interact with race $(b=.30[-.10, .70], t=1.47, B=.05, p=.143)$, gender $(b=.11[-.30, .51], t=.52, B=.02, p=.604)$, or race and gender $(b=-.48[-1.28, .33], t=-1.17$, $B=-.04, p=.243), n=904$. See Supplementary Materials Section 2.5 for more information about Experiment 9, including further analyses of the results and norming data for the selected photographs.

We also note that our broader set of experiments bolsters the claim that the Virtuous Victim effect is not moderated by target gender. Experiment 9 was our only experiment to manipulate target gender via a photograph. However, we manipulated target gender by varying the target's name and pronouns across a much larger set of experiments. In particular, Experiments 1-7, 9 and 13-15 all both manipulated victim status and manipulated target gender in this way (although note that Experiment 4 specifically manipulated gender in the iPad theft but not verbal attack or sexual aggression vignettes). In an aggregate analysis of these experiments (effect coding our independent variables as described above), we find a significant Virtuous Victim effect that is not significantly moderated by target gender, both when predicting morality (main effect: $b=.39[.31, .47], t=9.41, B=.13, p<.001$; gender interaction: $b=-.10[-.26, .06], t=-1.23, B=-.02, p=.219$ ) and trustworthiness (main effect: $b$ $=.42[.33, .50], t=9.75, B=.14, p<.001$; gender interaction: $b=-.01[-.18, .16], t=-.09, B=-.001, p$ $=.927), n=4,829$. For more information about the experimental conditions included in this analysis, see Supplementary Materials Section 2.6.

Thus, we find no evidence that the Virtuous Victim effect is moderated by target gender or White versus Black race. Of course, the lack of evidence for moderation is not definitive evidence of absence. The confidence intervals on the coefficients reported above reveal the upper bounds of interaction effects that are plausible in light of our results, and highlight that our null interaction effects are more precisely estimated in the context of our aggregate gender analysis (which draws on eleven different experiments) than Experiment 9. We do note, however, that we find evidence that the Virtuous Victim effect can hold for both Black and White victims, and for both male and female victims.

In particular, when evaluating the Virtuous Victim effect within each race group in Experiment 9 (while controlling for target gender), we find significant effects among Black targets (morality $b=.51$ $[.24, .78], t=3.74, B=.17, p<.001$; trustworthiness $b=.58[.30, .86], t=4.10, B=.19, p<.001 ; n=$ 
460). Among White targets, we find a significant effect on morality $(b=.37[.09, .65], t=2.60, B=$ $.12, p=.010)$, and a marginally significant effect on trustworthiness $(b=.28[-.01, .57], t=1.92, B=$ $.09, p=.056 ; n=444)$. Additionally, when evaluating the Virtuous Victim effect within each gender group in Experiment 9 (while controlling for target race), we find significant effects among female targets (morality $b=.41[.14, .68], t=2.99, B=.14, p=.003$; trustworthiness $b=.48[.22, .75], t=$ $3.56, B=.17, p<.001 ; n=449$ ), and among male targets (morality $b=.48[.20, .76], t=3.35, B=.16$, $p=.001$; trustworthiness $b=.39[.09, .69], t=2.54, p=.011 ; n=455)$. And finally, when drawing on the data from our aggregate gender analysis, we find significant effects among female targets (morality $b=.34[.23, .46], t=5.81, B=.12, p<.001$; trustworthiness $b=.42[.30, .54], t=6.85, B=.14, p<$ $.001 ; n=2,361$ ), and among male targets (morality $b=.45[.33, .56], t=7.67, B=.15, p<.001$; trustworthiness $b=.42[.30, .54], t=6.98, B=.14, p<.001 ; n=2,468)$.

In sum, our results suggest are consistent with the hypothesis that the Virtuous Victim effect can hold regardless of victim gender or (White vs. Black) race.

\section{Support for the Justice Restoration Hypothesis}

Next, we turn to evaluating potential explanations for this Virtuous Victim effect. We begin by considering our proposed Justice Restoration Hypothesis, which argues that people see victims as morally virtuous because (i) people typically face incentives for justice-restorative action, and (ii) seeing victims as virtuous serves to motivate people to help victims and punish perpetrators.

To preview our results, we find two important pieces of support for this hypothesis. First, we find that seeing victims as virtuous does, in fact, motivate people to help victims and punish perpetrators, as assumed by the Justice Restoration Hypothesis. And second, we find that introducing disincentives to help victims and punish perpetrators eliminates the Virtuous Victim effect, as predicted by the Justice Restoration Hypothesis.

\section{Seeing victims as virtuous motivates justice-restorative action}

To evaluate the Justice Restoration Hypothesis, we begin by testing its key assumption: that seeing victims as virtuous motivates justice-restorative action. To this end, in Experiment 10 ( $n=598$, preregistered), we investigated whether describing victims as morally good motivates people to help them, and to punish the perpetrators who have harmed them. Consistent with this prediction, a recent paper showed that people are more willing to help victims who are described as virtuous - and that such victims are seen as more deserving of help (56). Experiment 10 serves to bolster this evidence, and show that virtuous victims can also motivate punishment of perpetrators.

In Experiment 10, we assigned all subjects to the victim condition of our idea theft vignette (in which the target's idea is stolen). However, before presenting the idea theft vignette, we provided subjects with background information about the target. We used this information to manipulate the target's morality, describing her as more morally good (e.g., as more likely to donate money, volunteer, and behave prosocially towards friends and family) in the "moral" condition than the "control" condition. After reading this information, subjects learned that the target's idea was stolen and then rated, on a series of 1-9 Likert scales, their willingness to punish the perpetrator and help the target (as well as the target's morality, as a manipulation check).

Comparing the control and moral conditions $(0=$ control, $1=$ moral $)$, we find that subjects in the moral condition perceived the target as more moral, $b=3.55[3.30,3.80], t=27.80, B=.81, p<.001$. And, critically, they were more willing to help her, $b=3.02[2.70,3.34], t=18.46, B=.68, p<.001$, and to punish on her behalf, $b=.56[.19, .93], t=2.99, B=.15, p=.003, n=401$ (Fig. 2). We thus find 
evidence, consistent with previous research (56), that seeing victims as virtuous serves to motivate justice-restorative action — as assumed by the Justice Restoration Hypothesis.

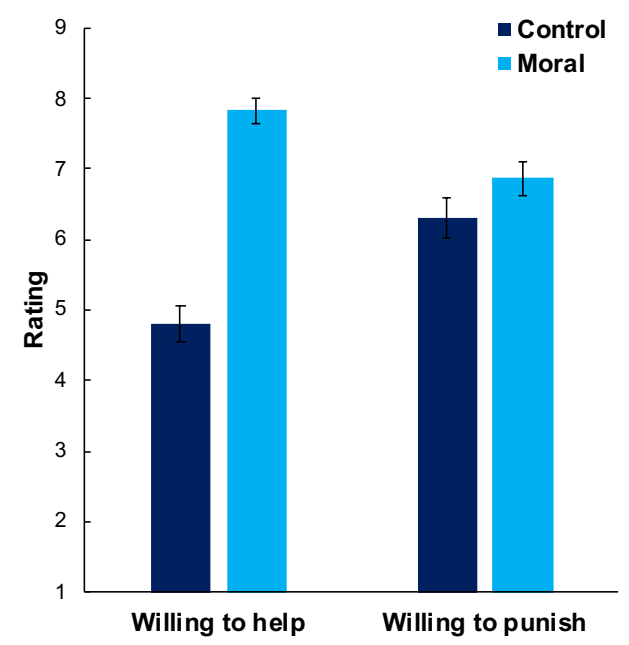

Fig. 2. Seeing victims as virtuous motivates justice-restorative action. We plot the effect of our victim morality manipulation on ratings of willingness to help and punish in Experiment $10(n=401)$. When the victim is described as morally virtuous, subjects are more willing to help her, and to punish the perpetrator who harmed her. Error bars are 95\% CIs.

We also note that Experiment 10 included a third condition, in which we described the target as particularly competent (rather than moral). Relative to the control, subjects in this "competent" condition were more willing to help the target, but no more willing to punish the perpetrator. Furthermore, they were less willing than subjects in the "moral" condition both to help and to punish. Thus, we find some evidence that describing victims as morally virtuous may be especially effective at motivating justice-restorative action. However, this evidence is merely suggestive, because our morality manipulation was (unexpectedly) stronger than our competence manipulation (i.e., it had a larger effect on perceived morality than the competence manipulation had on perceived competence); see Supplementary Materials Section 2.7 for more detail.

In sum, Experiment 10 reveals that seeing victims as virtuous motivates justice-restorative action. But is motivating justice-restorative action actually the function of the Virtuous Victim effect, as proposed by the Justice Restoration Hypothesis? In other words, do people see victims as moral because this perception bolsters motivation to help victims and punish perpetrators? If so, then introducing disincentives for justice-restorative action - such that bolstering these motivations is no longer adaptive - should eliminate the Virtuous Victim effect. We next turn to evaluating this prediction.

\section{Introducing disincentives for justice-restorative action eliminates the Virtuous Victim effect}

In Experiment 11a ( $n=801$, pre-registered), we investigate whether introducing disincentives to punish perpetrators and help victims causes the Virtuous Victim effect to disappear (Fig. 3). To this end, Experiment 11a crossed our standard victim manipulation with a manipulation of disincentives (versus incentives) for justice-restorative action.

Before presenting our idea theft vignette, we asked subjects to imagine working for an advertising agency where ideas are brainstormed in teams, creating the potential for idea theft. In the "incentives" condition, we also asked subject to imagine (i) believing that idea theft occurs frequently and (ii) 
having therefore been a vocal critic of the brainstorming system at work. In contrast, in the "disincentives" condition, we asked subjects to imagine (i) believing that idea theft, while unjust, happens rarely - and that the brainstorming system is otherwise very effective and (ii) having therefore been a vocal defender of the brainstorming system.

In this way, we attempted to manipulate whether subjects, in the scenario they imagined, would face incentives versus disincentives to respond to idea theft with justice-restorative action. We reasoned that engaging in justice-restorative action (i.e., punishing perpetrators and helping victims of idea theft) would call attention to the problem of idea theft - potentially reducing support for the brainstorming system at work. And critically, this outcome was described as consistent with subjects' imagined goals in the "incentives" condition, but inconsistent with subjects' imagined goals in the "disincentives" condition. Furthermore, we reasoned that in the "incentives" condition, calling attention to idea theft would validate subjects' imagined public stance (that idea theft was common and the brainstorming system was bad), conferring reputational benefits. In contrast, in the "disincentives condition", calling attention to idea theft would undermine subjects' imagined public stance (that idea theft was rare and the brainstorming system was good), conferring reputational costs. For these reasons, we anticipated that our "disincentives" condition would convey to subjects that, in the imagined scenario, engaging in justice-restorative action would carry meaningful disadvantages - offsetting the incentives for justicerestorative action that subjects might otherwise face.

After presenting this disincentives manipulation, we presented our idea theft vignette, manipulating whether or not the target character became a victim of idea theft, and then asked subjects to rate the target's moral character. We found a significant negative interaction between disincentives $(0=$ "incentives", $1=$ "disincentives") and victim status $(0=$ neutral, $1=$ victim $)$ on morality, $b=-.74[-$ $1.20,-.29], t=-3.20, B=-.20, p=.001$, and trustworthiness, $b=-.73[-1.18,-.27], t=-3.15, B=-.19, p$ $=.002, n=801$. In the "incentives" condition, victims were rated as more moral, $b=.58[.27, .88], t=$ $3.71, B=.18, p<.001$, and trustworthy, $b=.69[.38,1.00], t=4.39, B=.21, p<.001, n=405$, than neutral targets. In contrast, in the "disincentives" condition, there was no significant victim effect on morality, $b=-.17[-.51, .17], t=-.97, B=-.05, p=.334$, or trustworthiness, $b=-.04[-.38, .29], t=$ $.25, B=-.01, p=.807, n=396$.

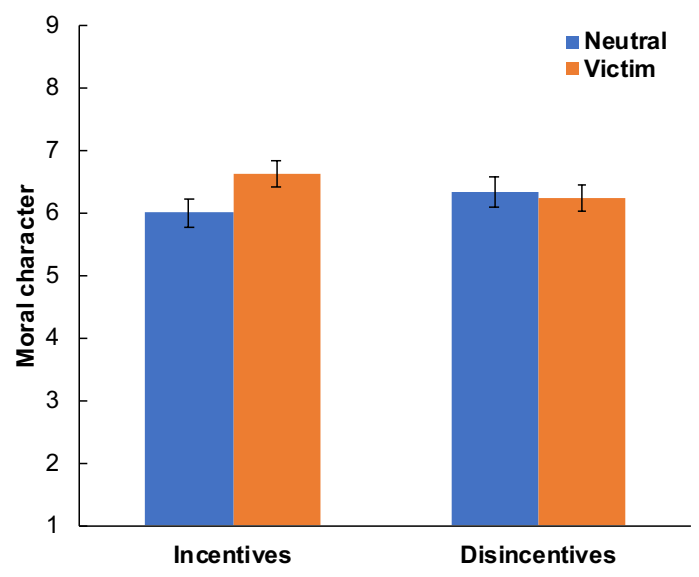

Fig. 3. Introducing disincentives for justice-restorative action eliminates the Virtuous Victim effect. We plot ratings of moral character (computed by averaging ratings of morality and trustworthiness) as a function of our disincentives manipulation and victim status in Experiment $11 \mathrm{a}(n$ $=801$ ). We find that when subjects imagine facing disincentives to punish perpetrators and help victims, the Virtuous Victim effect disappears. Error bars are 95\% CIs. 
Thus, the "incentives" condition of Experiment 11a replicated the Virtuous Victim effect that we typically observe in experiments without an incentives manipulation. In contrast, the "disincentives" condition of Experiment 11a caused the Virtuous Victim effect to disappear. These results are consistent with the hypothesis that people typically face incentives for justice-restorative action, and thus behave by default as if such incentives are present. Aligning with this proposal, the Virtuous Victim effect occurs in experiments with no incentives manipulation, and when subjects imagine facing concrete and specific incentives for justice-restorative action (in the "incentives" condition of Experiment 11a). However, when subjects imagine facing concrete and specific disincentives to engage in justice-restorative action (in the "disincentives" condition of Experiment 11a), they cease to elevate victims.

But did our disincentives manipulation actually influence perceived incentives for justice-restorative action? Or might the "disincentives" condition have eliminated the Virtuous Victim effect for an unrelated reason? In particular, subjects in the "disincentives" condition were asked to imagine believing that idea theft, while unjust, is rare-which could conceivably have prevented them from seeing the target of idea theft as a true victim.

To investigate, we conducted Experiment $11 \mathrm{~b}(n=399$, not pre-registered), which served as a post-hoc manipulation check for Experiment 11a. (For a discussion of secondary variables collected in Experiment 11a that can also speak to the consequences of our disincentives manipulation, see Supplementary Materials Section 4.1.2). We designed Experiment $11 \mathrm{~b}$ to achieve two key aims. First, we sought to confirm that subjects actually perceive weaker incentives for justice-restorative action in the scenario described by our "disincentives" (vs. "incentives") condition. And second, we sought to confirm that taking on the perspective described by our "disincentives" condition does not prevent people from seeing idea theft as a genuine transgression that creates genuine victims.

To achieve our first aim, we assigned subjects in Experiment $11 \mathrm{~b}$ to evaluate, from an objective thirdparty perspective, the incentives that subjects in Experiment 11a imagined facing. Subjects in Experiment $11 \mathrm{~b}$ thus read about a person named James, who opposed (in the "incentives" condition) or supported (in the "disincentives" condition) the brainstorming system. Critically, we described James and his perspective using the same language that we used in Experiment 11a to describe subjects' imagined perspectives. Then, all subjects in Experiment $11 \mathrm{~b}$ (i) read the victim version of our idea theft vignette (in which theft occurs) and (ii) rated James' incentives to punish the perpetrator and help the victim. Specifically, subjects rated, on 1-9 Likert scales, the extent to which these actions would each "help James to achieve his goals" and "be in James' self interest" ( 1 = "It would strongly [hurt his goals/be against his interests]", 5 = "It would be neutral", 9 = "It would strongly [help his goals/be in his interests]"). For each action, we averaged these two questions together to form a composite measure of perceived incentives.

To achieve our second aim, we asked subjects to take James' perspective (in particular, by imagining that idea theft occurs either frequently or rarely) and then investigated whether subjects saw the target of idea theft as a victim. Subjects answered the question "To what extent do you think [target] is a victim of wrongdoing?" ( $1=$ "[Target] is not at all a victim", $5=$ "[Target] is somewhat a victim", $9=$ "[Target] is very much a victim").

We found that, in absolute terms, subjects in the "incentives" condition both clearly saw the target as a victim $(M=8.29, S D=1.25)$, and clearly saw James as facing positive incentives to help the victim $(M$ $=6.67, S D=1.75)$ and punish the perpetrator $(M=6.64, S D=1.55)$. In contrast, subjects in the 
"disincentives" condition also clearly saw the target as a victim $(M=8.04, S D=1.49)$, but did not see James as facing strong incentives to help $(M=5.81, S D=1.98)$ or punish $(M=4.99, S D=2.17)$. Comparing the two conditions $(0=$ "incentives", $1=$ "disincentives"), we find robust differences for incentives to help, $b=-.86[-1.23,-.49], t=-4.55, B=-.22, p<.001$, and to punish, $b=-1.65[-2.03$, 1.27], $t=-8.59, B=-.40, p<.001$, as well as a marginally significant difference for victim ratings, $b=$ $-.25[-.53, .02], t=-1.81, B=-.09, p=.071, n=399$.

We thus find evidence that our "disincentives" condition meaningfully weakens perceived incentives for justice-restorative action, as intended. Furthermore, it does not prevent subjects from seeing the target of idea theft as a victim: victim ratings were very high in both conditions of Experiment $11 \mathrm{~b}$, despite the marginal difference between them. Together, these results suggest that the "disincentives" condition really did eliminate the Virtuous Victim effect by reducing incentives for justice-restorative action - and not simply by preventing subjects from seeing idea theft as a genuine transgression that creates genuine victims.

Therefore, Experiment 11 supports a key prediction of the Justice Restoration Hypothesis: introducing disincentives for justice-restorative action causes the Virtuous Victim effect to disappear. Alternative explanations for the Virtuous Victim effect struggle to parsimoniously explain this finding. If the Virtuous Victim effect merely reflected that (i) victims stand in positive contrast to perpetrators, (ii) people feel sympathy for victims and are therefore inclined to evaluate them positively, (iii) people hold a genuine belief that victims tend to behave morally, or (iv) people are impressed that the victims in our vignettes do not lash out at their perpetrators, one would expect the effect to persist in our "disincentives" condition.

Finally, Experiment 11 also provides evidence that the Virtuous Victim effect does not merely reflect a shallow attempt by subjects to communicate their disapproval of the perpetrator. In Experiment 11a, before subjects evaluated the target's morality, they evaluated the morality of her manager (who, in the victim conditions, stole her idea). Thus, subjects in the victim conditions had a direct opportunity to express disapproval of the perpetrator before evaluating the victim — and yet the "incentives" condition still produced a significant Virtuous Victim effect.

\section{Evidence against alternative explanations}

Together, Experiments 10-11 support the Justice Restoration Hypothesis and challenge other hypotheses. In the final section of our results, we build on these findings by more directly testing three alternative explanations for the Virtuous Victim effect. And in doing so, we both find evidence against these alternatives and further elucidate the effect's underlying mechanisms.

To preview our results, we find that the Virtuous Victim effect (i) does not extend to all parties who stand in contrast to the perpetrator (suggesting that it is not merely a contrast effect), (ii) is specific to victims of immorality and to moral virtue (suggesting that it does not merely reflect a general inclination to positively evaluate anybody who has suffered), and (iii) holds for perceptions of moral character, but not predictions of moral behavior (suggesting that it does not merely reflect a genuine belief about the typical conduct of victims).

\section{The Virtuous Victim effect is not merely a contrast effect}

First, we more directly test the hypothesis that the Virtuous Victim effect merely reflects a contrast effect, whereby victims look good because they stand in contrast to perpetrators. According to this hypothesis, we should expect reading about a transgression to make all non-perpetrator parties look 
equally good - even if they are not victims. Yet we find evidence that after subjects read about wrongdoing, they see victims as more moral than non-victim parties.

Experiment 1 contrasted our standard iPad victim condition (in which Gabrielle stole Sarah's iPad) with an "other victim" condition (in which Gabrielle, after using Sarah's iPad to study, stole an iPad from somebody else named Rachel). Subjects then always evaluated Sarah's moral character. In both the standard and other victim conditions, subjects could contrast Sarah to Gabrielle, but only in the standard victim condition was Sarah a victim. Comparing these conditions $(0=$ other victim, $1=$ standard victim), we find that subjects in the standard victim condition rated Sarah as marginally significantly more moral, $b=.31[-.03, .64], t=1.81, B=.09, p=.071$, but not significantly more trustworthy, $b=.28[-.07, .63], t=1.55, B=.08, p=.121, n=399$.

These results provide suggestive evidence, but are equivocal. However, while Sarah was not victimized in the "other victim" condition of Experiment 1, because Gabrielle borrowed her iPad before stealing Rachel's iPad, subjects may have seen Sarah as a potential victim. To avoid this perception, in Experiment 12 ( $n=602$, pre-registered) we modified the "other victim" condition such that, after borrowing Sarah's iPad, Gabrielle stole something else from Rachel (specifically, her valuable box of jewelry). (Experiment 12 also differed from Experiment 1 by including a hypothetical economic game with the target, discussed further below.) In Experiment 12, we found that relative to the other victim condition (in which Gabrielle stole Rachel's jewelry), subjects in the standard victim condition (in which Gabrielle stole Sarah's iPad) rated Sarah as significantly more moral, $b=.43[.13$, $.73], t=2.82, B=.14, p=.005$, and trustworthy, $b=.48[.16, .80], t=2.96, B=.15, p=.003, n=402$.

Together, Experiments 1 and 12 provide evidence that after subjects read about a transgression, they see the victim as more moral than other parties - suggesting that the Virtuous Victim effect does not merely reflect a contrast effect.

\section{The Virtuous Victim effect is specific to morality, suggesting that it is not merely a simple sympathy effect}

Next, we consider the hypothesis that the Virtuous Victim effect merely reflects that subjects feel sympathy for victims, and are thus driven to evaluate them positively. According to this hypothesis, we should expect the Virtuous Victim effect to be quite general: it should extend to all sorts of positive traits, and apply to anybody who has suffered. Yet we instead find that the Virtuous Victim effect is specific to victims of moral transgressions (i.e., it does not extend to victims of accidental misfortune) and to moral virtue (i.e., it does not extend equally to positive but nonmoral traits) (Fig. 4).

Supporting these claims, in Experiment 3 we included our standard victim condition (in which the target's iPad was stolen) and neutral condition (in which nothing happened to the iPad). We also included two accident conditions, in which the target's iPad was accidentally knocked off a shelf and destroyed (either due to an earthquake or a stray cat). Furthermore, in addition to rating target morality and trustworthiness, subjects also rated how intelligent, athletic, sociable, and funny the target was. Thus, we measured four positive but nonmoral traits. 


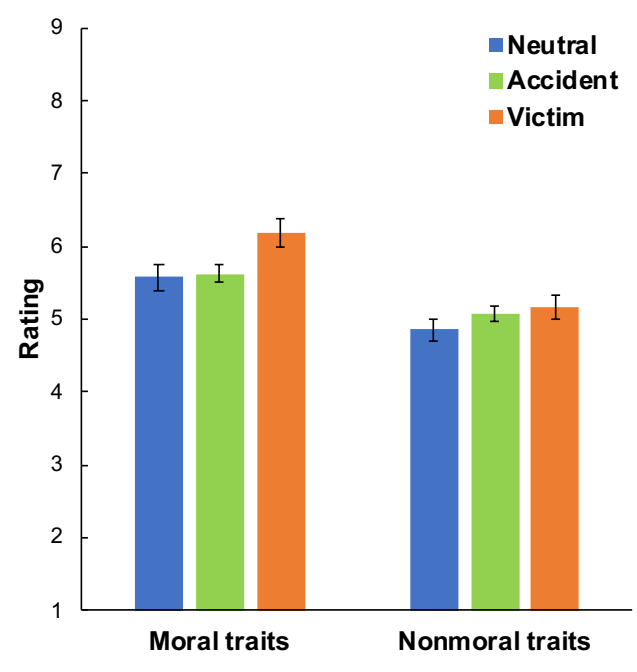

Fig. 4. The Virtuous Victim effect is specific to victims of immorality and to moral virtue. We plot average ratings of moral (morality and trustworthiness) and nonmoral (intelligence, athleticism, sociability, and funniness) traits in the neutral, accident (combined earthquake and cat), and victim conditions in Experiment $3(n=803)$. We find that both victims of immorality and accidental misfortune are seen slightly more positively than neutral targets in the context of nonmoral traits. But victims of immorality are seen even more positively in the context of moral traits, while accident victims are seen as no more moral than neutral. Error bars are 95\% CIs.

The results of Experiment 3 suggest that victims of immorality receive a selective boost on moral traits. Comparing victims of immorality to neutral targets $(0=$ neutral, $1=$ immorality victim; $n=400)$, we find that victims are seen more positively on both nonmoral traits $(b=.32[.11, .53], t=3.00, B=$ $.15, p=.003)$ and moral traits $(b=.61[.35, .87], t=4.65, B=.23, p<.001)$, but the contrast is significantly more positive for moral traits, $F(1,1998)=4.91, p=.027$. (Interactions between victim status and trait type computed using mixed-model ANOVAs; see Supplementary Materials Section 1.3 for details.) In contrast, comparing accident victims to neutral targets $(0=$ neutral, $1=$ accident victim; $n=605)$, we find that accident victims are seen more positively on nonmoral traits $(b=.24[.06, .41], t$ $=2.56, B=.11, p=.008)$ but not moral traits $(b=.05[-.16, .26], t=.46, B=.02, p=.646)$, such that the contrast is marginally significantly more positive for nonmoral traits, $F(1,3023)=2.97, p=.085$. And finally, comparing victims of immorality to accident victims $(0=$ accident victim, $1=$ immorality victim; $n=601$ ), we find that victims of immorality are not seen significantly more positively on nonmoral traits $(b=.08[-.10, .26], t=0.89, B=.04, p=.376)$, but are seen more positively on moral traits $(b=.56[.35, .77], t=5.19, B=.21, p<.001)$, such that the contrast is significantly more positive for moral traits, $F(1,3003)=19.70, p<.001$. We note that these analyses aggregate across our two accident conditions, as well as our sets of moral and nonmoral traits; see Supplementary Materials Section 2.2 for more fine-grained analyses, which support the same conclusions.

Thus, subjects in Experiment 3 saw victims of immorality, but not victims of accidents, as especially morally virtuous. Other experiments also corroborate these patterns. First, Experiment 13 ( $n=602$, pre-registered) also provides evidence that victims of immorality are seen as more moral than accident victims. Experiment 13 included our standard iPad theft victim condition and our earthquake condition, and measured moral (but not nonmoral) traits. Relative to earthquake victims, theft victims were seen as marginally significantly more moral, $b=.25[-.03, .54], t=1.75, B=.09, p=.081$, and significantly more trustworthy, $b=.51[.20, .81], t=3.28, B=.16, p=.001, n=403$. 
Second, several experiments find that victims of immorality receive a larger boost on moral than nonmoral traits. In addition to Experiment 3, Experiments 5-7 all employed our basic design and measured ratings of target morality, trustworthiness, intelligence, and athleticism. We report the effect of our basic victim manipulation on each of these four traits, in an aggregate analysis of the standard neutral and immorality victim conditions of these experiments $(n=1,601)$.

We find a significant positive effect of victim status on morality, $b=.40[.26, .54], t=5.75, B=.14, p$ $<.001$, that holds when controlling for intelligence and athleticism, $b=.35[.24, .47], t=6.10, B=.12$, $p<.001$. Likewise, we find a significant positive effect of victim status on trustworthiness, $b=.41$ $[.27, .55], t=5.80, B=.14, p<.001$, that holds when controlling for intelligence and athleticism, $b=$ $.37[.25, .48], t=6.09, B=.13, p<.001$. (We do not control for trustworthiness when predicting morality, or vice versa, because both tap the same underlying construct of moral character.) In contrast, we do not find an effect of victim status on intelligence, $b=.04[-.09, .17], t=.58, B=.01, p=.559$, and find a negative effect when controlling for morality, trustworthiness, and athleticism, $b=-.22$ [$.33,-.11], t=-3.83, B=-.08, p<.001$. Finally, we find a significant (but relatively smaller) positive effect of victim status on athleticism, $b=.21[.07, .36], t=2.87, B=.06, p=.004$, that becomes marginally significant when controlling for morality, trustworthiness, and intelligence, $b=.12[-.02$, $.27], t=1.69, B=.04, p=.090$. Across these four experiments, mixed-model ANOVAs reveal that victim status has a more positive effect on moral traits than it does on intelligence, $F(1,3197)=42.09$, $p<.001$, or athleticism, $F(1,3197)=7.22, p=.007$.

In sum, the Virtuous Victim effect does not extend to accidents, or equally to positive nonmoral traits. This interesting feature of the Virtuous Victim effect suggests that it does not merely reflect a simple sympathy effect, whereby subjects are generally inclined to positively evaluate anybody who has suffered a negative outcome. Importantly, it does not rule out the possibility that sympathy is an important part of the psychology surrounding the Virtuous Victim effect. In fact, many of our experiments included sympathy as a secondary variable, and our data are consistent with the possibility that sympathy may be a proximate cause, or consequence, of the Virtuous Victim effect (for analyses and further discussion, see Supplementary Materials Section 4.2.1). But critically, any sympathy-based explanation for the Virtuous Victim effect must account for its specificity to morality. And this poses a challenge for the simple proposal that people are generally compelled to positively evaluate targets who have suffered.

We also argue that the specificity of the Virtuous Victim effect to morality is compatible with the Justice Restoration Hypothesis. First, consider that the Virtuous Victim effect does not extend equally to positive nonmoral traits. Given this finding, the Justice Restoration Hypothesis should predict that, relative to moral traits, positive nonmoral traits are less effective at motivating justice-restorative action. In other words, we should expect people to be especially motivated to help and punish on behalf of morally virtuous victims. Future research should investigate this interesting possibility, but recall that Experiment 10 actually provided some suggestive evidence for it.

Second, consider that the Virtuous Victim effect does not extend to victims of accidental misfortune. Given this finding, the Justice Restoration Hypothesis should predict that, relative to cases of immorality, accidents create weaker incentives to help victims and/or punish perpetrators. This is clearly the case with respect for incentives for punishing perpetrators: when accidents occur, there are no perpetrators to punish (or incentives to punish them). And interestingly, we also find empirical evidence that it is the case with respect to helping of victims. Even though accidents $d o$ create victims who may need help, we find that subjects nonetheless perceive weaker incentives to help victims of accidents than victims of immorality. 
Specifically, Experiment 13 used our iPad vignette to measure perceived (reputation-based) incentives to help different types of targets. Subjects in Experiment 13 were assigned to our neutral condition, our theft victim condition, or our earthquake accident condition, and evaluated how good helping the target would look in the eyes of others (before evaluating the target's moral character). We found that subjects in the theft victim condition reported that helping the target would look better in the eyes of others, both relative to the neutral condition, $b=.74[.43,1.05], t=4.73, B=.23, p<.001, n=400$, and the accident condition, $b=.81[.48,1.13], t=4.90, B=.24, p<.001, n=403$. In contrast, relative to neutral, subjects in the accident condition did not report stronger incentives to help, $b=-.06[-.37$, $.24], t=-.42, B=-.02, p=.667, n=401$.

Thus, while accidents create victims who may need help, subjects perceive relatively stronger (reputation-based) incentives to help victims of immorality. This finding is interesting, and to our knowledge has not previously been documented. One plausible explanation is that, while all helping behavior signals general prosociality, helping victims of immorality specifically has the added benefit of conveying disapproval of a moral transgression — and thus signaling, like moralistic punishment does $(30,31)$, that the helper is unlikely to herself transgress.

Regardless, Experiment 13 highlights that the Justice Restoration hypothesis is compatible with our finding that the Virtuous Victim effect does not extend to accident victims. The Justice Restoration Hypothesis predicts that the Virtuous Victim effect will specifically occur in contexts where people perceive incentives to help victims and punish perpetrators - and these incentives appear to be weaker in cases of accidents.

\section{The Virtuous Victim effect does not extend to predicted behavior, suggesting that it does not merely reflect a genuine belief about the typical conduct of victims}

Finally, we consider the hypothesis that the Virtuous Victim effect merely reflects a genuine belief about the typical conduct of victims. According to this hypothesis, people see victims as morally good because they have evaluated, perhaps accurately, that victims tend to be people who behave morally. If this were true, we would expect subjects to rate victims as more likely to behave virtuously (and/or less likely to behave unethically). Yet we instead find, interestingly, that subjects see victims as possessing elevated moral character (i.e., as being more moral and trustworthy people), but do not expect victims to behave more morally.

Thus far, we have exclusively discussed evaluations of moral character as our key dependent variable. However, Experiments 1, 7, 12, 14 ( $n=403$, pre-registered), and 15 ( $n=401$, pre-registered) all also measured subjects' predictions about target behavior in moral contexts. These experiments also all employed our standard neutral and victim conditions, allowing us to investigate whether the Virtuous Victim effect extends to predicted moral behavior (Fig. 5).

Most of these experiments (specifically, Experiments 1, 7, 14, and 15) measured predicted behavior via 1-9 Likert scales, making it possible to aggregate data across these experiments. And when comparing the standard victim and neutral conditions of these experiments (see Fig. 5A), we find no effect of victim status on predicted moral $(b=-.03[-.18, .12], t=-.38, B=-.01, p=.707, n=1,608)$ or immoral $(b=.05[-.15, .25], t=.51, B=.01, p=.613, n=1,207)$ behavior.

In Experiment 12, we likewise measured predicted moral behavior. However, rather than using Likert Scale measures, we asked subjects to predict how much money the target would return in a hypothetical economic Trust Game (measured as a proportion that could range from 0 to 1). And in 
this experiment (see Fig. 5B), we again found no effect of victim status on predicted moral behavior $(b$ $=.01[-.04, .06], t=.29, B=.01, p=.775, n=400)$.

Moreover, when individually analyzing each of our experiments with Likert scale measures of predicted behavior (i.e., each of Experiments 1, 7, 14, and 15), we do not find a single significant positive victim effect on predicted moral behavior, or a negative victim effect on predicted immoral behavior. These null effects span many measures: Experiment 1 measured predictions of past and future, general and specific, moral and immoral behavior (via eight items). Experiments 7 and 14 measured predictions about four specific moral (e.g., volunteering to tutor) and immoral (e.g., spreading mean gossip) behaviors. And Experiment 15 measured predictions about four specific moral behaviors, two of which were habitual (e.g., habitually recycling) and two of which were more active (e.g., surprising one's mom with a thoughtful gift). Furthermore, Experiment 15 provides evidence against the hypothesis that victims are not expected to behave more morally simply because they are perceived to be upset following their victimization. See Supplementary Materials Section 2.9 for more details.
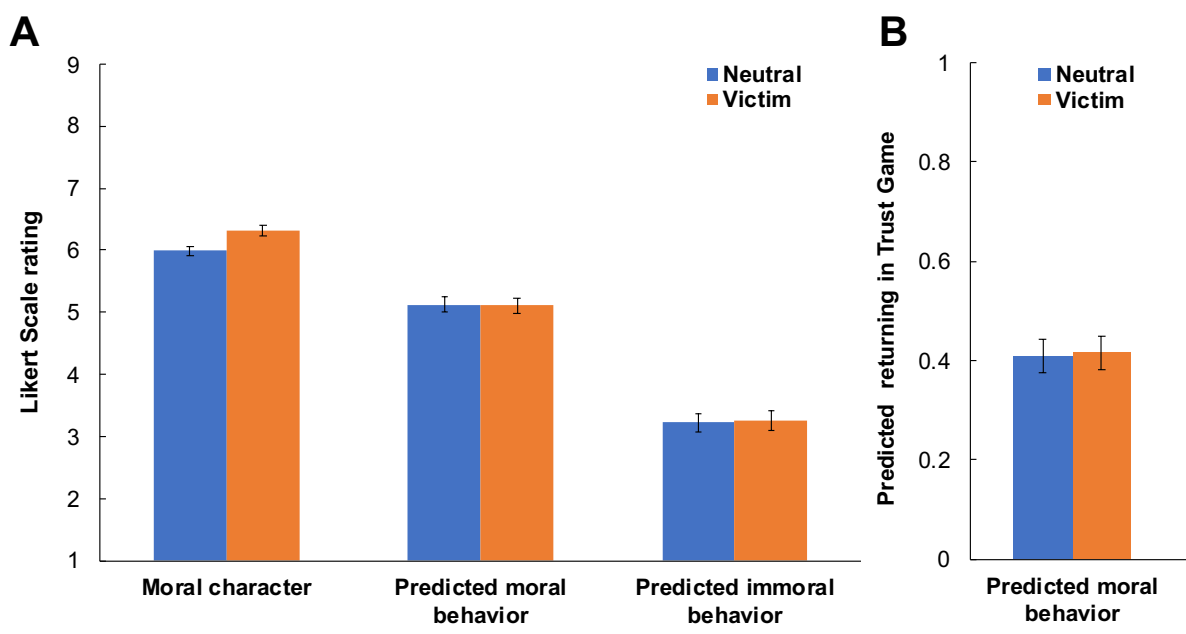

Fig. 5. Victims are seen as having elevated moral character but are not expected to behave more morally. We plot the effects of victim status on perceived moral character, predicted moral behavior, and predicted immoral behavior. Panel A shows moral character data (across our set of experiments that measured both moral character and behavior predictions: Experiments 1, 7, 12, 14, and 15, $n=$ 2,008), as well as behavior prediction data from experiments featuring Likert Scale measures of predicted behavior (moral behavior data from Experiments 1, 7, 14, and 15, $n=1,608$; immoral behavior data from Experiments 1, 7, and 14, $n=1,207$ ). Panel B shows behavior prediction data from Experiment $12(n=400)$, which measured predicted moral behavior by asking subjects to predict how much money the target would return in a hypothetical economic Trust Game. We find that victims are seen as having elevated moral character, but are not expected to behave more morally or less immorally. Error bars are 95\% CIs.

We also note that all of our experiments that measured behavior predictions additionally measured moral character ratings, and the order of measures (character ratings vs. behavior predictions) varied across experiments. And even when we measured behavior predictions before character ratings (in Experiments 12,14, and 15), while subjects did not expect victims to behave more morally, we did find some evidence that they saw victims as having better character. These three experiments were not included in our aggregated analyses of the basic Virtuous Victim effect (shown in Fig. 1), because they differed from our basic design by measuring behavior predictions before character ratings. Yet when 
pooling data across these three experiments, we find that, relative to neutral targets, victims were rated as more moral, $b=.21[.05, .37], t=2.58, B=.07, p=.010$, and trustworthy, $b=.29[.12, .46], t=$ $3.38, B=.10, p=.001, n=1,204$. We do note, however, that these effects are not consistently significant within individual experiments; see Supplementary Materials Section 2.1 (and in particular Table S3 and Fig. S1) for more detail.

Does the dissociation between behavior predictions and character ratings merely reflect that it is too difficult to manipulate behavior predictions? In Experiment $16(n=201$, not pre-registered), we test this possibility by investigating the effect of a direct morality manipulation on behavior predictions. To directly manipulate morality, we presented subjects with a modified version of the neutral condition of our iPad vignette. In our positively-valanced control condition, we modified the vignette by adding that the target "is fun to be around and has a good sense of humor". In our direct morality condition, we noted these positive traits and called the target "a moral and trustworthy person". Then, we measured character ratings and then behavior predictions (on a 1-9 Likert scale, using the four moral and four immoral behaviors from Experiment 14).

Like our victim manipulation, this direct morality manipulation $(0=$ control, $1=$ moral $)$ increased ratings of target morality, $b=.45[.07, .82], t=2.36, B=.17, p=.019$, and trustworthiness, $b=.54$ $[.15, .94], t=2.73, B=.19, p=.007, n=201$. Furthermore, the magnitudes of these effects are comparable to those of our victim manipulation. Yet unlike our victim manipulation, our direct morality manipulation also increased predicted moral behavior, $b=.55[.15, .94], t=2.75, B=.19, p=$ .006 - although it had no significant effect on predicted immoral behavior, $b=-.28[-.72, .16], t=-$ $1.26, B=-.09, p=.211, n=201$. Thus, we find evidence that the null effects of our victim manipulation on predicted moral behavior do not simply reflect that predicted moral behavior cannot readily be manipulated.

In sum, subjects see victims as having elevated moral character, but do not expect them to behave more morally. This interesting dissociation was unexpected. But, critically, it provides evidence against the hypothesis that the Virtuous Victim effect merely reflects a genuine belief that victims tend to be people who behave morally. It also challenges other alternative explanations: if the Virtuous Victim effect were driven by a contrast with the perpetrator or a sympathy-based desire to positively evaluate people who have suffered, it would seem natural for the effect to extend to behavior predictions.

In contrast, we argue that the observed character-behavior dissociation is more readily compatible with the Justice Restoration Hypothesis. The Justice Restoration Hypothesis predicts that people will perceive victims in ways that motivate justice-restorative action. Yet in our view, it does not make a specific prediction about whether this will merely involve seeing victims as morally good people, or will also involve believing that victims are likely to behave morally. Furthermore, insofar as victims do not, in reality, behave any more morally than non-victims, it may be costly to believe that they do. Thus, elevating the character of victims without expecting them to behave more morally might plausibly function to (i) motivate justice-restorative action while (ii) allowing people to avoid the costs of holding inaccurate beliefs. This hypothesis is only speculative, and should be investigated in future research. Regardless, however, we argue that the observed character-behavior dissociation provides strong evidence that the Virtuous Victim effect does not reflect a genuine belief about the typical conduct of victims, and that the dissociation is more readily compatible with the Justice Restoration Hypothesis. 


\section{Discussion}

Across 17 experiments (total $n=9,676$ ), we have documented and explored the Virtuous Victim effect. Strikingly, we find that victims are frequently seen as more virtuous than non-victims-not because of their own behavior, but because others have mistreated them. We observe this effect across a range of moral transgressions, and find evidence that it is not moderated by the victim's (White vs. Black) race or gender. Humans ubiquitously - and perhaps increasingly $(1,2)$ - encounter narratives about immoral acts and their victims. By demonstrating that these narratives have the power to confer moral status, our results shed new light on the ways that victims are perceived by society.

We have also explored the boundaries of the Virtuous Victim effect and illuminated the mechanisms that underlie it. For example, we find that the Virtuous Victim effect may be especially likely to flow from victim narratives that describe a transgression's perpetrator, and are presented by a third-person narrator (or perhaps, more generally, a narrator who is unlikely to be doubted). We also find that the effect is specific to victims of immorality (i.e., it does not extend to accident victims) and to moral virtue (i.e., it does not extend equally to positive but nonmoral traits). And interestingly, the effect shapes perceptions of moral character but not predictions about moral behavior.

Finally, we have evaluated several potential explanations for the Virtuous Victim effect. Ultimately, our results provide evidence for the Justice Restoration Hypothesis, which proposes that people see victims as virtuous because this perception serves to motivate punishment of perpetrators and helping of victims - and people frequently face incentives to enact or encourage these justice-restorative actions. Indeed, we find empirical support for the assumption that seeing victims as virtuous motivates justice-restorative action. And, critically, we find that introducing disincentives for justice-restorative action causes the Virtuous Victim effect to disappear. Moreover, our results provide direct evidence that the effect does not merely reflect (i) that victims look good in contrast to perpetrators, (ii) that people are generally inclined to positively evaluate those who have suffered, or (iii) that people hold a genuine belief that victims tend to behave morally.

By supporting the Justice Restoration Hypothesis, our work advances our understanding of how people evaluate the moral character of others. Previous research has established that moral character evaluations are shaped by the direct personal attributes of evaluated individuals - such as their moral or immoral behaviors (12-15), social group affiliations (16-20), or physical attractiveness $(21,22)$. Our results suggest that, because people frequently face incentives to respond to wrongdoing with justice-restorative action, moral character evaluations can also be influenced by whether an individual was the recipient of immoral treatment. And in this way, our results contribute to a growing body of evidence from psychology that moral judgements can be colored by self-interested incentives $(43,52-$ $54)$.

By proposing a link between perceptions of victim virtue and justice-restorative action, the Justice Restoration Hypothesis also aligns with theories of "indirect reciprocity". Such theories posit that people track the reputation status of individuals in their community, and the normative value of a particular action (e.g., helping or stealing from somebody) can depend on the recipient's reputation standing $(57,58)$. For example, in some cultures, stealing from somebody in good reputational standing is considered a norm violation, but stealing from somebody in bad reputational standing (e.g., somebody who himself is a thief) is not (59). According to this framework, a harmful act is more likely to be viewed by society as a transgression that merits justice-restorative action if the victim is morally virtuous. Thus, it stands to reason that seeing a victim as virtuous would boost motivation for justicerestorative action - and that, when we face incentives to enact or encourage justice-restorative action, we would therefore benefit from elevating the victim's character. 
An interesting question for future research is whether incentives for justice-restorative action influence our perceptions of victims in other ways. We find that the Virtuous Victim effect does not extend equally to certain positive nonmoral traits (e.g., intelligence, athleticism). And, providing a potential explanation for this pattern, we find some suggestive evidence that describing victims as competent may be less effective at motivating justice-restorative action than describing victims as moral. But insofar as other traits beyond morality (e.g., helplessness or innocence) are particularly effective at motivating justice-restorative action, we might expect people to elevate victims on those traits.

This proposal may also relate to evidence, described in the introduction, that people typecast moral "patients" (i.e., the recipients of moral action), including victims, as passive (7-9). This phenomenon is distinct from the Virtuous Victim effect (being passive is not the same thing as being moral), and is unlikely to account for our results. If the Virtuous Victim effect simply reflected that victims are seen as passive patients who are incapable of wrongdoing, we would have expected the effect to extend to predicted immoral behavior-but subjects did not rate victims as any less likely to commit immoral acts (e.g., spreading mean gossip). However, future research should investigate whether there may be a psychological link between seeing victims as moral and as passive, insofar as both perceptions could plausibly motivate justice-restorative action.

Another open question is whether the Virtuous Victim effect may ever extend to victims of accidental misfortune. In our experiments, subjects did not see accident victims as more morally virtuous than neutral targets. When viewed through the lens of the Justice Restoration Hypothesis, this pattern makes sense: when accidents occur, there are no perpetrators (and thus no incentives for punishment). And, while accidents do create victims who may need help, our subjects did not perceive strong incentives to help them. In fact, our subjects did not expect helping accident victims to look any better than helping neutral targets. Yet the accident victims in our experiments suffered relatively minor consequences (the loss of an iPad). When more serious accidents occur (e.g., natural disasters in poor countries), people might plausibly perceive stronger reputational incentives to help - in which case we would expect people to elevate the character of accident victims. Importantly, however, our theory and results also suggest that, holding constant the harm suffered, moral transgressions will create stronger incentives for justice-restorative action than accidents - and thus victims of immorality will reliably be seen as more virtuous than accident victims.

Future research should also investigate how our results relate to victim blaming. As noted in the introduction, there is ample evidence that people sometimes blame victims for causing their own victimization (3-6). Importantly, this observation is not incompatible with our findings: one could conceivably see a victim as morally good and as having contributed, causally, to their victimization. Yet moral evaluations of victims may nonetheless correlate interestingly with attributions of causal blame. For example, in some contexts, people face disincentives for justice-restorative action (and thus face pressure not to punish perpetrators and help victims, but rather to excuse wrongdoing and dismiss victims). Our theorizing predicts that in these contexts, people are unlikely to morally elevate victims (and may even derogate their moral character). Indeed, in the "disincentives" condition of Experiment $11 \mathrm{a}$, it was relatively easy to evoke such a context - and consequently eliminate the Virtuous Victim effect - by encouraging subjects to imagine some hypothetical drawbacks of justice-restorative action. And it seems plausible that in contexts where people perceive disincentives for justice-restorative action, they may also be more likely to attribute causal blame to victims. Future research should test this hypothesis, which is broadly consistent with evidence that motivation (60) and ideology (5) can influence empathy for victims. 
Relatedly, it is interesting to consider why our sexual aggression vignette did not produce a significant Virtuous Victim effect, while our rape vignette produced a strong effect. In the victim condition of our sexual aggression vignette, the target initially participated in a consensual sexual encounter with the perpetrator (who then continued making advances after she asked him to stop). The vignette was also vague: the nature of the continued advances was unclear and it was thus unclear whether a sexual assault occurred. In contrast, in the victim condition of our rape vignette, the target did not consent to any kind of a sexual encounter, and the vignette described an unambiguous assault. We thus speculate that subjects may have perceived the rape vignette as describing a context that would create greater social consensus that a moral transgression occurred-giving rise to stronger incentives for justicerestorative action and thus a stronger Virtuous Victim effect. Future research should directly test this proposal, and more generally investigate when victims of sexual coercion are judged to be morally virtuous.

It is also interesting that, in our experiments, the Virtuous Victim effect was not significantly moderated by target gender or (White vs. Black) race, and extended to female and Black victims. When viewed through the lens of the Justice Restoration Hypothesis, these findings suggest that subjects in our experiments perceived incentives to help victims and punish the perpetrators who wronged them - including when the victims in question were female and/or Black. Importantly, however, this perception may not always hold, at least for all subsets of the population. And in contexts where people do not perceive incentives to engage in justice-restorative action on behalf of female and/or Black victims (or victims from other historically or currently marginalized groups), our theoretical framework suggests that the Virtuous Victim effect may not extend to members of these groups For example, individuals who perceive incentives to excuse (rather than punish) police violence against Black Americans may fail to elevate (and, as described above, perhaps even derogate) the character of such victims. Further research should investigate this important possibility.

Another open question is whether the Virtuous Victim effect obtains across cultures, including in populations that are not "WEIRD" (Western, Educated, Industrialized, Rich and Democratic) (61). As just articulated, our theorizing predicts that the generalizability of the Virtuous Victim effect across cultures is likely to depend on the universality of incentives for punishing perpetrators and helping victims. For example, in cultures and contexts where victims are seen as contaminated (5) and helping them is not socially rewarded, we predict that the Virtuous Victim effect may disappear (or even reverse).

Further research should also investigate the Virtuous Victim effect outside of the laboratory. A limitation of our work is that we relied on hypothetical vignettes, most of which were presented in third-person by a presumptively objective narrator. Thus, future work should explore perceptions of real-world victims, both in contexts where victim narratives are presented by third parties (e.g., news coverage of or gossip about immoral acts and their victims) as well as victims themselves.

Relatedly, future work should attempt to shed further light on our finding that the Virtuous Victim effect can, but does not always, extend from third-person to first-person narratives. We have speculated that this finding may reflect that narrator credibility is crucial for the Virtuous Victim effect. And while people may be especially likely to question first-person narrators, perceived credibility might also play an important role in shaping evaluations of third-person victim narrativesespecially in contexts where narrators seem less objective than they did in our vignettes.

Finally, future research should investigate the broader societal implications of the Virtuous Victim effect. How does the perception that victims are morally virtuous shape the treatment of victims by 
society (both in daily life and in domains like policy and law) and the roles that victim narratives play in social debates? And what are the implications of the Virtuous Victim effect for the behavior and psychology of victims? For example, when victims are bestowed with moral status, what are the downstream consequences for their moral self-concepts and behavior $(62,63)$ ? And are people aware that being seen as a victim can make them appear moral? Recent research has documented a correlation between the tendency to signal one's victim status and the tendency to signal one's moral character (56), and our work shows that victim status can itself serve to boost an individual's perceived moral character. These results raise the question of whether people are motivated to share their victimization in order to appear virtuous. On the other hand, however, do victims anticipate the pitfalls that may come with personally sharing their first-person narratives? Future work should investigate how these considerations shape the ways that victims choose to come forward with their stories.

In conclusion, we have shown that people frequently see victims of wrongdoing as morally good, and provided evidence that this "Virtuous Victim effect" flows from incentives for justice-restorative action. This work has important implications for the role of victim narratives in society, and raises many interesting directions for future research.

\section{Materials and Methods}

We recruited subjects online via Amazon Turk, and in-lab via a university subject pool. All experiments followed IRB guidelines, and informed consent was obtained from all subjects. In all experiments, subjects read vignette(s), evaluated target character(s) on key dependent measure(s), and answered basic demographic questions. Some experiments also included secondary dependent measures (e.g., sympathy for the target), which are not analyzed in the main text. Table 1 provides a design overview of each experiment; see Supplementary Materials for full design details including secondary variables (Sections 1 and 5), as well as supplemental analyses of some of our secondary variables (Section 4). We individually pre-registered all experiments except Experiments $11 \mathrm{~b}$ and 16; see Supplementary Materials Table S1 for links to all pre-registrations, and Supplementary Materials Section 3 for a discussion of pre-registered predictions.

Finally, we note that our "basic design" refers to the neutral and standard victim conditions of Experiments 1, 2, 3, 4, 7, and 8, as well as the third-person conditions of Experiments 5-6. These conditions all used a very similar design, in which subjects were not exposed to other manipulations, and did not complete other measures before rating target moral character (with the exception that in Experiments 3, 5-7, on the same page that subjects rated target moral character, they also rated the target on positive nonmoral traits). 


\begin{tabular}{|c|c|c|c|}
\hline Experiment & Vignette & $\begin{array}{l}\text { Key conditions } \\
\text { (between-subjects) }\end{array}$ & Key dependent measures \\
\hline $1(n=802$, Mturk $)$ & iPad theft & $\begin{array}{l}\text { Neutral; standard victim; other } \\
\text { victim; minimal narrative } \\
\text { victim }\end{array}$ & $\begin{array}{l}\text { Morality; trustworthiness; predicted } \\
\text { past/future, general/specific, moral/immoral } \\
\text { behavior }\end{array}$ \\
\hline $2(n=207$, lab $)$ & iPad theft & Neutral; standard victim & Morality; trustworthiness \\
\hline $3(n=803$, Mturk $)$ & iPad theft & $\begin{array}{l}\text { Neutral; standard victim; } \\
\text { accident victim: cat; accident } \\
\text { victim: earthquake }\end{array}$ & $\begin{array}{l}\text { Morality; trustworthiness; intelligence; } \\
\text { athleticism; funniness; sociability }\end{array}$ \\
\hline $4(n=510$, Mturk $)$ & $\begin{array}{l}\text { iPad theft; verbal } \\
\text { attack; sexual } \\
\text { aggression } \\
\text { (within-subjects) }\end{array}$ & Neutral; standard victim & Morality; trustworthiness \\
\hline $5(n=803$, Mturk $)$ & iPad theft & $\begin{array}{l}\text { First-person vs. third-person } X \\
\text { Neutral vs. standard victim }\end{array}$ & $\begin{array}{l}\text { Morality; trustworthiness; intelligence; } \\
\text { athleticism }\end{array}$ \\
\hline $6(n=802$, Mturk $)$ & Idea theft & $\begin{array}{l}\text { First-person vs. third-person } \mathrm{X} \\
\text { Neutral vs. standard victim }\end{array}$ & $\begin{array}{l}\text { Morality; trustworthiness; intelligence; } \\
\text { athleticism }\end{array}$ \\
\hline $7(n=401$, Mturk $)$ & Corrupt doctor & Neutral; standard victim & $\begin{array}{l}\text { Morality; trustworthiness; intelligence; } \\
\text { athleticism; predictions for four moral and } \\
\text { four immoral behaviors }\end{array}$ \\
\hline $8(n=437$, Mturk $)$ & Rape & Neutral; standard victim & Morality; trustworthiness \\
\hline $9(n=904$, Mturk $)$ & iPad theft & $\begin{array}{l}\text { Neutral vs. standard victim X } \\
\text { Male vs. female target X } \\
\text { White vs. Black target }\end{array}$ & Morality; trustworthiness \\
\hline $10(n=598$, Mturk $)$ & Idea theft & $\begin{array}{l}\text { Control victim; moral victim; } \\
\text { competent victim }\end{array}$ & $\begin{array}{l}\text { Morality; willingness to help; willingness } \\
\text { to punish }\end{array}$ \\
\hline 11a $(n=801$, Mturk $)$ & Idea theft & $\begin{array}{l}\text { Incentives vs. disincentives } X \\
\text { Neutral vs. standard victim }\end{array}$ & Morality; trustworthiness \\
\hline $11 \mathrm{~b}(n=399$, Mturk $)$ & Idea theft & Incentives vs. disincentives & $\begin{array}{l}\text { Incentives to punish; incentives to help; } \\
\text { extent to which victim is a victim }\end{array}$ \\
\hline $12(n=602$, Mturk $)$ & iPad theft & $\begin{array}{l}\text { Neutral; standard victim; other } \\
\text { victim }\end{array}$ & $\begin{array}{l}\text { Predicted money returned in hypothetical } \\
\text { economic Trust Game; morality; } \\
\text { trustworthiness }\end{array}$ \\
\hline $13(n=602$, Mturk $)$ & iPad theft & $\begin{array}{l}\text { Neutral; standard victim; } \\
\text { accident victim: earthquake }\end{array}$ & $\begin{array}{l}\text { Reputation-based incentives to help; } \\
\text { morality; trustworthiness }\end{array}$ \\
\hline $14(n=403$, Mturk $)$ & iPad theft & Neutral; standard victim & $\begin{array}{l}\text { Predictions for four moral and four immoral } \\
\text { behaviors; morality; trustworthiness }\end{array}$ \\
\hline $15(n=401$, Mturk $)$ & iPad theft & Neutral; standard victim & $\begin{array}{l}\text { Predictions for four moral behaviors; } \\
\text { morality; trustworthiness }\end{array}$ \\
\hline $16(n=201$, Mturk $)$ & $\begin{array}{l}\text { [no victim } \\
\text { narrative; drew } \\
\text { from iPad theft] }\end{array}$ & $\begin{array}{l}\text { Positively-valanced control; } \\
\text { direct morality }\end{array}$ & $\begin{array}{l}\text { Morality; trustworthiness; predictions for } \\
\text { four moral and four immoral behaviors }\end{array}$ \\
\hline
\end{tabular}

Table 1. Overview of experimental designs. We report, for each experiment, the sample source and size, vignette(s) used, key conditions, and key DVs. We note that while only Experiment 9 manipulated target gender (male vs. female) via photographs and as a primary manipulation, Experiments 1-7, 9, and 13-15 also manipulated target gender via names and pronouns. We also note that for Experiments 8 and 9, we report the sample sizes for our pre-registered primary analyses, which restricted to subjects who passed a set of attention checks; our unrestricted sample sizes for these experiments are $n=503$ (Experiment 8) and $n=999$ (Experiment 9). (We pre-registered attentionbased restrictions for Experiments 8 and 9 only because these experiments were conducted chronologically last, and during a time in which we had greater concerns about inattention in the Mturk subject pool.) 


\section{References}

1. G. Lukianoff, J. Haidt, The coddling of the American mind. The Atlantic. 316, 42-52 (2015).

2. N. Haslam, Concept creep: Psychology's expanding concepts of harm and pathology. Psychol. Inq. 27, 1-17 (2016).

3. A. Furnham, Belief in a just world: Research progress over the past decade. Personal. Individ. Differ. 34, 795-817 (2003).

4. M. D. Alicke, Culpable control and the psychology of blame. Psychol. Bull. 126, 556 (2000).

5. L. Niemi, L. Young, When and why we see victims as responsible: The impact of ideology on attitudes toward victims. Pers. Soc. Psychol. Bull. 42, 1227-1242 (2016).

6. L. Niemi, L. Young, Blaming the victim in the case of rape. Psychol. Inq. 25, 230-233 (2014).

7. K. Gray, D. M. Wegner, Moral typecasting: divergent perceptions of moral agents and moral patients. J. Pers. Soc. Psychol. 96, 505 (2009).

8. K. Gray, A. Waytz, L. Young, The moral dyad: A fundamental template unifying moral judgment. Psychol. Inq. 23, 206-215 (2012).

9. K. Gray, D. M. Wegner, To escape blame, don't be a hero-Be a victim. J. Exp. Soc. Psychol. 47, 516-519 (2011).

10. G. P. Goodwin, J. Piazza, P. Rozin, Moral character predominates in person perception and evaluation. J. Pers. Soc. Psychol. 106, 148 (2014).

11. B. Wojciszke, R. Bazinska, M. Jaworski, On the dominance of moral categories in impression formation. Pers. Soc. Psychol. Bull. 24, 1251-1263 (1998).

12. P. Barclay, Strategies for cooperation in biological markets, especially for humans. Evol. Hum. Behav. 34, 164-175 (2013).

13. S. T. Fiske, A. J. C. Cuddy, P. Glick, Universal dimensions of social cognition: warmth and competence. Trends Cogn. Sci. 11, 77-83 (2007).

14. N. Baumard, J.-B. André, D. Sperber, A mutualistic approach to morality: the evolution of fairness by partner choice. Behav. Brain Sci. 36, 59-78 (2013).

15. C. R. Critcher, Y. Inbar, D. A. Pizarro, How quick decisions illuminate moral character. Soc. Psychol. Personal. Sci. 4, 308-315 (2013).

16. W. M. Gervais, A. F. Shariff, A. Norenzayan, Do you believe in atheists? Distrust is central to antiatheist prejudice. J. Pers. Soc. Psychol. 101, 1189 (2011).

17. E. J. Finkel, C. A. Bail, M. Cikara, P. H. Ditto, S. Iyengar, S. Klar, L. Mason, M. C. McGrath, B. Nyhan, D. G. Rand, Political sectarianism in America. Science. 370, 533-536 (2020). 
18. K. Bruchmann, B. Koopmann-Holm, A. Scherer, Seeing beyond political affiliations: The mediating role of perceived moral foundations on the partisan similarity-liking effect. PloS One. 13, e0202101 (2018).

19. D. A. Stanley, P. Sokol-Hessner, M. R. Banaji, E. A. Phelps, Implicit race attitudes predict trustworthiness judgments and economic trust decisions. Proc. Natl. Acad. Sci. 108, 7710-7715 (2011).

20. C. Fershtman, U. Gneezy, Discrimination in a segmented society: An experimental approach. Q. J. Econ. 116, 351-377 (2001).

21. K. Dion, E. Berscheid, E. Walster, What is beautiful is good. J. Pers. Soc. Psychol. 24, 285 (1972).

22. R. K. Wilson, C. C. Eckel, Judging a book by its cover: Beauty and expectations in the trust game. Polit. Res. Q. 59, 189-202 (2006).

23. J. Henrich, R. McElreath, A. Barr, J. Ensminger, C. Barrett, A. Bolyanatz, J. C. Cardenas, M. Gurven, E. Gwako, N. Henrich, C. Lesorogol, F. W. Marlowe, D. Tracer, J. Ziker, Costly punishment across human societies. Science. 312, 1767-1770 (2006).

24. E. Fehr, U. Fischbacher, Third-party punishment and social norms. Evol. Hum. Behav. 25, 63-87 (2004).

25. J. M. Darley, T. S. Pittman, The psychology of compensatory and retributive justice. Personal. Soc. Psychol. Rev. 7, 324-336 (2003).

26. O. FeldmanHall, P. Sokol-Hessner, J. J. Van Bavel, E. A. Phelps, Fairness violations elicit greater punishment on behalf of another than for oneself. Nat. Commun. 5 (2014).

27. K. Daly, Revisiting the relationship between retributive and restorative justice. Restor. Justice Philos. Pract., 33-54 (2000).

28. A. K. Chavez, C. Bicchieri, Third-party sanctioning and compensation behavior: Findings from the ultimatum game. J. Econ. Psychol. 39, 268-277 (2013).

29. J. J. Jordan, D. Rand, Third-party punishment as a costly signal of high continuation probabilities in repeated games. J. Theor. Biol. 421, 189-202 (2017).

30. J. J. Jordan, M. Hoffman, P. Bloom, D. Rand, Third-party punishment as a costly signal of trustworthiness. Nature. 530, 473-476 (2016).

31. P. Barclay, Reputational benefits for altruistic punishment. Evol. Hum. Behav. 27, 325-344 (2006).

32. R. Nelissen, The price you pay: cost-dependent reputation effects of altruistic punishment. Evol. Hum. Behav. 29, 242-248 (2008).

33. N. J. Raihani, R. Bshary, The reputation of punishers. Trends Ecol. Evol. (2015).

34. R. Boyd, P. J. Richerson, Punishment allows the evolution of cooperation (or anything else) in sizeable groups. Ethol. Sociobiol. 13, 171-195 (1992). 
35. H. Ohtsuki, Y. Iwasa, M. A. Nowak, Indirect reciprocity provides only a narrow margin of efficiency for costly punishment. Nature. 457, 79-82 (2009).

36. J. J. Jordan, R. Sommers, P. Bloom, D. G. Rand, Why Do We Hate Hypocrites? Evidence for a Theory of False Signaling. Psychol. Sci. 28, 356-368 (2017).

37. J. Henrich, J. Ensminger, R. McElreath, A. Barr, C. Barrett, A. Bolyanatz, J. C. Cardenas, M. Gurven, E. Gwako, N. Henrich, C. Lesorogol, F. W. Marlowe, D. Tracer, J. Ziker, Markets, Religion, Community Size, and the Evolution of Fairness and Punishment. Science. 327, 14801484 (2010).

38. J. Henrich, Cooperation, punishment, and the evolution of human institutions. Science(Washington). 311, 60-61 (2006).

39. J. Henrich, R. Boyd, Why people punish defectors: Weak conformist transmission can stabilize costly enforcement of norms in cooperative dilemmas. J. Theor. Biol. 208, 79-89 (2001).

40. R. Boyd, H. Gintis, S. Bowles, Coordinated punishment of defectors sustains cooperation and can proliferate when rare. Science. 328, 617-620 (2010).

41. R. Boyd, H. Gintis, S. Bowles, P. J. Richerson, The evolution of altruistic punishment. Proc. Natl. Acad. Sci. 100, 3531-3535 (2003).

42. R. Boyd, P. J. Richerson, Group beneficial norms can spread rapidly in a structured population. $J$. Theor. Biol. 215, 287-296 (2002).

43. J. J. Jordan, D. G. Rand, Signaling when nobody is watching: A reputation heuristics account of outrage and punishment in one-shot anonymous interactions. J. Pers. Soc. Psychol. (2019).

44. M. A. Nowak, Five rules for the evolution of cooperation. Science. 314, 1560-1563 (2006).

45. I. Patil, N. Dhaliwal, F. Cushman, Reputational and cooperative benefits of third-party compensation (2018).

46. G. S. Adams, E. Mullen, Increased voting for candidates who compensate victims rather than punish offenders. Soc. Justice Res. 26, 168-192 (2013).

47. N. J. Raihani, R. Bshary, Third-party punishers are rewarded-but third-party helpers even more so. Evolution (2015).

48. P. Wiessner, Norm enforcement among the Ju/'hoansi Bushmen. Hum. Nat. 16, 115-145 (2005).

49. C. Boehm, H. B. Barclay, R. K. Dentan, M.-C. Dupre, J. D. Hill, S. Kent, B. M. Knauft, K. F. Otterbein, S. Rayner, Egalitarian behavior and reverse dominance hierarchy [and comments and reply]. Curr. Anthropol. 34, 227-254 (1993).

50. N. Q. Mahdi, Pukhtunwali: Ostracism and honor among the Pathan Hill tribes. Ethol. Sociobiol. 7, 295-304 (1986).

51. P. DeScioli, R. Kurzban, A solution to the mysteries of morality. Psychol. Bull. 139, 477 (2013). 
52. D. E. Melnikoff, N. Strohminger, The automatic influence of advocacy on lawyers and novices. Nat. Hum. Behav., 1-7 (2020).

53. L. Babcock, G. Loewenstein, Explaining bargaining impasse: The role of self-serving biases. $J$. Econ. Perspect. 11, 109-126 (1997).

54. W. Von Hippel, R. Trivers, The evolution and psychology of self-deception. Behav. Brain Sci. 34, 1 (2011).

55. D. S. Ma, J. Correll, B. Wittenbrink, The Chicago face database: A free stimulus set of faces and norming data. Behav. Res. Methods. 47, 1122-1135 (2015).

56. E. Ok, Y. Qian, B. Strejcek, K. Aquino, Signaling virtuous victimhood as indicators of Dark Triad personalities. J. Pers. Soc. Psychol. (2020).

57. R. Boyd, P. J. Richerson, The evolution of indirect reciprocity. Soc. Netw. 11, 213-236 (1989).

58. K. Panchanathan, R. Boyd, A tale of two defectors: the importance of standing for evolution of indirect reciprocity. J. Theor. Biol. 224, 115-126 (2003).

59. R. Bhui, M. Chudek, J. Henrich, How exploitation launched human cooperation. Behav. Ecol. Sociobiol. 73, 78 (2019).

60. J. Zaki, Empathy: a motivated account. Psychol. Bull. 140, 1608 (2014).

61. J. Henrich, S. J. Heine, A. Norenzayan, The weirdest people in the world? Behav. Brain Sci. 33, 61-83 (2010).

62. A. H. Jordan, B. Monin, From sucker to saint: Moralization in response to self-threat. Psychol. Sci. 19, 809-815 (2008).

63. E. M. Zitek, A. H. Jordan, B. Monin, F. R. Leach, Victim entitlement to behave selfishly. J. Pers. Soc. Psychol. 98, 245 (2010). 


\title{
Supplementary Materials for
}

\section{Virtuous Victims}

\author{
Jillian J. Jordan*, Maryam Kouchaki \\ *Corresponding author. Email: jillianjordan@,hbs.edu
}

\section{This PDF file includes:}

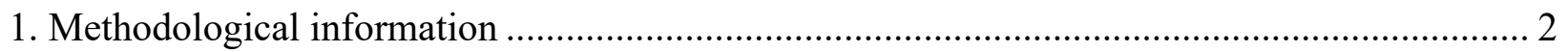

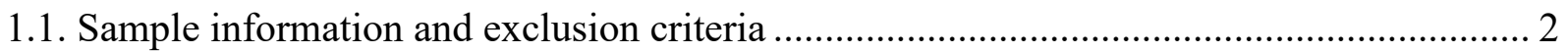

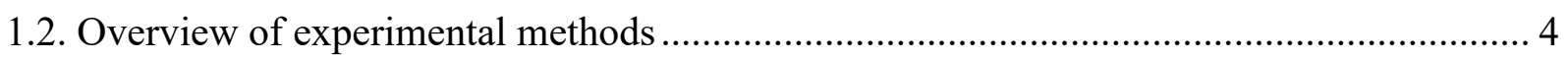

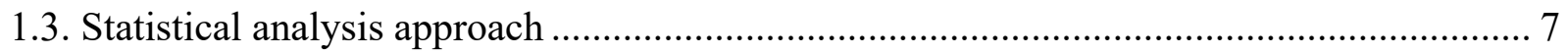

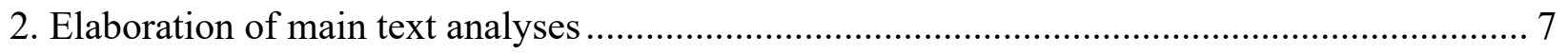

2.1 Analyses of the Virtuous Victim effect on morality and trustworthiness, within each ........ 7

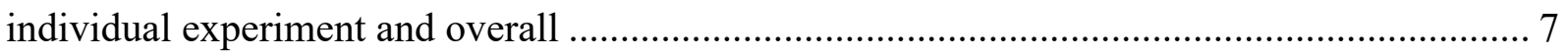

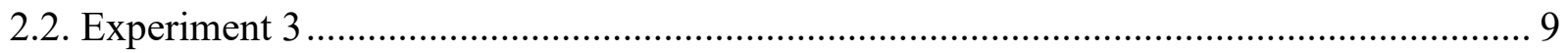

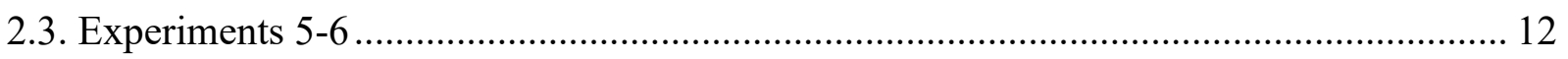

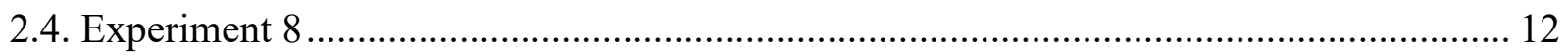

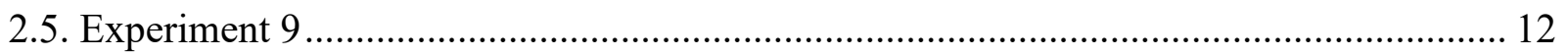

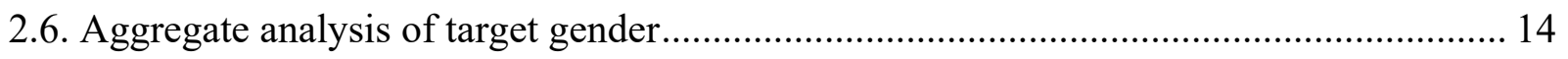

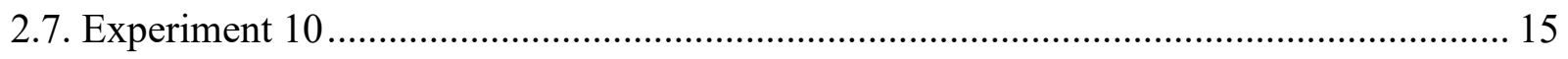

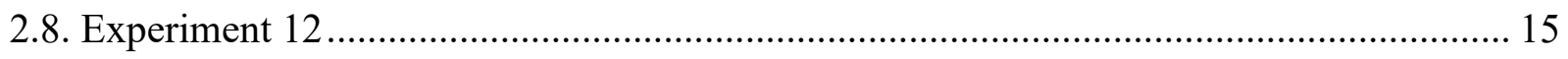

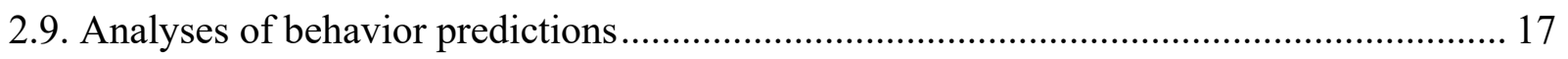

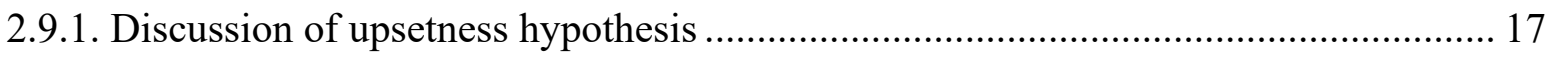

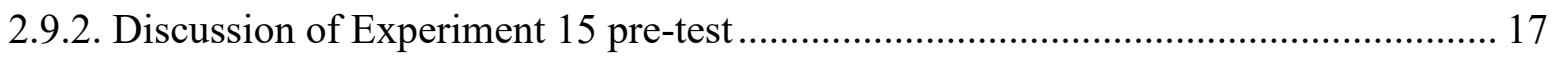

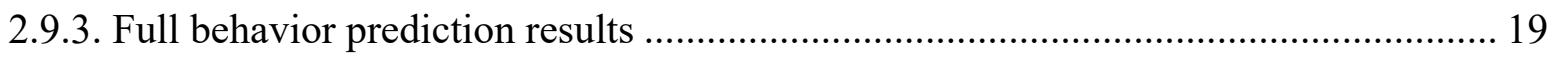

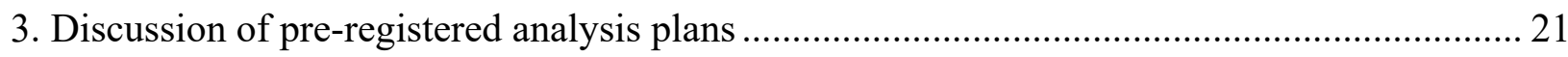

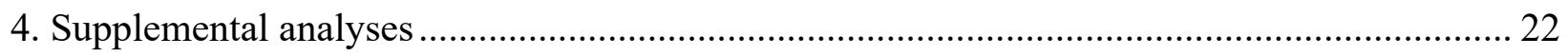

4.1. Analyses pertaining to primary deviations from pre-registrations .................................. 22

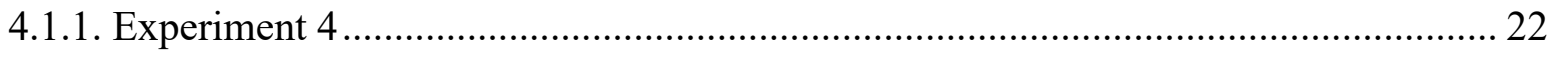

4.1.2. Experiment 11a ............................................................................................ 24 


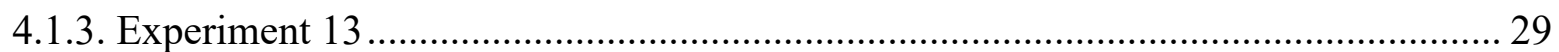

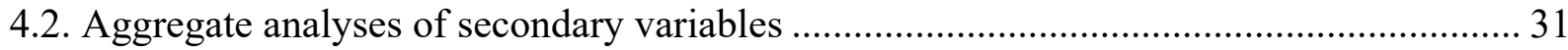

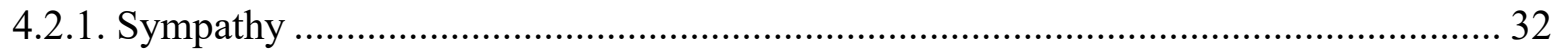

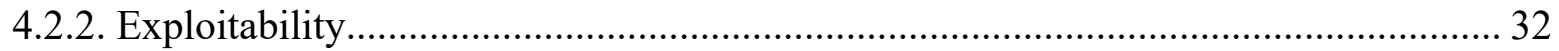

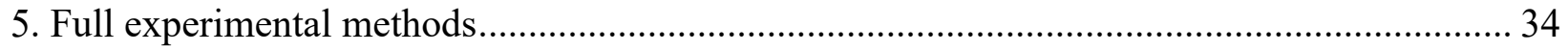

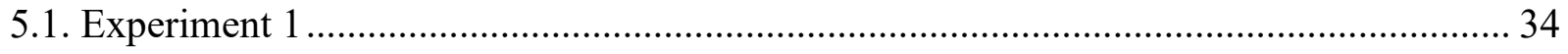

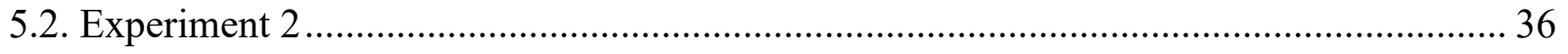

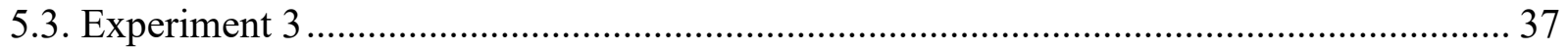

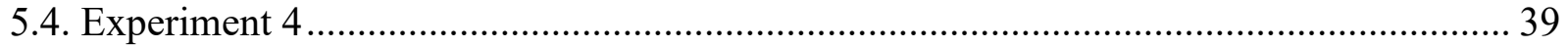

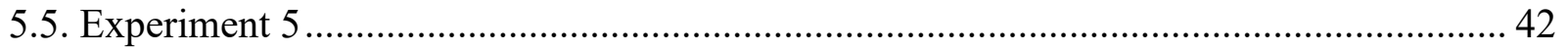

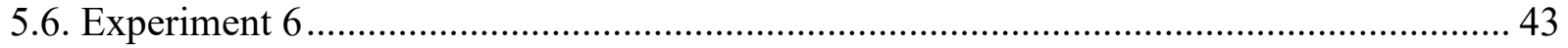

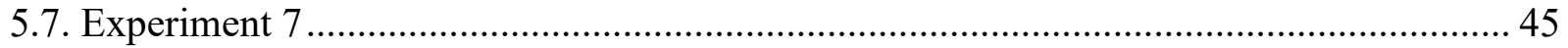

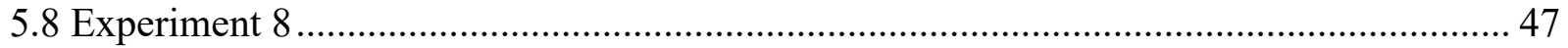

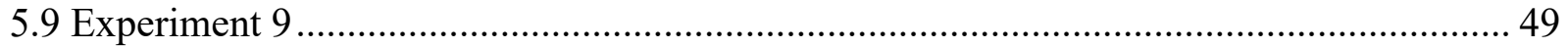

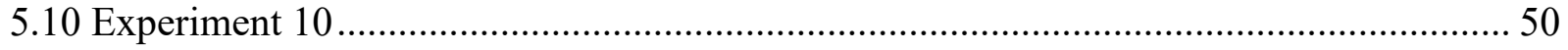

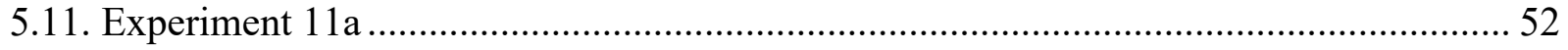

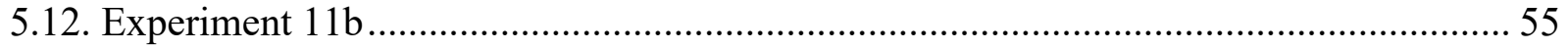

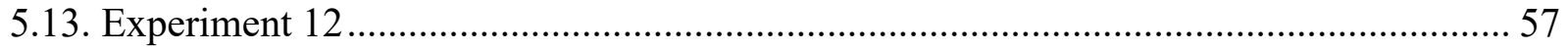

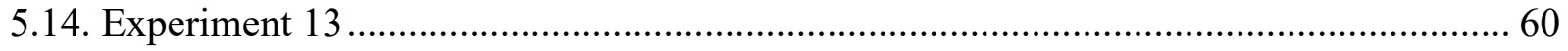

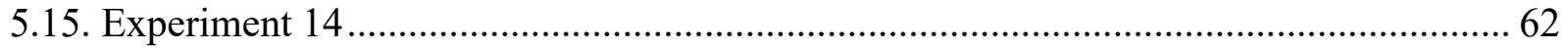

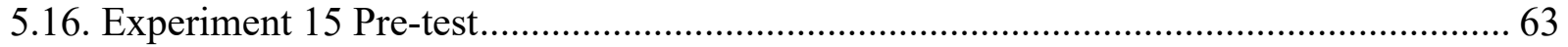

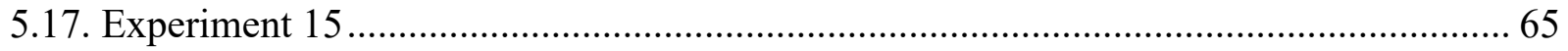

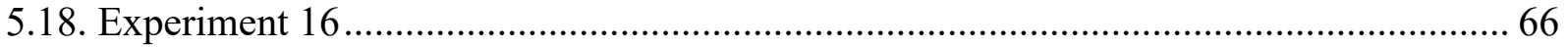

\section{Methodological information}

\subsection{Sample information and exclusion criteria}

We recruited subjects online via Amazon Mechanical Turk, or "Mturk" (Experiments 1, 3-16), and in-lab via a university subject pool (Experiment 2). Furthermore, for all of our experiments (as specified in all of our pre-registrations), (i) when we collected duplicate responses from the same IP address or Mturk worker ID, we included only the chronologically first response, and (ii) we excluded responses from subjects who did not complete all the required measures before our demographic questions. Finally, we note that when using Mturk, it is possible to receive slightly more data than requested (if subjects complete the survey, but do not indicate that they have done so on the Mturk platform), so our final simple sizes have the potential to be slightly larger than our target sample sizes. In Table S1, we report sample information (target sample size, total final sample size, final sample size by cell, and age and gender information), as well as links to our pre-registrations, for each experiment. 


\begin{tabular}{|c|c|c|c|c|}
\hline Experiment & \begin{tabular}{|c|} 
Mean \\
age
\end{tabular} \mid & \begin{tabular}{|c|} 
Percentage \\
male
\end{tabular} & Sample size of each cell & Pre-registration link \\
\hline $1($ Target $\mathrm{n}=800$, final $\mathrm{n}=802)$ & 36.43 & 39.90 & $\begin{array}{l}\text { Neutral }(\mathrm{n}=204), \text { standard victim }(\mathrm{n}=199) \\
\text { other victim }(\mathrm{n}=200) \\
\text { minimal narrative victim }(\mathrm{n}=199)\end{array}$ & http://aspredicted.org/blind.php? $x=e z 3 \mathrm{~km} 8$ \\
\hline 2 (Target $n=200$, final $n=207)$ & 20.65 & 30.92 & Neutral $(n=103)$, standard victim $(n=104)$ & http://aspredicted.org/blind.php?x=ib7fu7 \\
\hline $3($ Target $n=800, n=803)$ & 35.08 & 39.85 & $\begin{array}{c}\text { Neutral }(\mathrm{n}=202), \text { standard victim }(\mathrm{n}=198) \\
\text { accident victim: cat }(\mathrm{n}=201) \\
\text { accident victim: earthquake }(\mathrm{n}=202)\end{array}$ & $\underline{\text { http://aspredicted.org/blind.php? } x=m n 4 j 6 s}$ \\
\hline $4($ Target $n=500$, final $n=510)$ & 35.09 & 40.20 & Neutral $(\mathrm{n}=255)$, standard victim $(\mathrm{n}=255)$ & http://aspredicted.org/blind.php?x=fm5kv3 \\
\hline $5($ Target $\mathrm{n}=800$, final $\mathrm{n}=803)$ & 35.35 & 42.47 & $\begin{array}{c}\text { Neutral first-person }(\mathrm{n}=204), \\
\text { neutral third-person }(\mathrm{n}=201), \\
\text { standard victim first-person }(\mathrm{n}=202), \\
\text { standard victim third-person }(\mathrm{n}=196)\end{array}$ & http://aspredicted.org/blind.php?x=wn8f8h \\
\hline $6($ Target $\mathrm{n}=800$, final $\mathrm{n}=802)$ & 34.68 & 41.90 & $\begin{array}{c}\text { Neutral first-person }(\mathrm{n}=196), \\
\text { neutral third-person }(\mathrm{n}=198), \\
\text { standard victim first-person }(\mathrm{n}=203), \\
\text { standard victim third-person }(\mathrm{n}=205)\end{array}$ & http://aspredicted.org/blind.php?x=57jf3a \\
\hline $7($ Target $n=400$, final $n=401)$ & 35.85 & 45.89 & Neutral $(n=199)$, standard victim $(n=202)$ & http://aspredicted.org/blind.php?x=38yz33 \\
\hline $\begin{array}{c}\text { (Target } n=500, \text { final } n=503, \\
\text { primary analysis } n=437)\end{array}$ & 37.65 & 49.43 & Neutral $(n=222)$, standard victim $(n=215)$ & https://aspredicted.org/blind.php? $x=59 h 29 \mathrm{w}$ \\
\hline $\begin{array}{l}9(\text { Target } n=1000, \text { final } n=999, \\
\text { primary analysis } n=904)\end{array}$ & 41.69 & 50.77 & $\begin{array}{l}\quad \text { Neutral } \mathrm{n}=441 \\
\text { (White male } \mathrm{n}=88, \text { White female } \mathrm{n}=101 \text {, } \\
\text { Black male } \mathrm{n}=125, \text { Black female } \mathrm{n}=127 \text {, } \\
\qquad \text { Standard victim } \mathrm{n}=463 \\
\text { (White male } \mathrm{n}=134, \text { White female } \mathrm{n}=121 \text {, } \\
\text { Black male } \mathrm{n}=108, \text { Black female } \mathrm{n}=100 \text { ) }\end{array}$ & $\underline{\text { https://aspredicted.org/blind.php? } x=7 q \text { h5 } 99}$ \\
\hline $10($ Target $\mathrm{n}=600$, final $n=598)$ & 40.34 & 44.15 & $\begin{array}{c}\text { Control }(n=189), \text { moral }(n=212) \\
\text { competent }(n=197)\end{array}$ & https://aspredicted.org/blind.php? $x=c a 22 f 3$ \\
\hline $\begin{array}{c}\text { 11a }(\text { Target } \mathrm{n}=800, \text { final } \mathrm{n}= \\
801)\end{array}$ & 35.50 & 41.82 & $\begin{array}{c}\text { Neutral incentives }(\mathrm{n}=200) \\
\text { neutral disincentives }(\mathrm{n}=201) \\
\text { standard victim incentives }(\mathrm{n}=205) \\
\text { standard victim disincentives }(\mathrm{n}=195)\end{array}$ & http://aspredicted.org/blind.php? $\mathrm{x}=\mathrm{q} 4 \mathrm{be} 2 \mathrm{q}$ \\
\hline $11 \mathrm{~b}($ Target $\mathrm{n}=400, n=399)$ & 39.16 & 55.14 & Incentives $(n=180)$, disincentives $(n=219)$ & Not pre-registered \\
\hline $12($ Target $\mathrm{n}=600$, final $\mathrm{n}=602)$ & 35.76 & 40.37 & $\begin{array}{c}\text { Neutral }(n=200), \text { standard victim }(n=200), \\
\text { other victim }(n=202)\end{array}$ & http://aspredicted.org/blind.php? $x=d v 2 e w 7$ \\
\hline $13($ Target $\mathrm{n}=600$, final $\mathrm{n}=602$ ) & 34.98 & 46.18 & $\begin{array}{l}\text { Neutral }(\mathrm{n}=199), \text { standard victim }(\mathrm{n}=201) \\
\text { accident victim: earthquake }(\mathrm{n}=202)\end{array}$ & http://aspredicted.org/blind.php? $x=m 437 z d$ \\
\hline $14($ Target $\mathrm{n}=400$, final $\mathrm{n}=403)$ & 33.74 & 44.67 & Neutral $(n=201)$, standard victim $(n=202)$ & http://aspredicted.org/blind.php?x=ez3xt6 \\
\hline $\begin{array}{c}\text { Pre-test for } 15 \\
\text { (Target } \mathrm{n}=800 \text {, final } \mathrm{n}=803 \text { ) }\end{array}$ & 35.71 & 42.96 & $\begin{array}{l}\text { Not upset immoral }(\mathrm{n}=202) \\
\text { not upset moral }(\mathrm{n}=202), \\
\text { upset immoral }(\mathrm{n}=201) \text {, upset moral }(\mathrm{n}=198)\end{array}$ & Not pre-registered \\
\hline $15($ Target $\mathrm{n}=400$, final $\mathrm{n}=401)$ & 35.53 & 45.39 & Neutral $(n=200)$, standard victim $(n=201)$ & http://aspredicted.org/blind.php? $x=8 \mathrm{dr} 6 \mathrm{xz}$ \\
\hline $16($ Target $\mathrm{n}=200$, final $\mathrm{n}=201)$ & 35.61 & 51.24 & $\begin{array}{l}\text { Positively-valanced control }(\mathrm{n}=103), \\
\text { direct morality }(\mathrm{n}=98)\end{array}$ & Not pre-registered \\
\hline
\end{tabular}

Table S1. Sample information and pre-registraiton links for each experiment. Note that in Experiments 9, 10, and 11b, sample sizes are relatively less even across cells because we did not use the "evenly present elements" feature on Qualtrics to ensure equal sample sizes across cells. Note also that Experiments 8-9 included three attention checks and, per our pre-registrations, our primary analyses restrict to subjects who passed all three checks. For these experiments, the reported information about age, gender, and the size of each cell comes specifically from our primary analysis sample. Finally, note that Experiments 2, 8 and 9 (but no other experiments) included a "non-binary/other" option in our measure of subject gender; in Experiment 2, no subjects selected this option; in Experiment 8, the gender distribution was $49.43 \%$ male, 49.89\% female, and .69\% non-binary/other; and in Experiment 9 , the gender distribution was $50.77 \%$ male, $48.78 \%$ female, and $.44 \%$ non-binary/other. 


\subsection{Overview of experimental methods}

In Tables S2a-b, we provide a detailed overview of the design of each of our experiments. For each table, we report the vignette used, key dependent measures (defined as the variables that we analyzed in the main text), secondary dependent measures (defined as the variables that we did not analyze in the main text), and notes about some salient features of the design.

Then, in the "full experimental methods" section at the end of this document, we provide more extensive design information about each of our experiments. Specifically, for each experiment, we provide a design overview, including the full texts of all versions of our vignettes, and report all measures collected (as well as information about the order in which our measures were collected). Additionally, all of our materials, data, and scripts are available online at https://osf.io/ckxb3/.

We note that Table S2b, the "full experimental methods" section of this document, and our OSF page all include information about a pre-test for Experiment 15; however, this, pre-test is not reported in main text Table 1 (or in the study count or total $n$ reported in the main text) because it was merely used to select stimuli for Experiment 15 and its data is not included in any main text analyses. 


\begin{tabular}{|c|c|c|c|c|c|}
\hline Experiment & Vignette & $\begin{array}{c}\text { Conditions } \\
\text { (between-subjects) }\end{array}$ & $\begin{array}{c}\begin{array}{c}\text { Key dependent measures } \\
\text { (analyzed in main text) }\end{array} \\
\text { Note: all variables are with reference } \\
\text { to target }\end{array}$ & $\begin{array}{c}\text { Secondary dependent measures } \\
\text { (not analyzed in main text) } \\
\text { Note: only some variables are with } \\
\text { reference to target, } \\
\text { as specified below }\end{array}$ & Design notes \\
\hline $1(n=802$, Mturk $)$ & iPad theft & $\begin{array}{l}\text { Neutral; standard victim; } \\
\text { other victim; } \\
\text { minimal narrative victim }\end{array}$ & $\begin{array}{l}\text { Morality; trustworthiness; predicted } \\
\text { past/future, general/specific, } \\
\text { moral/immoral behavior }\end{array}$ & $\begin{array}{c}\text { Sympathy towards target; } \\
\text { exploitability of target (not including } \\
\text { trusting item); } \\
\text { blame of "other person" (in all } \\
\text { conditions besides neutral) }\end{array}$ & $\begin{array}{l}\text { Randomized gender of characters; two- } \\
\text { item Belief in Just World (BJW) scale } \\
\text { included in demographic survey (at end } \\
\text { of experiment) as potential moderator }\end{array}$ \\
\hline $2(n=207$, lab $)$ & iPad theft & Neutral; standard victim & Morality; trustworthiness & $\begin{array}{c}\text { Sympathy towards target; } \\
\text { exploitability of target (including } \\
\text { trusting item) }\end{array}$ & $\begin{array}{c}\text { Randomized gender of characters; two- } \\
\text { item BJW scale included in } \\
\text { demographic survey (at end of } \\
\text { experiment) as potential moderator } \\
\end{array}$ \\
\hline $3(n=803$, Mturk $)$ & iPad theft & $\begin{array}{l}\text { Neutral; standard victim; } \\
\text { accident victim: cat; } \\
\text { accident victim: earthquake }\end{array}$ & $\begin{array}{c}\text { Morality; trustworthiness; intelligence; } \\
\text { athleticism; funniness; sociability }\end{array}$ & $\begin{array}{c}\text { Sympathy towards target; } \\
\text { exploitability of target (including } \\
\text { trusting item) } \\
\end{array}$ & Randomized gender of characters \\
\hline $4(n=510$, Mturk $)$ & $\begin{array}{l}\text { iPad theft; } \\
\text { verbal attack; } \\
\text { sexual aggression } \\
\text { (within-subjects) }\end{array}$ & Neutral; standard victim & Morality; trustworthiness & $\begin{array}{l}\text { Sympathy towards target; } \\
\text { exploitability of target } \\
\text { (not including trusting item); } \\
\text { blame of "other person" } \\
\text { (in standard victim) }\end{array}$ & \begin{tabular}{|} 
Randomized gender of characters for \\
iPad theft vignette only; \\
before evaluating vignettes (i.e., at \\
start of experiment), presented \\
demographic survey (with two-item \\
BJW scale) and a set of questions \\
assessing ideology (including about \\
guns, sexual harrassment/assault, and \\
general political ideology), as potential \\
moderators
\end{tabular} \\
\hline $5(n=803$, Mturk $)$ & iPad theft & $\begin{array}{l}\text { First-person vs. third-person } X \\
\text { Neutral vs. standard victim }\end{array}$ & $\begin{array}{c}\text { Morality; trustworthiness; intelligence; } \\
\text { athleticism }\end{array}$ & $\begin{array}{c}\text { Sympathy towards target; } \\
\text { exploitability of target (including } \\
\text { trusting item) }\end{array}$ & Randomized gender of characters \\
\hline $6(n=802$, Mturk $)$ & Idea theft & $\begin{array}{l}\text { First-person vs. third-person } X \\
\text { Neutral vs. standard victim }\end{array}$ & $\begin{array}{c}\text { Morality; trustworthiness; intelligence; } \\
\text { athleticism }\end{array}$ & $\begin{array}{c}\text { Sympathy towards target; } \\
\text { exploitability of target (including } \\
\text { trusting item); evaluation of target as } \\
\text { angry, unforgiving, negative, and } \\
\text { entitled; subjects' self-reported belief } \\
\text { that events described in vignette were } \\
\text { true } \\
\end{array}$ & Randomized gender of characters \\
\hline $7(n=401$, Mturk $)$ & Corrupt doctor & Neutral; standard victim & $\begin{array}{c}\text { Morality; trustworthiness; intelligence; } \\
\text { athleticism; predictions for four moral } \\
\text { and four immoral behaviors }\end{array}$ & $\begin{array}{c}\text { Sympathy towards target; } \\
\text { exploitability of target (including } \\
\text { trusting item) }\end{array}$ & $\begin{array}{c}\text { Randomized gender of characters; } \\
\text { vignette provides morally relevant } \\
\text { background information about the } \\
\text { target character }\end{array}$ \\
\hline $\begin{array}{c}8(n=503, \text { primary } \\
\text { analysis } n=437 \\
\text { Mturk })\end{array}$ & Rape & Neutral; standard victim & Morality; trustworthiness & & \\
\hline $\begin{array}{c}9(n=999, \text { primary } \\
\text { analysis } n=904 \\
\text { Mturk })\end{array}$ & iPad theft & $\begin{array}{l}\text { Neutral vs. standard victim } X \\
\text { Male vs. female target } X \\
\text { White vs. Black target }\end{array}$ & Morality; trustworthiness & & $\begin{array}{c}\text { Provided a photograph of target in all } \\
\text { conditions (each subject was randomly } \\
\text { presented with one of three potential } \\
\text { phtoographs corresponding to their } \\
\text { race/gender condition) }\end{array}$ \\
\hline
\end{tabular}

Table S2a. Design overview for Experiments 1-9. 


\begin{tabular}{|c|c|c|c|c|c|}
\hline Experiment & Vignette & $\begin{array}{c}\text { Conditions } \\
\text { (between-subjects) }\end{array}$ & \begin{tabular}{|c|} 
Key dependent measures \\
(analyzed in main text) \\
Note: all variables are with reference \\
to target, unless otherwise specified
\end{tabular} & \begin{tabular}{|}
$\begin{array}{c}\text { Secondary dependent measures } \\
\text { (not analyzed in main text) }\end{array}$ \\
Note: only some variables are with \\
reference to target, as specified below
\end{tabular} & Design notes \\
\hline $10(n=598$, Mturk $)$ & Idea theft & Control; moral; competent & $\begin{array}{l}\text { Morality; willingness to help target; } \\
\text { willingness to punish perpetrator }\end{array}$ & Competence of target & $\begin{array}{c}\text { All subjects saw "victim" condition of } \\
\text { idea theft vignette }\end{array}$ \\
\hline $\begin{array}{l}11 \mathrm{a}(n=801 \\
\quad \text { Mturk })\end{array}$ & Idea theft & $\begin{array}{l}\text { Incentives vs. disincentives } X \\
\text { Neutral vs. standard victim }\end{array}$ & Morality; trustworthiness & $\begin{array}{l}\text { Morality of "other person"; } \\
\text { trustworthiness of "other person"; } \\
\text { sympathy towards target; } \\
\text { reputation-based incentives to help } \\
\text { target; willingness to help target; } \\
\text { reputation-based incentives to punish } \\
\text { "other person"; willingness to punish } \\
\text { "other person"; blame of "other person" } \\
\text { (in standard victim); } \\
\text { anger towards "other person" } \\
\text { (in standard victim) }\end{array}$ & $\begin{array}{l}\text { Manipulation of incentives to vs. not } \\
\text { to punish employed an imagination } \\
\text { exercise that involved a writing task }\end{array}$ \\
\hline $\begin{array}{c}11 \mathrm{~b}(n=399 \\
\text { Mturk })\end{array}$ & Idea theft & Incentives vs. disincentives & $\begin{array}{c}\text { Incentives to punish; incentives to } \\
\text { help; extent to which victim is a } \\
\text { victim }\end{array}$ & & $\begin{array}{c}\text { All subjects saw "victim" condition of } \\
\text { idea theft vignette }\end{array}$ \\
\hline $12(n=602$, Mturk $)$ & iPad theft & $\begin{array}{l}\text { Neutral; standard victim; } \\
\text { other victim }\end{array}$ & $\begin{array}{l}\text { Predicted money returned in } \\
\text { hypothetical economic Trust Game; } \\
\text { morality; trustworthiness }\end{array}$ & $\begin{array}{c}\text { Money sent in hypothetical economic } \\
\text { Trust Game }\end{array}$ & $\begin{array}{c}\text { Experiment featured a hypothetical } \\
\text { Trust Game, in which the subject was } \\
\text { the first-mover (i.e., Trustor) and the } \\
\text { vignette target was the second-mover } \\
\text { (i.e., Trustee), and in which subjects } \\
\text { completed a set of Trust Game } \\
\text { comprehension questions } \\
\end{array}$ \\
\hline $13(n=602$, Mturk $)$ & iPad theft & $\begin{array}{l}\text { Neutral; standard victim; } \\
\text { accident victim: earthquake }\end{array}$ & $\begin{array}{l}\text { Reputation-based incentives to help } \\
\text { target; morality; trustworthiness }\end{array}$ & $\begin{array}{c}\text { Willingness to help target; Reputation- } \\
\text { based incentives to affiliate with target; } \\
\text { willingness to affiliate with target; } \\
\text { sympathy towards target }\end{array}$ & Randomized gender of characters \\
\hline $14(n=403$, Mturk $)$ & iPad theft & Neutral; standard victim & $\begin{array}{l}\text { Predictions for four moral and four } \\
\text { immoral behaviors; morality; } \\
\text { trustworthiness }\end{array}$ & $\begin{array}{l}\text { Intelligence of target; athleticism of } \\
\text { target; sympathy towards target; } \\
\text { exploitability of target (including } \\
\text { trusting item) }\end{array}$ & $\begin{array}{l}\text { Randomized gender of characters; } \\
\text { modified the "victim" condition of the } \\
\text { vignette to avoid stating that the target } \\
\text { was upset following their victimization }\end{array}$ \\
\hline $\begin{array}{l}\text { Pre-test for } 15 \\
(n=803, \text { Mturk })\end{array}$ & $\begin{array}{c}\text { [did not use a } \\
\text { standard vignette] }\end{array}$ & $\begin{array}{l}\text { Immoral vs. moral target } X \\
\text { Not upset vs. upset target }\end{array}$ & Predictions for 12 candidate behaviors & & $\begin{array}{c}\text { Randomized gender of characters; each } \\
\text { subject evaluated a random set of } 6 \text { of } \\
\text { the } 12 \text { candidate behaviors }\end{array}$ \\
\hline $15(n=401$, Mturk $)$ & iPad theft & Neutral; standard victim & $\begin{array}{l}\text { Predictions for four moral behaviors; } \\
\text { morality; trustworthiness }\end{array}$ & Upsetness of target & $\begin{array}{c}\text { Randomized gender of characters; used } \\
\text { pre-test to select behaviors for behavior } \\
\text { predictions DVs. Specifically, two of } \\
\text { the moral behaviors were pre-tested to } \\
\text { be seen as less likely among upset } \\
\text { actors, and two were pre-tested not to } \\
\text { be }\end{array}$ \\
\hline $16(n=201$, Mturk $)$ & $\begin{array}{c}\text { [no victim narrative; } \\
\text { drew from iPad } \\
\text { theft] }\end{array}$ & $\begin{array}{l}\text { Positively-valanced control; } \\
\text { direct morality }\end{array}$ & $\begin{array}{c}\text { Morality; trustworthiness; predictions } \\
\text { for four moral and four immoral } \\
\text { behaviors }\end{array}$ & $\begin{array}{c}\text { Intelligence of target; athleticism of } \\
\text { target }\end{array}$ & Randomized gender of characters \\
\hline
\end{tabular}

Table S2b. Design overview for Experiments 10-16. 


\subsection{Statistical analysis approach}

In general, our statistical analyses use linear regression. Whenever we aggregate data across experiments, we include experiment dummies in our statistical models. In Experiment 4, subjects evaluated three different vignettes and thus we have three sets of observations for each subject; in analyses that that include all of these observations (i.e., because they simultaneously analyze more than just one vignette from Experiment 4), our regressions cluster standard error on subject to account for the repeated observations. Additionally, in our analyses of Experiment 3, as well as an aggregate analysis of Experiments 3, 5-7, we compare the effects of our manipulations on ratings of the target on different traits. In these analyses, we use mixed-model ANOVAs in which trait type (e.g., moral vs. nonmoral) is a within-subjects factor and condition (as well as experiment, in our aggregate analysis of Experiments 3, 5-7) is a between-subjects factor.

\section{Elaboration of main text analyses}

\subsection{Analyses of the Virtuous Victim effect on morality and trustworthiness, within each individual experiment and overall}

In the main text, we claim that the Virtuous Victim effect is robust, and comparable in magnitude, for both our morality and trustworthiness dependent variables. Here, we support this claim by reporting analyses of the Virtuous Victim effect on each of these dependent variables, within each individual experiment and overall.

To this end, in Table S3 (below), we report results from comparisons of our neutral and standard victim conditions $(0=$ neutral, $1=$ standard victim $)$ within each individual experiment that featured these conditions. For each experiment, we report the vignette used, whether the experiment featured our "basic design" (and if not, how the designed differed from our basic design), the sample size, and the effects of our neutral vs. standard victim comparison on morality and trustworthiness. We also report results from an analysis comparing the magnitude of these two effects (i.e., investigating whether the Virtuous Victim effect was significantly different in size for our morality vs. trustworthiness DVs). To conduct these analyses, we shape our data to have one observation per subject-DV. Then, we predict DV ratings as a function of condition $(0=$ neutral, $1=$ standard victim $)$, DV type $(0=$ trustworthiness, $1=$ morality $)$, and their interaction, clustering standard error on subject to account for repeated measures. We then report the interaction coefficient.

We note that for Experiments 5-6, which crossed our "neutral vs. standard victim" manipulation with a "first vs. third person" manipulation, we report the effects from the third person conditions. This choice reflects that (i) all of our other experiments featured only third person conditions, and (ii) our third person conditions more reliably produced a Virtuous Victim effect, thus creating a more informative test of whether that effect was stronger for morality vs. trustworthiness. Similarly, for Experiment 11a, which crossed our "neutral vs. standard victim" manipulation with a manipulation of incentives versus disincentives for justice-restorative action, we report the effects from the incentives conditions. This choice reflects that we only predicted and observed a Virtuous Victim effect within our incentives conditions. Finally, we note that in Experiment 9, we report results from the comparison of our neutral and standard victim conditions, collapsing across our manipulations of race and gender.

Table S3 also reports, in bold, results from analyses that pool data across our experiments (and include experiment dummies, as in all aggregate analyses in this paper). In particular, we 
conduct one set of analyses that pools data across all of our experiments, and one set of analyses that pools data across our basic design experiments only.

Finally, we note that because subjects in Experiment 4 evaluated three different vignettes, we analyze Experiment 4 three times - once for each of the three vignettes. In our pooled analyses (which include Experiment 4), we shape our Experiment 4 data to have one observation per subject-vignette, clustering standard error on subject to account for repeated measures. (And, in our analyses comparing our morality vs. trustworthiness DVs, we shape our Experiment 4 data to have one observation per subject-vignette-DV.)

\begin{tabular}{|c|c|c|c|c|c|c|}
\hline Experiment & Vignette & Basic design? & Sample size & Morality effect & Trustworthiness effect & $\begin{array}{c}\text { Morality vs. trustworthiness } \\
\text { comparison }\end{array}$ \\
\hline 1 & iPad theft & Yes & 403 & $\mathrm{~b}=.74, \mathrm{t}=5.42, \mathrm{p}<.001$ & $\mathrm{~b}=.61, \mathrm{t}=4.05, \mathrm{p}<.001$ & $\mathrm{~b}=.14, \mathrm{t}=1.16, \mathrm{p}=.246$ \\
\hline 2 & iPad theft & Yes & 207 & $\mathrm{~b}=.52, \mathrm{t}=3.15, \mathrm{p}=.002$ & $\mathrm{~b}=.31, \mathrm{t}=1.64, \mathrm{p}=.102$ & $\mathrm{~b}=.21, \mathrm{t}=1.49, \mathrm{p}=.137$ \\
\hline 3 & iPad theft & Yes & 400 & $\mathrm{~b}=.61, \mathrm{t}=4.36, \mathrm{p}<.001$ & $\mathrm{~b}=.61, \mathrm{t}=3.97, \mathrm{p}<.001$ & $\mathrm{~b}=.01, \mathrm{t}=.06, \mathrm{p}=.948$ \\
\hline 4 & iPad theft & Yes & 510 & $\mathrm{~b}=.44, \mathrm{t}=3.14, \mathrm{p}=.002$ & $\mathrm{~b}=.52, \mathrm{t}=3.67, \mathrm{p}<.001$ & $\mathrm{~b}=-.08, \mathrm{t}=-.88, \mathrm{p}=.379$ \\
\hline 4 & Verbal attack & Yes & 510 & $\mathrm{~b}=.52, \mathrm{t}=3.86, \mathrm{p}<.001$ & $\mathrm{~b}=.47, \mathrm{t}=3.32, \mathrm{p}=.001$ & $\mathrm{~b}=.05, \mathrm{t}=.63, \mathrm{p}=.531$ \\
\hline 4 & Sexual agression & Yes & 510 & $\mathrm{~b}=.19, \mathrm{t}=1.16, \mathrm{p}=.245$ & $\mathrm{~b}=.18, \mathrm{t}=1.14, \mathrm{p}=.256$ & $\mathrm{~b}=.01, \mathrm{t}=.13, \mathrm{p}=.897$ \\
\hline $\begin{array}{c}5 \text { (third-person } \\
\text { conditions only) }\end{array}$ & iPad theft & Yes & 397 & $\mathrm{~b}=.29, \mathrm{t}=2.08, \mathrm{p}=.038$ & $\mathrm{~b}=.34, \mathrm{t}=2.45, \mathrm{p}=.015$ & $\mathrm{~b}=-.06, \mathrm{t}=-0.49, \mathrm{p}=.621$ \\
\hline $\begin{array}{l}6 \text { (third-person } \\
\text { conditions only) }\end{array}$ & Idea theft & Yes & 403 & $\mathrm{~b}=.39, \mathrm{t}=2.93, \mathrm{p}=.004$ & $\mathrm{~b}=.48, \mathrm{t}=3.58, \mathrm{p}<.001$ & $\mathrm{~b}=-.09, \mathrm{t}=-0.79, \mathrm{p}=.429$ \\
\hline 7 & \begin{tabular}{|l|} 
Corrupt doctor \\
\end{tabular} & Yes & 401 & $\mathrm{~b}=.30, \mathrm{t}=2.12, \mathrm{p}=.034$ & $\mathrm{~b}=.20, \mathrm{t}=1.49, \mathrm{p}=.138$ & $\mathrm{~b}=.11, \mathrm{t}=1.06, \mathrm{p}=.290$ \\
\hline 8 & Rape & Yes & 437 & $\mathrm{~b}=.99, \mathrm{t}=6.98, \mathrm{p}<.001$ & $\mathrm{~b}=1.10, \mathrm{t}=7.64, \mathrm{p}<.001$ & $\mathrm{~b}=-.11, \mathrm{t}=-1.31, \mathrm{p}=.192$ \\
\hline 9 & iPad theft & No (included photos of target) & 904 & $\mathrm{~b}=.40, \mathrm{t}=4.11, \mathrm{p}<.001$ & $\mathrm{~b}=.40, \mathrm{t}=3.90, \mathrm{p}<.001$ & $\mathrm{~b}=.01, \mathrm{t}=0.11, \mathrm{p}=.911$ \\
\hline $\begin{array}{c}11 \text { a (incentives } \\
\text { conditions only) }\end{array}$ & Idea theft & No (included incentives manipulation) & 405 & $\mathrm{~b}=.58, \mathrm{t}=3.71, \mathrm{p}<.001$ & $\mathrm{~b}=.69, \mathrm{t}=4.39, \mathrm{p}<.001$ & $\mathrm{~b}=-.11, \mathrm{t}=-1.43, \mathrm{p}=.153$ \\
\hline 12 & iPad theft & $\begin{array}{c}\text { No (measured predicted moral behavior } \\
\text { before measuring moral character) }\end{array}$ & 400 & $\mathrm{~b}=.35, \mathrm{t}=2.43, \mathrm{p}=.015$ & $\mathrm{~b}=.26, \mathrm{t}=1.73, \mathrm{p}=.085$ & $\mathrm{~b}=.09, \mathrm{t}=0.92, \mathrm{p}=.360$ \\
\hline 13 & iPad theft & $\begin{array}{l}\text { No (measured incentives/willingness to } \\
\text { help/affiliate with target before measuring } \\
\text { moral character) }\end{array}$ & 400 & $\mathrm{~b}=.32, \mathrm{t}=2.14, \mathrm{p}=.033$ & $\mathrm{~b}=.45, \mathrm{t}=2.86, \mathrm{p}=.004$ & $\mathrm{~b}=-.12, \mathrm{t}=-1.28, \mathrm{p}=.202$ \\
\hline 14 & iPad theft & $\begin{array}{c}\text { No (measured predicted moral behavior } \\
\text { before measuring moral character) }\end{array}$ & 403 & $\mathrm{~b}=.14, \mathrm{t}=.94, \mathrm{p}=.349$ & $\mathrm{~b}=.39, \mathrm{t}=2.35, \mathrm{p}=.019$ & $\mathrm{~b}=-.25, \mathrm{t}=-2.37, \mathrm{p}=.018$ \\
\hline 15 & iPad theft & $\begin{array}{c}\text { No (measured predicted moral behavior } \\
\text { before measuring moral character) }\end{array}$ & 401 & $\mathrm{~b}=.14, \mathrm{t}=1.10, \mathrm{p}=.271$ & $\mathrm{~b}=.23, \mathrm{t}=1.73, \mathrm{p}=.085$ & $\mathrm{~b}=-.09, \mathrm{t}=-0.97, \mathrm{p}=.334$ \\
\hline $\begin{array}{c}\text { All experiments, } \\
\text { pooled }\end{array}$ & & & $\begin{array}{r}7091 \text { obs, } 6071 \\
\text { unique subjects }\end{array}$ & $\mathrm{b}=.43, \mathrm{t}=11.32, \mathrm{p}<.001$ & $\mathrm{~b}=.45, \mathrm{t}=11.67, \mathrm{p}<.001$ & $\mathrm{~b}=-.02, \mathrm{t}=-0.9, \mathrm{p}=.370$ \\
\hline $\begin{array}{c}\text { All basic design } \\
\text { experiments, pooled }\end{array}$ & & & \begin{tabular}{|l|}
4178 obs, 3158 \\
unique subjects
\end{tabular} & $\mathrm{b}=.50, \mathrm{t}=9.50, \mathrm{p}<.001$ & $\mathrm{~b}=.49, \mathrm{t}=9.28, \mathrm{p}<.001$ & $\mathrm{~b}=.01, \mathrm{t}=0.23, \mathrm{p}=.815$ \\
\hline
\end{tabular}

Table S3. The Virtuous Victim effect on morality and trustworthiness, across individual experiments and in aggregate analyses.

Together, the analyses presented in Table S3 suggest that the Virtuous Victim effect is robust, and comparable in magnitude, for both our morality and trustworthiness DVs. We also visually illustrate these points in Fig. S1, which displays forest plots from random-effects metaanalyses of the effects reported in Table S3, generated using the "metan" function in STATA. We conducted separate analyses for (i) all experiments in Table S3 (Panels A-B) and (ii) the experiments in Table S3 featuring our basic design (Panels C-D). The overall effects are computed via the DerSimonian-Laird (DL) random-effects model.

Finally, we note that the aggregate analyses reported in Table S3 provide relatively strong evidence that the magnitude of the Virtuous Victim effect does not differ meaningfully across our morality versus trustworthiness DVs. For our aggregate analysis of all experiments, the unstandardized coefficient for the interaction between victim status and DV type is $b=-.02$; the $95 \%$ confidence interval on this coefficient is [-.07, .03]. For our aggregate analysis of all basic design experiments, the unstandardized interaction coefficient is $b=.01$; the $95 \%$ confidence interval is $[-.06, .07]$. Given that the overall effect of victim status is about $b=.44$ for all experiments and $b=.50$ for our basic design experiments, these CIs suggest that even the upper bounds of plausible interaction effects are relatively small in comparison. 
A

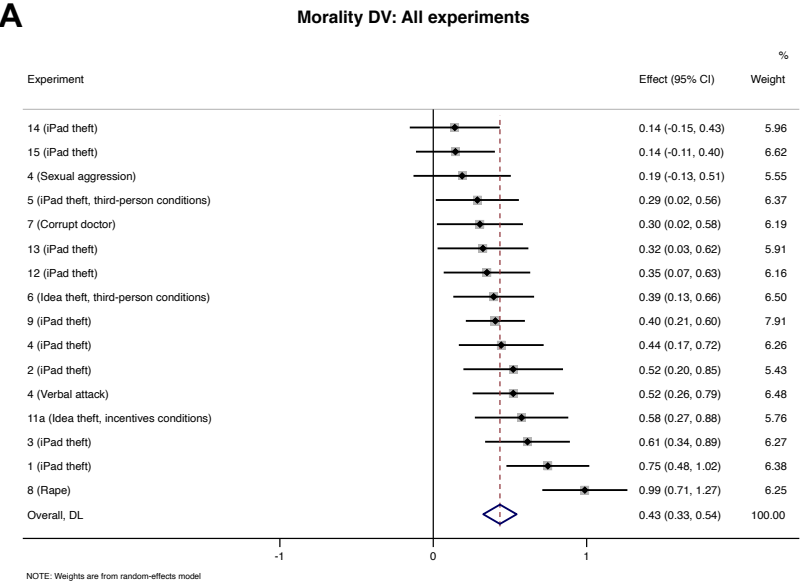

B

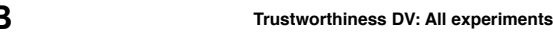

C

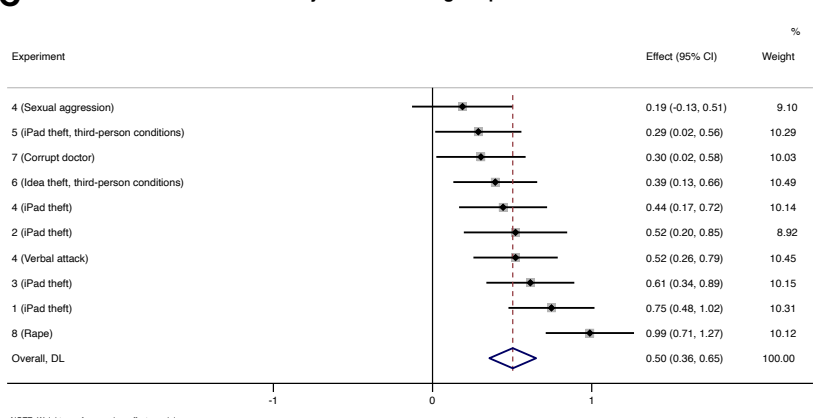

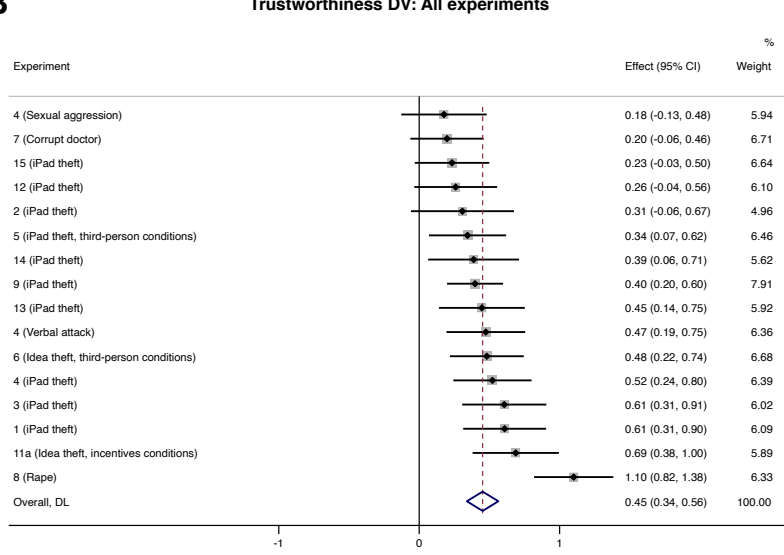

D

Trustworthiness DV: Basic design experiments

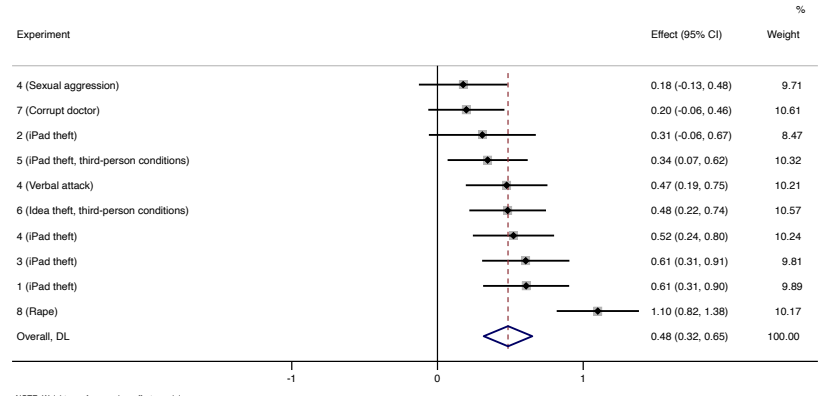

Fig. S1. Forest plots from meta-analyses of the effects reported in Table S3.

\subsection{Experiment 3}

In main text, we presented analyses of Experiment 3 that aggregated both of our two accident conditions (earthquake and cat), as well as our sets of moral (moral and trustworthy) and nonmoral (intelligent, athletic, funny, and sociable) traits. Here, we elaborate on these analyses. In Fig. S2, we plot ratings of each individual trait in each individual condition, and in Table S4a-b, we present more extensive statistical analyses of these data.

In Table S4a, we present analyses in which we continue to aggregate across our set of moral traits, and across our set of nonmoral traits. For both aggregate moral traits and aggregate nonmoral traits, we report results from linear regressions comparing the victim vs. neutral, accident vs. neutral, and victim vs. accident conditions. Then, we compare the effect of each of these condition contrasts on moral vs. nonmoral traits. To do so, we (i) conduct a mixed-model ANOVA in which the relevant condition contrast is the between-subjects factor and trait type (i.e., moral vs. nonmoral) is the within-subjects factor, and (ii) report the interaction between condition and trait type.

In Table S4b, we present analyses of individual traits. For each trait, we report results from linear regressions comparing the victim vs. neutral, accident vs. neutral, and victim vs. accident conditions.

Throughout Table S4a-b, for all comparisons involving accident conditions, we report results from three tests: one aggregating data from the earthquake and cat conditions, one using data from the earthquake condition only, and one using data from the cat condition only. 


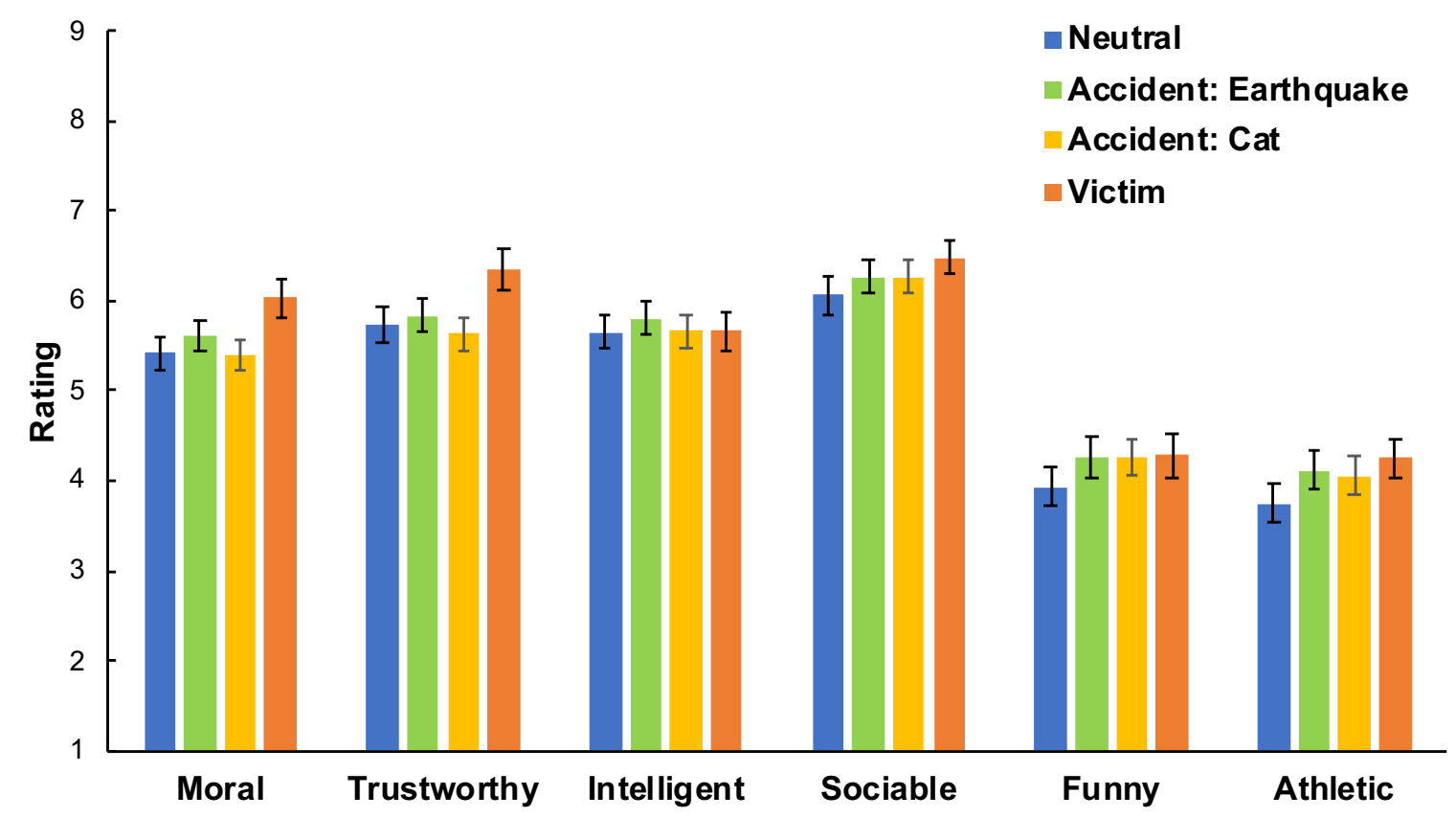

Fig. S2. Trait ratings across conditions in Experiment 3.

\begin{tabular}{|c|c|c|c|}
\hline & $\begin{array}{l}\text { Victim vs. Neutral } \\
\qquad(\mathrm{n}=\mathbf{4 0 0})\end{array}$ & $\begin{array}{c}\text { Accident vs. Neutral } \\
\text { Both accident conditions vs. Neutral: } n=605 \\
\text { Earthquake vs. Neutral: } n=404 \\
\text { Cat vs. Neutral: } n=403 \\
\end{array}$ & $\begin{array}{l}\text { Victim vs. Accident } \\
\text { Victim vs. Both accident conditions: } n=601 \\
\text { Victim vs. Earthquake: } n=400 \\
\text { Victim vs. } \text { Cat: } n=399 \\
\end{array}$ \\
\hline \multirow{3}{*}{ Moral traits } & \multirow{3}{*}{$\begin{array}{c}\text { Neutral }=5.57, \text { Victim }=6.18 \\
\mathbf{b}=\mathbf{0 . 6 1}, \mathbf{t}=\mathbf{4 . 6 5}, \mathbf{p}<\mathbf{. 0 0 1}\end{array}$} & $\begin{aligned} \text { Neutral }= & 5.57, \text { Both accident conditions }=5.62 \\
& \mathbf{b}=\mathbf{0 . 0 5}, \mathbf{t}=\mathbf{0 . 4 6 ,}, \mathbf{p}=\mathbf{. 6 4 6}\end{aligned}$ & $\begin{array}{l}\text { Both accident conditions }=5.62 \text {, Victim }=6.18, \\
\mathbf{b}=\mathbf{0 . 5 6}, \mathbf{t}=\mathbf{5 . 1 9 ,} \mathbf{p}<\mathbf{. 0 0 1}\end{array}$ \\
\hline & & $\begin{array}{c}\text { Neutral }=5.57, \text { Earthquake }=5.73 \\
\mathbf{b}=\mathbf{0 . 1 5}, \mathbf{t}=\mathbf{1 . 2 3}, \mathbf{p}=\mathbf{. 2 1 8}\end{array}$ & $\begin{array}{c}\text { Earthquake }=5.73, \text { Victim }=6.18 \\
\mathbf{b}=\mathbf{0 . 4 6 , \mathbf { t }}=\mathbf{3 . 5 7}, \mathbf{p}<\mathbf{. 0 0 1}\end{array}$ \\
\hline & & $\begin{array}{c}\text { Neutral }=5.57, \text { Cat }=5.52 \\
\mathbf{b}=\mathbf{- 0 . 0 6 ,} \mathbf{t}=\mathbf{- 0 . 4 6 ,} \mathbf{p}=\mathbf{. 6 4 3}\end{array}$ & $\begin{array}{l}\text { Cat }=5.52, \text { Victim }=6.18, \\
\mathbf{b}=\mathbf{0 . 6 7}, \mathbf{t}=\mathbf{5 . 2 9}, \mathbf{p}<\mathbf{. 0 0 1}\end{array}$ \\
\hline \multirow{3}{*}{ Non-moral traits } & \multirow{3}{*}{$\begin{array}{l}\text { Neutral }=4.85, \text { Victim }=5.17 \\
\mathbf{b}=\mathbf{0 . 3 2}, \mathbf{t}=\mathbf{3 . 0 0}, \mathbf{p}=\mathbf{. 0 0 3}\end{array}$} & $\begin{aligned} \text { Neutral }= & 4.85, \text { Both accident conditions }=5.09, \mathbf{b} \\
& =\mathbf{0 . 2 4}, \mathbf{t}=\mathbf{2 . 6 5}, \mathbf{p}=\mathbf{. 0 0 8}\end{aligned}$ & $\begin{array}{l}\text { Both accident conditions }=5.09 \text {, Victim }=5.17, \mathbf{b}= \\
\mathbf{0 . 0 8 ,} \mathbf{t}=\mathbf{0 . 8 9}, \mathbf{p}=\mathbf{. 3 7 6}\end{array}$ \\
\hline & & $\begin{array}{c}\text { Neutral }=4.85, \text { Earthquake }=5.11 \\
\mathbf{b}=\mathbf{0 . 2 6}, \mathbf{t}=\mathbf{2 . 5 8 ,} \mathbf{p}=\mathbf{. 0 1 0}\end{array}$ & $\begin{array}{c}\text { Earthquake }=5.11, \text { Victim }=5.17 \\
\mathbf{b}=\mathbf{0 . 0 6}, \mathbf{t}=\mathbf{0 . 5 4}, \mathbf{p}=\mathbf{. 5 9 1}\end{array}$ \\
\hline & & $\begin{array}{l}\text { Neutral }=4.85, \text { Cat }=5.06 \\
\mathbf{b}=\mathbf{0 . 2 1}, \mathbf{t}=\mathbf{2 . 0 5}, \mathbf{p}=\mathbf{. 0 4 1}\end{array}$ & $\begin{array}{r}\text { Cat }=5.06, \text { Victim }=5.17 \\
\mathbf{b}=\mathbf{0 . 1 1}, \mathbf{t}=\mathbf{0 . 9 8}, \mathbf{p}=\mathbf{. 3 2 8}\end{array}$ \\
\hline \multirow{3}{*}{$\begin{array}{c}\text { Moral vs. } \\
\text { Non-moral traits }\end{array}$} & \multirow{3}{*}{$F=4.91, p=.027$} & Both accident conditions: $\mathbf{F}=\mathbf{2 . 9 7 ,} \mathbf{p}=\mathbf{. 0 8 5}$ & Both accident conditions: $\mathbf{F}=\mathbf{1 9 . 7 0 ,} \mathbf{p}<\mathbf{. 0 0 1}$ \\
\hline & & Earthquake: $\mathrm{F}=\mathbf{0 . 6 9 ,} \mathrm{p}=.406$ & Earthquake: $\mathbf{F}=\mathbf{9 . 8 7 ,} \mathbf{p}=.002$ \\
\hline & & Cat: $F=\mathbf{4 . 5 0}, p=.034$ & Cat: $F=\mathbf{2 0 . 1 0}, \mathbf{p}<.001$ \\
\hline
\end{tabular}

Table S4a. Analyses of aggregate traits in Experiment 3. 


\begin{tabular}{|c|c|c|c|}
\hline Trait & $\begin{array}{l}\text { Victim vs. Neutral } \\
\qquad(\mathrm{n}=\mathbf{4 0 0})\end{array}$ & $\begin{array}{l}\text { Accident vs. Neutral } \\
\text { Both accident conditions vs. Neutral: } n=605 \\
\text { Earthquake vs. Neutral: } n=404 \\
\text { Cat vs. Neutral: } n=403\end{array}$ & $\begin{array}{l}\text { Victim vs. Accident } \\
\text { Victim vs. Both accident conditions: } n=601 \\
\text { Victim vs. } \text { Earthquake: } n=400 \\
\text { Victim vs. } \text { Cat: } n=399\end{array}$ \\
\hline \multirow{3}{*}{ Moral } & \multirow{3}{*}{$\begin{array}{c}\text { Neutral }=5.41, \text { Victim }=6.03 \\
\mathbf{b}=\mathbf{0 . 6 1}, \mathbf{t}=\mathbf{4 . 3 6}, \mathbf{p}<\mathbf{. 0 0 1}\end{array}$} & $\begin{aligned} \text { Neutral }= & \text { 5.41, Both accident conditions }=5.51, \\
& \mathbf{b}=\mathbf{0 . 1 0}, \mathbf{t}=\mathbf{0 . 9 0}, \mathbf{p}=\mathbf{. 3 6 6}\end{aligned}$ & $\begin{array}{l}\text { Both accident conditions }=5.51 \text {, Victim }=6.03, \\
\qquad \mathbf{b}=\mathbf{0 . 5 1}, \mathbf{t}=\mathbf{4 . 5 1}, \mathbf{p}<\mathbf{. 0 0 1}\end{array}$ \\
\hline & & $\begin{array}{c}\text { Neutral }=5.41, \text { Earthquake }=5.62 \\
\mathbf{b}=\mathbf{0 . 2 1}, \mathbf{t}=\mathbf{1 . 5 9}, \mathbf{p}=\mathbf{. 1 1 2}\end{array}$ & 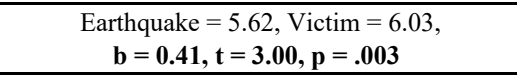 \\
\hline & & $\begin{array}{c}\text { Neutral }=5.41, \text { Cat }=5.40 \\
\mathbf{b}=\mathbf{- 0 . 0 1}, \mathbf{t}=\mathbf{- 0 . 0 6 ,} \mathbf{p}=\mathbf{. 9 5 1}\end{array}$ & $\begin{array}{r}\text { Cat }=5.40, \text { Victim }=6.03, \\
\mathbf{b}=\mathbf{0 . 6 2}, \mathbf{t}=\mathbf{4 . 6 4}, \mathbf{p}<\mathbf{. 0 0 1}\end{array}$ \\
\hline \multirow{3}{*}{ Trust } & \multirow{3}{*}{$\begin{array}{l}\text { Neutral }=5.74, \text { Victim }=6.34, \\
\mathbf{b}=\mathbf{0 . 6 1}, \mathbf{t}=\mathbf{3 . 9 7}, \mathbf{p}<\mathbf{. 0 0 1}\end{array}$} & $\begin{array}{c}\text { Neutral }=\text { 5.74, Both accident conditions }=5.73 \text {, } \\
\mathbf{b}=\mathbf{- 0 . 0 0 , t}=\mathbf{- 0 . 0 3 ,} \mathbf{p}=\mathbf{. 9 7 9}\end{array}$ & $\begin{array}{l}\text { Both accident conditions }=5.73 \text {, Victim }=6.34, \\
\mathbf{b}=\mathbf{0 . 6 1}, \mathbf{t}=\mathbf{4 . 8 2}, \mathbf{p}<\mathbf{. 0 0 1}\end{array}$ \\
\hline & & $\begin{array}{c}\text { Neutral }=5.74, \text { Earthquake }=5.84 \\
\mathbf{b}=\mathbf{0 . 1 0}, \mathbf{t}=\mathbf{0 . 7 0}, \mathbf{p}=\mathbf{. 4 8 3}\end{array}$ & $\begin{array}{c}\text { Earthquake }=5.84, \text { Victim }=6.34 \\
\mathbf{b}=\mathbf{0 . 5 1}, \mathbf{t}=\mathbf{3 . 4 0 ,}, \mathbf{p}=\mathbf{. 0 0 1}\end{array}$ \\
\hline & & $\begin{aligned} \text { Neutral }=5.74, \text { Cat }=5.63 \\
\mathbf{b}=\mathbf{- 0 . 1 1}, \mathbf{t}=\mathbf{- 0 . 7 5 ,} \mathbf{p}=\mathbf{. 4 5 5}\end{aligned}$ & $\begin{array}{r}\text { Cat }=5.63, \text { Victim }=6.34, \\
\mathbf{b}=\mathbf{0 . 7 1}, \mathbf{t}=\mathbf{4 . 7 6 ,}, \mathbf{p}<. \mathbf{0 0 1}\end{array}$ \\
\hline \multirow{3}{*}{ Intelligent } & \multirow{3}{*}{$\begin{array}{c}\text { Neutral }=5.65, \text { Victim }=5.66 \\
\mathbf{b}=\mathbf{0 . 0 1}, \mathbf{t}=\mathbf{0 . 0 6}, \mathbf{p}=\mathbf{. 9 5 5}\end{array}$} & $\begin{aligned} \text { Neutral }= & 5.65, \text { Both accident conditions }=5.73 \\
& \mathbf{b}=\mathbf{0 . 0 8}, \mathbf{t}=\mathbf{0 . 6 5}, \mathbf{p}=\mathbf{. 5 1 6}\end{aligned}$ & $\begin{array}{l}\text { Both accident conditions }=5.73 \text {, Victim }=5.66 \text {, } \\
\qquad \mathbf{b}=\mathbf{- 0 . 0 7}, \mathbf{t}=\mathbf{- 0 . 5 4}, \mathbf{p}=\mathbf{. 5 8 8}\end{array}$ \\
\hline & & $\begin{array}{c}\text { Neutral }=5.65 \text {, Earthquake }=5.80 \\
\mathbf{b}=\mathbf{0 . 1 5}, \mathbf{t}=\mathbf{1 . 1 3}, \mathbf{p}=\mathbf{. 2 6 0}\end{array}$ & $\begin{array}{l}\text { Earthquake }=5.80, \text { Victim }=5.66 \\
\mathbf{b}=\mathbf{- 0 . 1 4}, \mathbf{t}=\mathbf{- 0 . 9 7}, \mathbf{p}=\mathbf{. 3 3 4}\end{array}$ \\
\hline & & $\begin{array}{l}\text { Neutral }=5.65, \text { Cat }=5.66 \\
\mathbf{b}=\mathbf{0 . 0 0 ,} \mathbf{t}=\mathbf{0 . 0 2}, \mathbf{p}=\mathbf{. 9 8 1}\end{array}$ & $\begin{array}{r}\text { Cat }=5.66, \text { Victim }=5.66 \\
\mathbf{b}=\mathbf{0 . 0 0 , t}=\mathbf{0 . 0 3 , p}=\mathbf{. 9 7 4}\end{array}$ \\
\hline \multirow{3}{*}{ Sociable } & \multirow{3}{*}{$\begin{array}{c}\text { Neutral }=6.06, \text { Victim }=6.48 \\
\mathbf{b}=\mathbf{0 . 4 2}, \mathbf{t}=\mathbf{2 . 9 3}, \mathbf{p}=\mathbf{. 0 0 4}\end{array}$} & $\begin{aligned} \text { Neutral }= & 6.06, \text { Both accident conditions }=6.27, \\
& \mathbf{b}=\mathbf{0 . 2 0}, \mathbf{t}=\mathbf{1 . 6 3}, \mathbf{p}=\mathbf{. 1 0 5}\end{aligned}$ & $\begin{array}{l}\text { Both accident conditions }=6.27 \text {, Victim }=6.48, \\
\qquad \mathbf{b}=\mathbf{0 . 2 2}, \mathbf{t}=\mathbf{1 . 8 4 ,} \mathbf{p}=\mathbf{. 0 6 6}\end{array}$ \\
\hline & & $\begin{array}{l}\text { Neutral }=6.06, \text { Earthquake }=6.27 \\
\quad \mathbf{b}=\mathbf{0 . 2 0}, \mathbf{t}=\mathbf{1 . 4 0}, \mathbf{p}=\mathbf{. 1 6 3}\end{array}$ & $\begin{array}{l}\text { Earthquake }=6.27, \text { Victim }=6.48 \\
\mathbf{b}=\mathbf{0 . 2 2}, \mathbf{t}=\mathbf{1 . 5 9}, \mathbf{p}=\mathbf{. 1 1 3}\end{array}$ \\
\hline & & $\begin{array}{l}\text { Neutral }=6.06, \text { Cat }=6.26 \\
\mathbf{b}=\mathbf{0 . 2 0}, \mathbf{t}=\mathbf{1 . 3 7}, \mathbf{p}=\mathbf{. 1 7 0}\end{array}$ & $\begin{array}{l}\text { Cat }=6.26, \text { Victim }=6.48, \\
\mathbf{b}=\mathbf{0 . 2 2}, \mathbf{t}=\mathbf{1 . 6 2}, \mathbf{p}=\mathbf{. 1 0 7}\end{array}$ \\
\hline \multirow{3}{*}{ Funny } & \multirow{3}{*}{$\begin{array}{c}\text { Neutral }=3.93 \text {, Victim }=4.28 \\
\mathbf{b}=\mathbf{0 . 3 5}, \mathbf{t}=\mathbf{2 . 1 2}, \mathbf{p}=\mathbf{. 0 3 5}\end{array}$} & $\begin{aligned} \text { Neutral }= & 3.93, \text { Both accident conditions }=4.26, \\
& \mathbf{b}=\mathbf{0 . 3 3}, \mathbf{t}=\mathbf{2 . 4 2}, \mathbf{p}=\mathbf{. 0 1 6}\end{aligned}$ & $\begin{array}{l}\text { Both accident conditions }=4.26 \text {, Victim }=4.28, \\
\mathbf{b}=\mathbf{0 . 0 2}, \mathbf{t}=\mathbf{0 . 1 4}, \mathbf{p}=\mathbf{. 8 8 7}\end{array}$ \\
\hline & & $\begin{array}{c}\text { Neutral }=3.93 \text {, Earthquake }=4.25 \\
\mathbf{b}=\mathbf{0 . 3 2}, \mathbf{t}=\mathbf{2 . 0 1 ,} \mathbf{p}=\mathbf{. 0 4 5}\end{array}$ & $\begin{array}{c}\text { Earthquake }=4.25, \text { Victim }=4.28 \\
\mathbf{b}=\mathbf{0 . 0 3 ,} \mathbf{t}=\mathbf{0 . 1 5}, \mathbf{p}=\mathbf{. 8 7 8}\end{array}$ \\
\hline & & $\begin{array}{l}\text { Neutral }=3.93, \text { Cat }=4.26, \\
\mathbf{b}=\mathbf{0 . 3 3}, \mathbf{t}=\mathbf{2 . 1 6}, \mathbf{p}=\mathbf{. 0 3 1}\end{array}$ & $\begin{array}{r}\text { Cat }=4.26, \text { Victim }=4.28, \\
\mathbf{b}=\mathbf{0 . 0 1}, \mathbf{t}=\mathbf{0 . 0 9}, \mathbf{p}=\mathbf{. 9 2 9}\end{array}$ \\
\hline \multirow{3}{*}{ Athletic } & \multirow{3}{*}{$\begin{array}{c}\text { Neutral }=3.75, \text { Victim }=4.25 \\
\mathbf{b}=\mathbf{0 . 4 9}, \mathbf{t}=\mathbf{3 . 1 2}, \mathbf{p}=\mathbf{. 0 0 2}\end{array}$} & $\begin{aligned} \text { Neutral }= & 3.75, \text { Both accident conditions }=4.09, \\
& \mathbf{b}=\mathbf{0 . 3 4}, \mathbf{t}=\mathbf{2 . 4 8 ,} \mathbf{p}=\mathbf{. 0 1 4}\end{aligned}$ & $\begin{array}{l}\text { Both accident conditions }=4.09 \text {, Victim }=4.25 \text {, } \\
\qquad \mathbf{b}=\mathbf{0 . 1 6}, \mathbf{t}=\mathbf{1 . 1 6}, \mathbf{p}=\mathbf{. 2 4 7}\end{array}$ \\
\hline & & $\begin{array}{c}\text { Neutral }=3.75, \text { Earthquake }=4.12 \\
\quad \mathbf{b}=\mathbf{0 . 3 7}, \mathbf{t}=\mathbf{2 . 3 4}, \mathbf{p}=\mathbf{. 0 2 0}\end{array}$ & $\begin{array}{l}\text { Earthquake }=4.12, \text { Victim }=4.25 \\
\quad \mathbf{b}=\mathbf{0 . 1 3}, \mathbf{t}=\mathbf{0 . 8 2}, \mathbf{p}=\mathbf{. 4 1 3}\end{array}$ \\
\hline & & $\begin{array}{l}\text { Neutral }=3.75, \text { Cat }=4.06 \\
\mathbf{b}=\mathbf{0 . 3 1}, \mathbf{t}=\mathbf{1 . 9 4 ,}, \mathbf{p}=\mathbf{. 0 5 3}\end{array}$ & $\begin{array}{r}\text { Cat }=4.06, \text { Victim }=4.25, \\
\mathbf{b}=\mathbf{0 . 1 9}, \mathbf{t}=\mathbf{1 . 1 8}, \mathbf{p}=\mathbf{. 2 3 7}\end{array}$ \\
\hline
\end{tabular}

Table S4b. Analyses of individual traits in Experiment 3.

These more extensive analyses support our key conclusions from the main text, and reveal that these conclusions hold for each of our two accident conditions.

Looking to nonmoral traits, we find that both victims of immorality and accidental misfortune are seen slightly more positively than neutral targets (although this effect does not extend to intelligence). The magnitude of this boost is similar for victims of immorality vs. accidents, with no significant differences observed for aggregate nonmoral traits, or for any individual nonmoral traits. (We do, however, find that victims of immorality are seen as marginally significantly more sociable than accident victims - which makes some sense, given that sociability might plausibly be seen as somewhat morally relevant).

Looking to moral traits, we find that victims of immorality receive an even larger boost, relative to neutral targets, than they did for nonmoral traits - and this boost holds for both morality and trustworthiness. In contrast, accident victims are rated as no more moral or trustworthy than neutral targets.

Together, we thus find that immorality victims receive a selective boost on moral traits. 


\subsection{Experiments 5-6}

As described in the main text, Experiments 5 and 6 investigated whether the Virtuous Victim effect extends to first-person narratives. To this end, we crossed our victim manipulation with a third- vs. first-person manipulation, both in Experiment 5 (using our iPad vignette) and Experiment 6 (using our idea theft vignette). Here, we report results from these experiments.

In Experiment 5, we observed the Virtuous Victim effect within the third-person condition $(n=397)$ for both morality, $b=.29[.02, .56], t=2.08, B=.10, p=.038$, and trustworthiness, $b=.34[.07, .62], t=2.45, B=.12, p=.015$. However, within the first-person condition $(n=406)$, we found no significant effect for morality, $b=.17[-.12, .46], t=1.13, B=$ $.06, p=.259$, and found a marginally significant negative effect for trustworthiness, $b=-.28$ [$.59, .02], \mathrm{t}=-1.85, B=-.09, p=.065$. When predicting our DVs as a function of victim status (neutral $=0$, victim $=1)$, narrative type $(0=$ third-person, $1=$ third-person $)$, and their interaction, we did not observe a significant interaction for morality, $b=.12[-.28, .52], t=.59, B=.04, p=$ .552 , but we did for trustworthiness, $b=.63[.22,1.04], t=3.02, B=.18, p=.003, n=803$. Thus, in Experiment 5, the Virtuous Victim effect did not extend to first-person narratives.

In Experiment 6, we again observed the Virtuous Victim effect within the third-person condition $(n=403)$ for both morality, $b=.39[.13, .66], t=2.93, B=.14, p=.004$, and trustworthiness, $b=.48[.22, .75], t=3.58, B=.18, p<.001$. But we also observed the Virtuous Victim effect within the first-person condition $(n=399)$ for both morality, $b=.39[.08, .70], t=$ $2.46, B=.12, p=.014$, and trustworthiness, $b=.36[.07, .66], t=2.45, B=.12, p=.015$. And we did not observe a significant interaction between victim status and narrative type for either morality, $b=.01[-.40, .41], t=.04, B=.002, p=.970$, or trustworthiness, $b=.12[-.27, .51], t=$ $.59, B=.04, p=.554, n=802$. Thus, in Experiment 6 , the Virtuous Victim effect did extend to first-person narratives.

\subsection{Experiment 8}

In the main text, per our pre-registration, we report analyses of Experiment 8 that restrict to subjects who passed three attention checks $(n=437)$. Here, we demonstrate that the conclusions of Experiment 8 hold in secondary analyses that do not exclude subjects on the basis of attention check performance $(n=503)$. Indeed, analyses of all subjects reveal that, relative to neutral targets, victims were seen as significantly more moral, $b=.97[.72,1.23], t=7.51, B=$ $.32, p<.001$, and trustworthy, $b=1.07[.81,1.33], t=8.06, B=.34, p<.001, n=503$. Thus, in analyses of all subjects, we again find a Virtuous Victim effect in Experiment 8.

\subsection{Experiment 9}

As described in the main text, in Experiment 9 we investigated whether the Virtuous Victim effect is moderated by target race and/or gender. To this end, we manipulated victim status via our iPad theft vignette, but modified our basic design by providing a photograph of the target in all conditions. We used these photographs to manipulate target race (specifically, by contrasting White vs. Black targets) and gender. In particular, each subject was assigned to one race/gender condition (i.e., White male, White female, Black male, or Blackfemale) and then was randomly presented with one of three potential target photographs corresponding to their condition.

As described in Section 5.9 of this document, all photographs were selected from the Chicago Face Database (Ma et al., 2015). We selected photographs depicting a closed mouth smile, and of models who were roughly college-aged (given that the iPad theft vignette is about 
college students). We also selected photographs that were reasonably well-matched across race/gender conditions on perceived age, attractiveness, and trustworthiness (using norming data from the Chicago Face Database). In Fig. S3, we show the results of Experiment 9 along with example photographs corresponding to each race/gender condition, and in Table S5, we report relevant norming data for each photograph (and each race/gender condition on average).

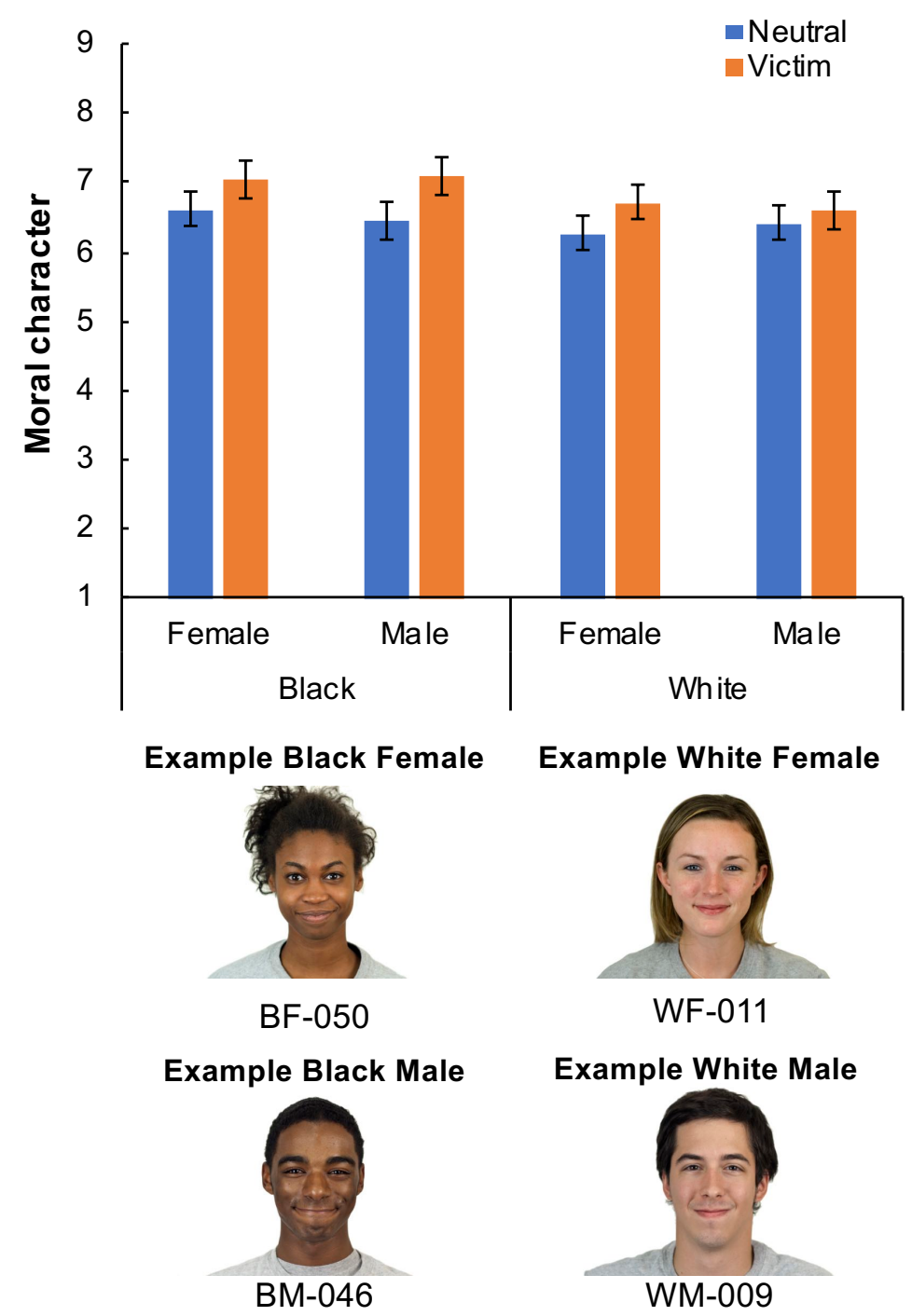

Fig. S3. We plot the results from Experiment 9 (among subjects who passed all attention checks, $n=904)$, along with the set of target photographs used across race and gender conditions. Photo Credit: The Chicago Face Database, University of Chicago, Center for Decision Research. 


\begin{tabular}{|c|c|c|c|c|c|}
\hline $\begin{array}{l}\text { Race/gender } \\
\text { condition }\end{array}$ & Model & $\begin{array}{c}\text { Perceived age } \\
\text { (years) }\end{array}$ & $\begin{array}{c}\text { Percieved } \\
\text { attractiveness } \\
\text { (1-7 Likert scale) }\end{array}$ & $\begin{array}{c}\text { Perceived } \\
\text { trustworthiness } \\
\text { (1-7 Likert scale) }\end{array}$ & Rater $\mathbf{N}$ \\
\hline \multirow{4}{*}{ Black female } & BF-028 & 22.62 & 3.73 & 4.08 & 93 \\
\hline & BF-049 & 20.83 & 4.45 & 4.11 & 94 \\
\hline & BF-050 & 22.38 & 3.79 & 3.43 & 96 \\
\hline & BF Average & 21.94 & 3.99 & 3.87 & \\
\hline \multirow{4}{*}{ Black male } & BM-026 & 26.99 & 3.90 & 3.67 & 93 \\
\hline & BM-037 & 20.89 & 4.04 & 3.49 & 90 \\
\hline & BM-046 & 22.06 & 3.77 & 3.49 & 89 \\
\hline & BM Average & 23.31 & 3.91 & 3.55 & \\
\hline \multirow{4}{*}{ White female } & WF-011 & 24.04 & 4.13 & 3.70 & 95 \\
\hline & WF-021 & 25.69 & 3.93 & 3.49 & 91 \\
\hline & WF-031 & 23.24 & 4.12 & 3.73 & 85 \\
\hline & WF Average & 24.32 & 4.06 & 3.64 & \\
\hline \multirow{4}{*}{ White male } & WM-003 & 23.35 & 3.68 & 3.58 & 83 \\
\hline & WM-009 & 23.70 & 4.08 & 3.51 & 92 \\
\hline & WM-033 & 26.59 & 3.85 & 3.58 & 91 \\
\hline & WM Average & 24.54 & 3.87 & 3.56 & \\
\hline
\end{tabular}

Table S5. Norming data from the Chicago Face Database for each of the photographs used in Experiment 9. We note that the labels for each model correspond to the labels used in the Chicago Face Database.

In the main text, per our pre-registration, we report analyses of Experiment 9 that restrict to subjects who passed three attention checks $(n=904)$. Here, we demonstrate that the conclusions of Experiment 9 hold in secondary analyses that do not exclude subjects on the basis of attention check performance $(n=999)$. To this end, we repeat our main analysis approach for Experiment 9 by predicting target morality, and trustworthiness, as a function of victim status ($.5=$ neutral, $.5=$ victim $)$, target race $(-.5=$ White, $.5=$ Black $)$, target gender $(-.5=$ male, $.5=$ female), all two-way interactions, and the three-way interaction.

Predicting morality, we find a main effect of victim status $(b=.43[.24, .61], t=4.54, B=$ $.14, \mathrm{p}<.001)$, and no significant interaction between victim status and target race $(b=.17[-.20$, $.54], t=.93, B=.03, \mathrm{p}=.355)$, victim status and target gender $(b=-.12[-.49, .25], t=-.66, B=-$ $.02, \mathrm{p}=.509)$, or victim status, target race, and target gender $(b=-.30[-1.04, .44], t=-.79, B=-$ $.02, p=.432)$. Predicting trustworthiness, we find a main effect of victim status $(b=.42[.23$, $.61], t=4.30, B=.14, \mathrm{p}<.001)$ that did not interact with race $(b=.29[-.10, .67], t=1.47, B=$ $.05, \mathrm{p}=.141)$, gender $(b=.09[-.29, .48], t=.46, B=.01, \mathrm{p}=.645)$, or race and gender $(b=-.34$ $[-1.11, .43], t=-.87, B=-.03, p=.383), n=999$. Thus, in analyses of all subjects, we again find a Virtuous Victim effect that is not significantly moderated by target race and/or gender.

\subsection{Aggregate analysis of target gender}

In the main text, we reported an aggregate analysis of our set of experiments that manipulated target gender. Specifically, we reported that, across this set of experiments, (i) the Virtuous Victim effect was not moderated by target gender and (ii) the Virtuous Victim effect held among both male and female targets. 
As described in the main text, Experiments 1-7, 9, and 13-15 all both manipulated victim status and manipulated target gender (although note that Experiment 4 specifically manipulated gender in the iPad theft but not verbal attack or sexual aggression vignettes). Within these experiments, our aggregate gender analysis specifically takes data from our "standard set of neutral vs. victim conditions". This label refers to the set of data that we analyze in Fig. S1 and Table S3: the standard victim and neutral conditions of all experiments that included both of these conditions, with the exceptions of (i) the first-person conditions of Experiments 5 and 6 , and (ii) the "disincentives" conditions of Experiment 11a. (As described in Section 2.1 of this document, these exceptions reflect that we expected that these conditions might meaningfully change the effects of our standard victim manipulation, and our results supported this expectation.) Note that we also draw on this standard set of neutral vs. victim conditions in our aggregate analyses of two secondary dependent variables (sympathy and exploitability), reported in Section 4.2 of this document.

\subsection{Experiment 10}

In the main text, we use Experiment 10 to show that when a victim of wrongdoing is described as more morally virtuous, subjects are more willing to help the victim and to punish the perpetrator. Furthermore, our main text also briefly mentions that Experiment 10 included an additional condition, in which we described the target as particularly competent (rather than moral). In total, then, Experiment 10 featured three conditions: control (in which the target was described as relatively less moral and relatively less competent), moral (in which the target was described as relatively more moral and relatively less competent), and competent (in which the target was described as relatively less moral and relatively more competent).

Here, we report results from the competent condition. Relative to the neutral condition, subjects in the competent condition perceived the target as more competent, $b=1.87[1.58$, 2.16], $t=12.79, B=.55, p<.001$, and were more willing to help her, $b=.46[.07, .85], t=2.31$, $B=.12, p=.021$, but were not significantly more willing to punish on her behalf, $b=.08$ [-.32, $.48], t=.39, B=.02, p=.698, n=386$. And relative to the competent condition, subjects in the moral condition were more willing to help the target, $b=2.56[2.23,2.90], t=15.07, B=.60, p<$ .001 , and to punish on her behalf, $b=.48[.11, .86], t=2.52, B=.12, p=.012, n=409$.

Thus, we find some evidence that describing victims as morally virtuous may be especially effective at motivating justice-restorative action. However, as we also mention in the main text, this evidence is merely suggestive because our morality manipulation (unexpectedly) turned out to be stronger than our competence manipulation. Specifically, the effect of the morality manipulation on perceived morality (as reported in the main text, $b=3.55[3.30,3.80], t$ $=27.80, B=.81, p<.001)$ was larger than the effect of the competence manipulation on perceived competence (as reported above, $b=1.87[1.58,2.16], t=12.79, B=.55, p<.001$ ).

We do note that the discrepancy between our manipulations appears to be relatively larger when considering our dependent variables (i.e., willingness to help and punish) than these traits (i.e., perceived morality and competence). But this comparison is nonetheless difficult to interpret, because the relationships between these traits and our dependent variables may not be linear.

\subsection{Experiment 12}

In the main text, we presented two sets of results from Experiment 12. First, we used Experiment 12 to support the claim that the Virtuous Victim effect is not merely a simple 
contrast effect. To this end, we reported that subjects in the standard victim condition rated the target as having better moral character than subjects in the other victim condition. Second, we used Experiment 12 to support the claim that the Virtuous Victim effect does not extend to behavior predictions. To this end, we reported that, relative to subjects in the neutral condition, subjects in the standard victim condition did not predict that victims would return more money in a hypothetical economic Trust Game.

Here, we report more complete Experiment 12 results. In Fig. S4, we plot values, by condition, of each of the four DVs that Experiment 12 measured. Specifically, in Panel A, we plot our Trust Game DVs: the amount sent to target (as a proportion of starting endowment) and the predicted amount returned by target (as a proportion of amount sent). Then, in Panel B, we plot ratings of target morality and trustworthiness. In Table S6, we report results from linear regressions comparing the victim vs. neutral conditions, and victim vs. other victim conditions, on each of these four DVs.
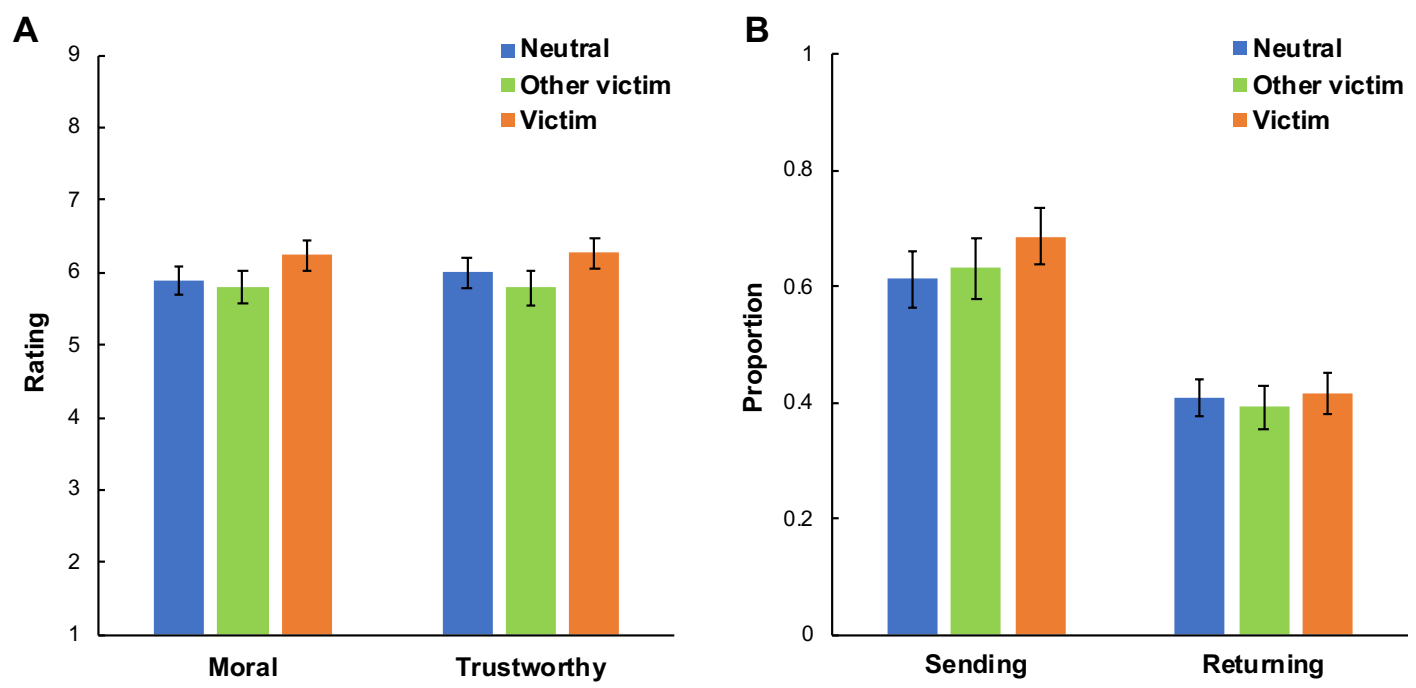

Fig. S4. Dependent variables across conditions in Experiment 12.

\begin{tabular}{c|c|c} 
Variable & $\begin{array}{c}\text { Victim vs. Neutral } \\
(\mathbf{n}=\mathbf{4 0 0})\end{array}$ & $\begin{array}{c}\text { Victim vs. Other victim } \\
(\mathbf{n}=\mathbf{4 0 2})\end{array}$ \\
\hline $\begin{array}{c}\text { Amount sent to target in } \\
\text { Trust Game }\end{array}$ & $\begin{array}{c}\text { Neutral }=0.61, \text { Victim }=0.69, \\
\mathbf{b}=\mathbf{0 . 0 7}, \mathbf{t}=\mathbf{2 . 1 4}, \mathbf{p}=\mathbf{. 0 3 3}\end{array}$ & $\begin{array}{c}\text { Other victim }=0.63, \text { Victim }=0.69, \\
\mathbf{b}=\mathbf{0 . 0 6}, \mathbf{t}=\mathbf{1 . 5 6}, \mathbf{p}=\mathbf{. 1 1 9}\end{array}$ \\
\hline $\begin{array}{c}\text { Predicted amount returned } \\
\text { by target in Trust Game }\end{array}$ & $\begin{array}{c}\text { Neutral }=0.41, \text { Victim }=0.42, \\
\mathbf{b}=\mathbf{0 . 0 1}, \mathbf{t}=\mathbf{0 . 2 9}, \mathbf{p}=\mathbf{. 7 7 5}\end{array}$ & $\begin{array}{c}\text { Other victim }=0.39, \text { Victim }=0.42, \\
\mathbf{b}=\mathbf{0 . 0 2}, \mathbf{t}=\mathbf{0 . 9 0}, \mathbf{p}=\mathbf{. 3 6 8}\end{array}$ \\
\hline $\begin{array}{c}\text { Rating of target } \\
\text { morality }\end{array}$ & $\begin{array}{c}\text { Neutral }=5.88, \text { Victim }=6.24, \\
\mathbf{b}=\mathbf{0 . 3 5}, \mathbf{t}=\mathbf{2 . 4 3}, \mathbf{p}=\mathbf{. 0 1 5}\end{array}$ & $\begin{array}{c}\text { Other victim }=5.81, \text { Victim }=6.24, \\
\mathbf{b}=\mathbf{0 . 4 3}, \mathbf{t}=\mathbf{2 . 8 2}, \mathbf{p}=\mathbf{. 0 0 5}\end{array}$ \\
\hline $\begin{array}{c}\text { Rating of target } \\
\text { trustworthiness }\end{array}$ & $\begin{array}{c}\text { Neutral }=6.00, \text { Victim }=6.26, \\
\mathbf{b}=\mathbf{0 . 2 6}, \mathbf{t}=\mathbf{1 . 7 3}, \mathbf{p}=\mathbf{. 0 8 5}\end{array}$ & $\begin{array}{c}\text { Other victim }=5.79, \text { Victim }=6.26, \\
\mathbf{b}=\mathbf{0 . 4 8}, \mathbf{t}=\mathbf{2 . 9 6}, \mathbf{p}=\mathbf{. 0 0 3}\end{array}$
\end{tabular}

Table S6. Effects of the victim condition on all dependent variables in Experiment 12.

Together, these results support the two key claims mentioned above. First, we find that people see victims as morally virtuous, and are willing to send them more money in a 
hypothetical Trust Game-despite not predicting that they will return more money. These results show that the Virtuous Victim effect extends to moral character (and that people are motivated to share money with victims), but that people do not expect victims to behave more morally.

Second, we find that the Virtuous Victim effect does not merely reflect a simple contrast effect with the perpetrator. The effects of victim status on morality, trustworthiness, and Trust Game sending do not extend equally to the other victim condition (in which subjects read about a perpetrator mistreating a character other than the target).

\subsection{Analyses of behavior predictions}

In the main text, we reported that across all of our experiments measuring behavior predictions, we found no significant positive effects of our victim manipulation on moral behavior, or significant negative effects on immoral behavior. Here, we support this claim by reporting more extensive analyses of behavior predictions across our experiments.

\subsubsection{Discussion of upsetness hypothesis}

First, however, we provide further discussion of one aim of these experiments, briefly mentioned in the main text. Specifically, one aim of these experiments was to investigate the hypothesis that the Virtuous Victim effect does not extend to behavior predictions because people expect victims to be upset following their victimization, and believe that upset individuals are inclined to behave thus less morally.

According to this "upsetness" hypothesis, the observed null effects of victim status on behavior predictions actually reflect two countervailing effects. The upsetness hypothesis proposes that, on the one hand, people expect victims to behave more morally because people see victims as having elevated moral character. Yet on the other hand, people expect victims to behave less morally because they are upset, resulting in no net effect of victim status on predicted moral behavior. Bolstering the credibility of this hypothesis, we note that the victim conditions of almost all of our vignettes ended by stating the target was very upset.

We sought to address this upsetness hypothesis in two ways. First, in Experiment 14 we modified our vignette text to omit the sentence stating that the victim was upset. We anticipated that this omission would reduce the salience of the victim's upsetness (although subjects could of course still reason that the victim was probably upset).

Second, and more substantively, in Experiment 15 we sought to systematically investigate the upsetness hypothesis. The upsetness hypothesis makes a testable prediction: insofar as there are moral behaviors that people do not think are less likely among upset actors (but $d o$ think are more likely among actors with superior moral character), there should be some contexts in which people do expect victims to behave more morally. Thus, in Experiment 15, we investigated the effect of our victim manipulation on predictions regarding four distinct moral behaviors. A pre-test revealed that subjects expected two of these behaviors to be less likely among upset actors, and two of them not to be less likely among upset actors (but all four to be more likely among actors with superior moral character). For the behaviors that pre-test subjects did not see as less likely among upset actors, the upsetness hypothesis predicts a positive effect of victim status on predicted moral behavior.

\subsubsection{Discussion of Experiment 15 pre-test}

Here, we provide a design overview of our Experiment 15 pre-test, which we used to identify the behaviors that we used in Experiment 15, and report the pre-test results. 
In our Experiment 15 pre-test, we generated a set of 13 candidate moral behaviors. We then employed a two-by-two, between-subject design, in which we directly manipulated target morality (immoral vs. moral) and upsetness (not upset vs. upset), and then asked each subject to rate the likelihood that the target would engage in a random subset of the candidate moral behaviors (resulting in a slightly different $n$ for each behavior). For more detail, including the full text description of each behavior, see the "full experimental details" section of this document.

In Table S7, we report two sets of analyses for each behavior included in our pre-test. First, we report the effect of target upsetness on the perceived likelihood of engaging in the behavior, within the "moral" condition. This comparison allows us to ask: if a target is a victim, and thus is seen as having relatively good moral character, will perceived upsetness make them seem less likely to engage in the relevant moral behavior?

Second, we report the effect of target morality on perceived likelihood of engaging in the behavior, within the "upset" condition. This comparison allows us to ask: if a target is a victim, and thus is seen as being upset, will perceived moral character make them seem more likely to engage in the relevant moral behavior?

\begin{tabular}{|c|c|c|}
\hline Behavior & Effect of upset if moral & Effect of moral if upset \\
\hline Select local and charitable coffee shop over Starbucks & 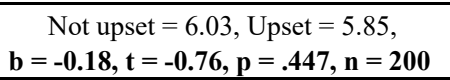 & $\begin{array}{c}\text { Immoral }=3.12, \text { Moral }=6.03, \\
\mathbf{b}=\mathbf{2 . 5 0}, \mathbf{t}=\mathbf{1 0 . 0 0}, \mathbf{p}<\mathbf{. 0 0 1}, \mathbf{n}=\mathbf{1 8 9}\end{array}$ \\
\hline Consent for waitress to give leftovers to homeless & $\begin{array}{c}\text { Not upset }=7.33, \text { Upset }=7.21 \\
\mathbf{b}=\mathbf{- 0 . 1 2}, \mathbf{t}=\mathbf{- 0 . 5 9 ,} \mathbf{p}=\mathbf{. 5 5 5}, \mathbf{n}=\mathbf{1 9 4}\end{array}$ & $\begin{array}{c}\text { Immoral }=4.20, \text { Moral }=7.33 \\
\mathbf{b}=\mathbf{2 . 7 1 ,} \mathbf{t}=\mathbf{1 0 . 0 5}, \mathbf{p}<\mathbf{. 0 0 1}, \mathbf{n}=\mathbf{2 0 0}\end{array}$ \\
\hline Make a habit of donating old clothes to Goodwill & $\begin{array}{c}\text { Not upset }=\text { 5.90, Upset }=5.64 \\
\mathbf{b}=\mathbf{- 0 . 2 6 , t}=\mathbf{- 1 . 0 7}, \mathbf{p}=\mathbf{. 2 8 6}, \mathbf{n}=\mathbf{2 0 7}\end{array}$ & $\begin{array}{c}\text { Immoral }=2.94, \text { Moral }=5.90 \\
\mathbf{b}=\mathbf{2 . 6 6 ,} \mathbf{t}=\mathbf{1 0 . 5 4}, \mathbf{p}<\mathbf{. 0 0 1}, \mathbf{n}=\mathbf{2 0 4}\end{array}$ \\
\hline Make a habit of tipping $20 \%$ at reastaurants & $\begin{array}{c}\text { Not upset }=\text { 5.81, Upset }=5.40 \\
\mathbf{b}=\mathbf{- 0 . 4 1 ,} \mathbf{t}=\mathbf{- 1 . 7 6 ,}, \mathbf{p}=\mathbf{. 0 7 9}, \mathbf{n}=\mathbf{2 1 8}\end{array}$ & $\begin{array}{c}\text { Immoral }=2.59, \text { Moral }=5.81 \\
\mathbf{b}=\mathbf{2 . 5 2}, \mathbf{t}=\mathbf{9 . 9 3 ,} \mathbf{p}<\mathbf{. 0 0 1}, \mathbf{n}=\mathbf{2 0 9}\end{array}$ \\
\hline Make a habit of recycling & $\begin{array}{c}\text { Not upset }=5.70, \text { Upset }=5.65 \\
\mathbf{b}=\mathbf{- 0 . 0 5 ,}, \mathbf{t}=\mathbf{- 0 . 2 1 ,}, \mathbf{p}=\mathbf{8 3 1}, \mathbf{n}=\mathbf{2 0 4}\end{array}$ & $\begin{array}{c}\text { Immoral }=2.93, \text { Moral }=5.70, \\
\mathbf{b}=\mathbf{2 . 5 1}, \mathbf{t}=\mathbf{1 0 . 0 6}, \mathbf{p}<\mathbf{. 0 0 1}, \mathbf{n}=\mathbf{2 0 5}\end{array}$ \\
\hline Always thanks driver before exiting bus/Uber & $\begin{array}{c}\text { Not upset }=6.51, \text { Upset }=6.21 \\
\mathbf{b}=\mathbf{- 0 . 3 0 ,}, \mathbf{t}=\mathbf{- 1 . 2 8 ,}, \mathbf{p}=\mathbf{. 2 0 1}, \mathbf{n}=\mathbf{1 9 5}\end{array}$ & $\begin{array}{c}\text { Immoral }=3.47, \text { Moral }=6.51, \\
\mathbf{b}=\mathbf{3 . 0 6}, \mathbf{t}=\mathbf{1 2 . 1 4}, \mathbf{p}<\mathbf{. 0 0 1}, \mathbf{n}=\mathbf{2 1 1}\end{array}$ \\
\hline Always polite and gracious to people working in service & $\begin{array}{c}\text { Not upset }=6.63, \text { Upset }=6.38 \\
\mathbf{b}=\mathbf{- 0 . 2 6 ,} \mathbf{t}=\mathbf{- 1 . 1 9 ,}, \mathbf{p}=\mathbf{. 2 3 5}, \mathbf{n}=\mathbf{1 8 3}\end{array}$ & $\begin{array}{c}\text { Immoral }=3.27, \text { Moral }=6.63 \\
\mathbf{b}=\mathbf{3 . 2 1}, \mathbf{t}=\mathbf{1 2 . 6 0}, \mathbf{p}<\mathbf{. 0 0 1}, \mathbf{n}=\mathbf{2 0 2}\end{array}$ \\
\hline Put efforting into planning surprise birthday party & $\begin{array}{c}\text { Not upset }=5.50, \text { Upset }=5.20 \\
\mathbf{b}=\mathbf{- 0 . 3 0 ,}=\mathbf{t}=\mathbf{- 1 . 3 2 ,} \mathbf{p}=\mathbf{. 1 8 9}, \mathbf{n}=\mathbf{2 2 0}\end{array}$ & $\begin{array}{c}\text { Immoral }=3.88, \text { Moral }=5.50 \\
\mathbf{b}=\mathbf{1 . 6 1}, \mathbf{t}=\mathbf{6 . 3 3}, \mathbf{p}<\mathbf{. 0 0 1}, \mathbf{n}=\mathbf{2 1 8}\end{array}$ \\
\hline Volunteer to help habitat for humanity & $\begin{array}{c}\text { Not upset }=5.10, \text { Upset }=4.98 \\
\mathbf{b}=\mathbf{- 0 . 1 2 ,}, \mathbf{t}=\mathbf{- 0 . 4 8 ,}, \mathbf{p}=\mathbf{. 6 2 9}, \mathbf{n}=\mathbf{1 9 0}\end{array}$ & $\begin{array}{c}\text { Immoral }=2.44, \text { Moral }=5.10 \\
\mathbf{b}=\mathbf{2 . 2 4}, \mathbf{t}=\mathbf{8 . 9 8}, \mathbf{p}<\mathbf{. 0 0 1}, \mathbf{n}=\mathbf{1 8 8}\end{array}$ \\
\hline Offer to loan money to a friend in need & $\begin{array}{c}\text { Not upset }=4.48, \text { Upset }=3.99 \\
\mathbf{b}=\mathbf{- 0 . 4 9 ,} \mathbf{t}=\mathbf{- 1 . 8 9 ,} \mathbf{p}=\mathbf{. 0 6 0}, \mathbf{n}=\mathbf{2 0 6}\end{array}$ & $\begin{array}{c}\text { Immoral }=2.45, \text { Moral }=4.48 \\
\mathbf{b}=\mathbf{1 . 5 4}, \mathbf{t}=\mathbf{6 . 2 1}, \mathbf{p}<\mathbf{. 0 0 1}, \mathbf{n}=\mathbf{2 0 2}\end{array}$ \\
\hline Surprise mom with gift & $\begin{array}{c}\text { Not upset }=6.13, \text { Upset }=5.00 \\
\mathbf{b}=\mathbf{- 1 . 1 3 ,} \mathbf{t}=\mathbf{- 4 . 2 3 ,} \mathbf{p}<\mathbf{. 0 0 1}, \mathbf{n}=\mathbf{1 8 8}\end{array}$ & $\begin{array}{c}\text { Immoral }=3.37, \text { Moral }=6.13 \\
\mathbf{b}=\mathbf{1 . 7 8 ,}, \mathbf{t}=\mathbf{6 . 5 2}, \mathbf{p}<\mathbf{. 0 0 1}, \mathbf{n}=\mathbf{1 9 1}\end{array}$ \\
\hline Stop patronizing racist sandwich shop & $\begin{array}{c}\text { Not upset }=5.42, \text { Upset }=5.05 \\
\mathbf{b}=\mathbf{- 0 . 3 7 ,} \mathbf{t}=\mathbf{- 1 . 1 2}, \mathbf{p}=\mathbf{. 2 6 3}, \mathbf{n}=\mathbf{1 9 5}\end{array}$ & $\begin{array}{c}\text { Immoral }=3.96, \text { Moral }=5.42 \\
\mathbf{b}=\mathbf{1 . 1 1}, \mathbf{t}=\mathbf{3 . 2 8}, \mathbf{p}=\mathbf{. 0 0 1}, \mathbf{n}=\mathbf{2 0 5}\end{array}$ \\
\hline
\end{tabular}

Table S7. Experiment 15 pre-test results.

Table S7 reveals that for all behaviors, we found a significant positive effect of morality (among upset targets) on the perceived likelihood of engaging in the behavior. In contrast, we only found a significant or marginally significant negative effect of upsetness (among moral targets) for two behaviors. The four behaviors we selected to use in Experiment 15 are bolded. The top two are the behaviors we selected that subjects did not expect to be less likely among upset targets: consenting to a waitress giving one's leftover food to a homeless person, and making a habit of recycling. The bottom two are the behaviors we selected that subjects did 
expect to be less likely among moral targets: offering to loan money to a friend in need and surprising one's mother with a gift.

\subsubsection{Full behavior prediction results}

In Table S8, we report the full set of results from each experiment that measured behavior predictions. We include both our set of victim manipulation experiments that measured behavior predictions (Experiments 1, 7, 12, 14, and 15 and our direct morality manipulation experiment (Experiment 16)). For each experiment, we report the effect of our manipulation (for our victim manipulation experiments, we compare the neutral and victim conditions, and for our direct morality manipulation experiment, we compare the control and moral conditions) on the perceived likelihood of engaging in each moral and immoral behavior included in the experiment. We also plot these comparisons in Fig. S5.

\begin{tabular}{|c|c|c|}
\hline & Effects of victim manipulation on moral behavior & Effects of victim manipulation on immoral behavior \\
\hline \multirow{4}{*}{$\begin{array}{l}\text { Experiment } 1 \\
\quad(n=403)\end{array}$} & $\begin{aligned} & \text { Behaved morally over the past year: } \\
& \text { Neutral }= 4.22, \text { Victim }=4.02, b=-0.20, t=-0.88, p=.382 \\
&\end{aligned}$ & $\begin{array}{c}\text { Behaved immorally over the past year: } \\
\text { Neutral }=4.20 \text {, Victim }=4.33, \mathrm{~b}=0.13, \mathrm{t}=0.60, \mathrm{p}=.549\end{array}$ \\
\hline & $\begin{array}{c}\text { Will behave morally over the next year: } \\
\text { Neutral }=4.19 \text {, Victim }=3.84, b=-0.35, t=-1.62, p=.106\end{array}$ & $\begin{array}{l}\text { Will behave immorally over the next year: } \\
\text { Neutral }=4.25 \text {, Victim }=4.36, b=0.11, \mathrm{t}=0.51, \mathrm{p}=.609\end{array}$ \\
\hline & $\begin{array}{l}\text { Volunteered to help others over the past year: } \\
\text { Neutral }=4.14, \text { Victim }=4.02, \mathrm{~b}=-0.12, \mathrm{t}=-0.53, \mathrm{p}=.594\end{array}$ & $\begin{aligned} & \text { Lied to others over the past year: } \\
& \text { Neutral }=4.09, \text { Victim }=4.15, b=0.06, t=0.27, p=.785\end{aligned}$ \\
\hline & $\begin{array}{l}\text { Will volunteer to help others over the next year: } \\
\text { Neutral }=4.24 \text {, Victim }=3.77, b=-0.47, t=-2.21, p=.028\end{array}$ & $\begin{array}{c}\text { Will lie to others over the next year: } \\
\text { Neutral }=4.21, \text { Victim }=4.16, b=-0.05, t=-0.22, p=.829\end{array}$ \\
\hline \multirow{4}{*}{$\begin{array}{l}\text { Experiment } 7 \\
\quad(\mathrm{n}=\mathbf{4 0 1})\end{array}$} & $\begin{array}{l}\text { Donate to charity: } \\
\text { Neutral }=6.52, \text { Victim }=6.58, b=0.06, t=0.40, p=.691\end{array}$ & $\begin{array}{c}\text { Flirt with others while married: } \\
\text { Neutral }=2.73, \text { Victim }=2.74, b=0.01, t=0.05, p=.963\end{array}$ \\
\hline & $\begin{array}{c}\text { Help coworker: } \\
\text { Neutral }=5.97, \text { Victim }=6.19, \mathrm{~b}=0.22, \mathrm{t}=1.33, \mathrm{p}=.184 \\
\end{array}$ & $\begin{array}{c}\text { Intentionally forget to pay friend back: } \\
\text { Neutral }=2.59, \text { Victim }=2.66, \mathrm{~b}=0.07, \mathrm{t}=0.38, \mathrm{p}=.705\end{array}$ \\
\hline & $\begin{aligned} & \text { Plan birthday surprise for spouse: } \\
\text { Neutral }= & 6.04, \text { Victim }=6.24, \mathrm{~b}=0.21, \mathrm{t}=1.23, \mathrm{p}=.220\end{aligned}$ & $\begin{array}{c}\text { Harshly scold coworker for honest mistake: } \\
\text { Neutral }=3.30, \text { Victim }=3.32, b=0.03, t=0.13, p=.895\end{array}$ \\
\hline & $\begin{array}{c}\text { Buy dinner for friend: } \\
\text { Neutral }=6.07, \text { Victim }=6.19, \mathrm{~b}=0.13, \mathrm{t}=0.85, \mathrm{p}=.397\end{array}$ & $\begin{array}{c}\text { Spread mean gossip: } \\
\text { Neutral }=2.78, \text { Victim }=2.74, \mathrm{~b}=-0.04, \mathrm{t}=-0.22, \mathrm{p}=.824 \\
\end{array}$ \\
\hline $\begin{array}{l}\text { Experiment } 12 \\
\quad(\mathrm{n}=400)\end{array}$ & $\begin{array}{l}\text { Return money in economic Trust Game: } \\
\text { Neutral }=0.41 \text {, Victim }=0.42, b=0.01, t=0.29, p=.775\end{array}$ & \\
\hline \multirow{4}{*}{$\begin{array}{l}\text { Experiment } 14 \\
\quad(\mathrm{n}=403)\end{array}$} & $\begin{array}{c}\text { Donate to charity: } \\
\text { Neutral }=4.69, \text { Victim }=4.93, \mathrm{~b}=0.24, \mathrm{t}=1.33, \mathrm{p}=.185\end{array}$ & $\begin{array}{c}\text { Flirt with others while in relationship: } \\
\text { Neutral }=2.82, \text { Victim }=2.73, \mathrm{~b}=-0.08, \mathrm{t}=-0.49, \mathrm{p}=.627\end{array}$ \\
\hline & $\begin{array}{c}\text { Help friend move: } \\
\text { Neutral }=5.84, \text { Victim }=5.70, \mathrm{~b}=-0.14, \mathrm{t}=-0.84, \mathrm{p}=.402\end{array}$ & $\begin{array}{c}\text { Intentionally forget to pay friend back: } \\
\text { Neutral }=2.46, \text { Victim }=2.61, \mathrm{~b}=0.16, \mathrm{t}=0.88, \mathrm{p}=.380\end{array}$ \\
\hline & $\begin{array}{c}\text { Volunteer to tutor: } \\
\text { Neutral }=4.52, \text { Victim }=4.80, \mathrm{~b}=0.28, \mathrm{t}=1.56, \mathrm{p}=.119\end{array}$ & $\begin{array}{c}\text { Exclude or betray friend to fit in: } \\
\text { Neutral }=2.60, \text { Victim }=2.64, \mathrm{~b}=0.04, \mathrm{t}=0.24, \mathrm{p}=.813\end{array}$ \\
\hline & $\begin{array}{c}\text { Give leftovers to homeless: } \\
\text { Neutral }=4.92, \text { Victim }=5.08, b=0.17, t=0.96, p=.339\end{array}$ & $\begin{array}{c}\text { Spread mean gossip: } \\
\text { Neutral }=2.62, \text { Victim }=2.80, \mathrm{~b}=0.18, \mathrm{t}=0.95, \mathrm{p}=.344\end{array}$ \\
\hline \multirow{4}{*}{$\begin{array}{l}\text { Experiment } 15 \\
\quad(n=401)\end{array}$} & $\begin{array}{c}\text { Consent for waitress to give leftovers to homeless: } \\
\text { Neutral }=6.80, \text { Victim }=6.28, b=-0.52, t=-3.12, p=.002\end{array}$ & \\
\hline & $\begin{array}{c}\text { Make a habit of recycling: } \\
\text { Neutral }=4.95, \text { Victim }=4.93, \mathrm{~b}=-0.02, \mathrm{t}=-0.16, \mathrm{p}=.877\end{array}$ & \\
\hline & $\begin{array}{c}\text { Offer to loan money to a friend: } \\
\text { Neutral }=3.69, \text { Victim }=3.78, b=0.08, t=0.43, p=.668\end{array}$ & \\
\hline & $\begin{array}{c}\text { Surprise mom with gift: } \\
\text { Neutral }=5.34, \text { Victim }=5.31, \mathrm{~b}=-0.03, \mathrm{t}=-0.16, \mathrm{p}=.870\end{array}$ & \\
\hline \multirow{4}{*}{$\begin{array}{c}\text { Experiment 16: } \\
\text { Direct morality } \\
\text { manipulation } \\
(\mathbf{n}=\mathbf{2 0 1})\end{array}$} & $\begin{array}{c}\text { Donate to charity: } \\
\text { Control }=4.97, \mathrm{Moral}=5.58, \mathrm{~b}=0.61, \mathrm{t}=2.65, \mathrm{p}=.009\end{array}$ & $\begin{array}{c}\text { Flirt with others while in relationship: } \\
\text { Control }=3.08, \mathrm{Moral}=2.66, \mathrm{~b}=-0.41, \mathrm{t}=-1.67, \mathrm{p}=.096\end{array}$ \\
\hline & $\begin{array}{c}\text { Help friend move: } \\
\text { Control }=5.98, \text { Moral }=6.49, \mathrm{~b}=0.51, \mathrm{t}=2.19, \mathrm{p}=.030\end{array}$ & $\begin{array}{c}\text { Intentionally forget to pay friend back: } \\
\text { Control }=2.78, \text { Moral }=2.45, \mathrm{~b}=-0.33, \mathrm{t}=-1.37, \mathrm{p}=.173\end{array}$ \\
\hline & $\begin{array}{c}\text { Volunteer to tutor: } \\
\text { Control }=4.87, \text { Moral }=5.53, \mathrm{~b}=0.66, \mathrm{t}=2.77, \mathrm{p}=.006\end{array}$ & $\begin{array}{c}\text { Exclude or betray friend to fit in: } \\
\text { Control }=2.66, \text { Moral }=2.52, \mathrm{~b}=-0.14, \mathrm{t}=-0.58, \mathrm{p}=.562 \\
\end{array}$ \\
\hline & $\begin{array}{c}\text { Give leftovers to homeless: } \\
\text { Control }=5.31, \text { Moral }=5.71, b=0.40, t=1.74, p=.084\end{array}$ & $\begin{array}{c}\text { Spread mean gossip: } \\
\text { Control }=2.78, \text { Moral }=2.54, \mathrm{~b}=-0.24, \mathrm{t}=-0.97, \mathrm{p}=.331\end{array}$ \\
\hline
\end{tabular}

Table S8. Effects of our victim manipulations (in Experiments 1,7,12,14,15) and our direct morality manipulation (in Experiment 16) on behavior predictions. 

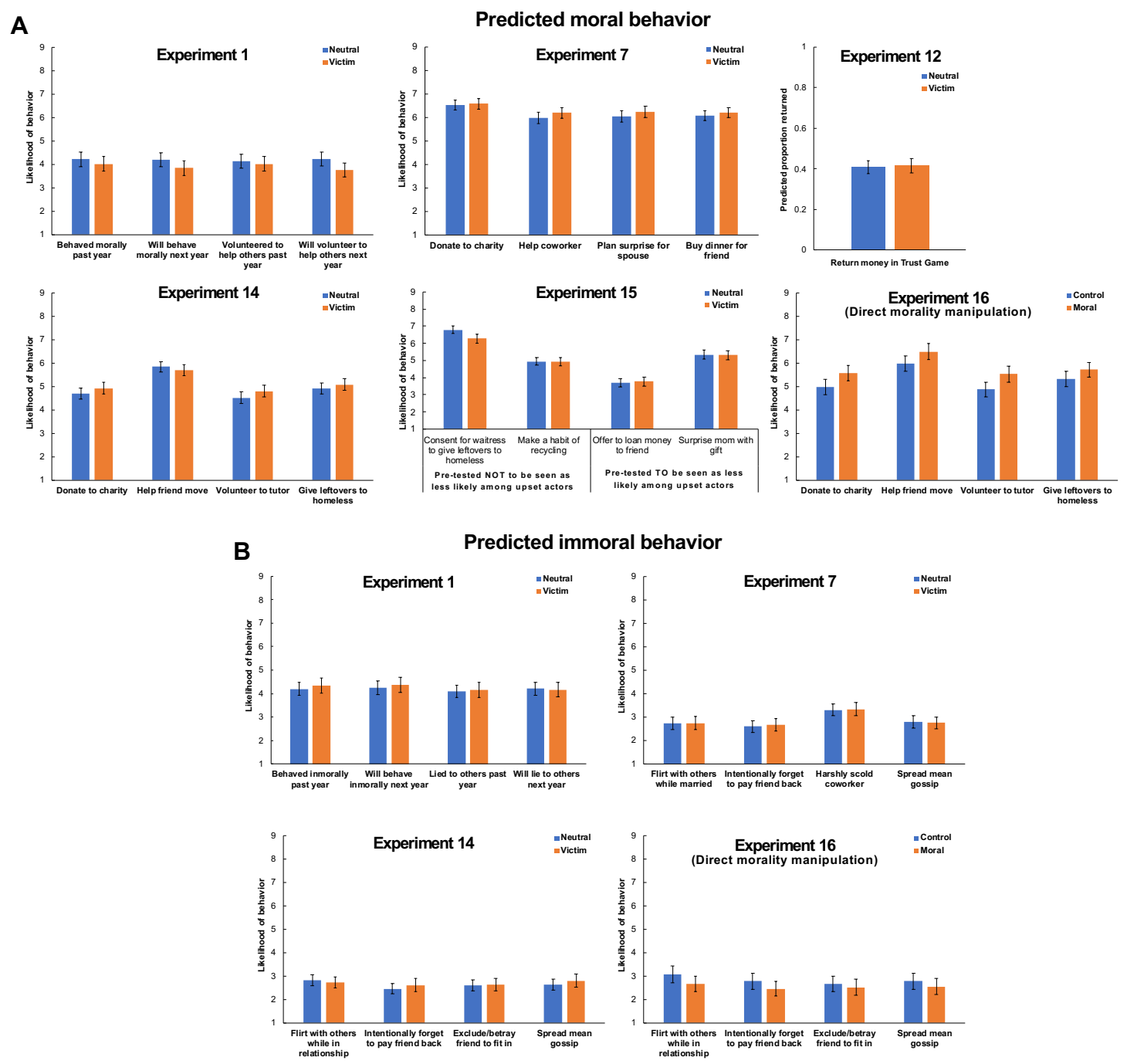

Fig. S5. Effects of our victim manipulations (in Experiments 1,7,12,14,15) and our direct morality manipulation (in Experiment 16) on behavior predictions.

These results reveal no significant positive effects of victim status on any moral behaviors, and no significant negative effects of victim status on any immoral behaviors. This pattern very robustly supports our claim that while subjects see victims as having elevated moral character, they do not see victims as more likely to behave morally or less likely to behave immorally. In contrast, in the context of our direct morality manipulation, which used the same set of behaviors as Experiment 14, we find a significant positive effect of the manipulation on three of the four moral behaviors, and a marginally significant positive effect on the fourth. We also find a marginally significant negative effect of the manipulation on one of the four immoral behaviors. These results suggest that the null effects of our victim manipulation on predicted moral behavior do not simply reflect that is too difficult to manipulate predicted behavior.

Our results also negate the hypothesis that the null effects of victim status on behavior predictions reflect that people expect victims to be upset following their victimization, and believe that upset individuals behave less morally. In Experiment 14, we did not directly inform subjects in the victim condition that the target was upset, and yet subjects still did not expect victims to behave more morally than non-victims. And in Experiment 15, we measured 
predictions regarding two behaviors that, according to our pre-test, subjects did not see as less likely among upset actors, but did see as more likely among moral actors (e.g., habitually recycling). Even for these behaviors, we found no positive effects of our victim manipulation. Together, these data suggest that the expectation that victims will be upset does not explain the observed discrepancy between the effect of victim status on perceived moral character and predicted moral behavior.

\section{Discussion of pre-registered analysis plans}

As described in the main text, we individually pre-registered 15 of our 17 experiments. However, because we conducted a large number of experiments employing similar designs, we chose not to individually report the results for each experiment. Instead, we structure our main text around a series of claims, and when many experiments are relevant to a particular claim, we report aggregate analyses to support that claim. This approach both facilitates brevity and allows us to provide statistical estimates that are less noisy and more precise. However, it also lead us to deviate from our pre-registered analysis plans.

In the interest of transparency, we have made all of our pre-registered analysis plans available (see Table S1 for links). Overall, the analyses we present in the main text (and the above elaborations of these analyses) adhere very closely to the primary analyses that we preregistered, despite some deviations or additional tests that were not pre-registered. Furthermore, in cases where we do not report the exact pre-registered analyses, we generally do still address the set of questions the pre-registered analyses sought to investigate (e.g., via analyses aggregating relevant data across experiments). However, we note that that labeling of conditions and variables in our paper deviates somewhat from the labeling used in our preregistrations (reflecting that our conceptual framework for this work, and thus the language we found most clear, evolved throughout the project).

Furthermore, for three of our experiments, there are pre-registered primary analyses investigating substantive questions that we do not address in our main text analyses or the above elaborations of them. In the "supplemental analyses" section of this document, below, we go through each of these "primary" deviations and explain the conceptual basis for the deviation, and report relevant analyses as appropriate.

We also note that our pre-registered analysis plans also involved several secondary and/or exploratory analyses investigating questions that we chose not to address in our main text analyses (or in the above elaborations of these analyses) For reasons of brevity, we do not discuss each of these "secondary" deviations in this document. However, in the "supplemental analyses" section of this document, below, we report aggregate analyses of two secondary dependent variables that we collected across multiple experiments (sympathy and exploitability). We also note that our data, including all secondary variables, are publicly available at https://osf.io/ckxb3/.

Finally, we note that in general, despite pre-registering several analyses involving mediation (mostly as secondary and/or exploratory analyses, but also as primary analyses in two cases, discussed in more detail below), we chose not to report the results of any mediation analyses in our main text or SM. We made this choice both for reasons of brevity (given the large number of experiments conducted and potential mediating variables collected), and also because mediation analyses are correlational, and thus do not allow us to make strong causal claims about mechanism (or discriminate between different causal models that predict the same 
correlation structure). For these reasons, we ultimately chose to support claims about mechanism only by considering the causal effects of our experimental manipulations.

\section{Supplemental analyses}

\subsection{Analyses pertaining to primary deviations from pre-registrations}

\subsubsection{Experiment 4}

As discussed in the main text, the Justice Restoration Hypothesis predicts that the Virtuous Victim effect should only occur when people perceive incentives for justice-restorative action. We provide direct evidence for this prediction in Experiment 11, in which we crossed our victim manipulation with a manipulation of disincentives for justice-restorative action. In Experiment 4, we also tried to provide evidence for this prediction — not by manipulating incentives for justice-restorative action, but instead by measuring a potential index of such incentives.

Specifically, in Experiment 4 we measured a set of ideology variables, and then employed two vignettes describing transgressions for which we anticipated that ideology would shape incentives for justice-restorative action: the verbal attack of a gun owner and sexual aggression. We predicted that in the context of our verbal attack vignette, individuals with conservative ideology (in general, and in particular with respect to the issue of gun control) would be more likely to show the Virtuous Victim effect, because they would perceive stronger incentives to punish the perpetrator and/or help the victim. And in the context of our sexual aggression vignette, we predicted that individuals with liberal ideology (in general, in particular with respect to the issue of sexual harassment) would be more likely to show the Virtuous Victim effect, because they would perceive stronger incentives for justice-restorative action.

However, we ended up finding that for both our verbal attack and sexual aggression vignettes, ideology predicted evaluations of target moral character even in the neutral condition (in which no transgression occurred). This finding suggests that ideology does not provide a clean index of incentives for justice-restorative action (to treat as a potential moderator of the Virtuous Victim effect), because ideology is associated with our dependent variable even when no transgression has occurred (and thus justice-restorative action is not relevant). Thus, in Experiment 11, we sought to provide a more informative test of the Justice Restoration Hypothesis by using a manipulation to introduce disincentives for justice-restorative action (rather than measuring an index of incentives for justice-restorative action).

For this reason, in the main text, we simply report the main effect of our victim manipulation on target moral character for each Experiment 4 vignette, and do not report analyses of moderation by ideology. Here, however, we do report these analyses.

As described in detail in the "full experimental methods" section of this document, we began Experiment 4 by measuring a set of ideology variables. In particular, we measured ideology (via three-item scales) with respect two specific moral issues that were related to vignettes included in Experiment 4: gun control (related to our verbal attack vignette, in which a gun owner is verbally attacked for his gun ownership) and sexual harassment (related to our sexual aggression vignette). We also measured ideology with respect to two "distractor" moral issues (racism by police officers and climate change), as well as general political ideology (via three questions about political party affiliation, social conservativism, and fiscal conservativism). 
We then used these measures to create three composite ideology variables, which coded for liberal ideology with respect to gun control, sexual harassment, and general political ideology, by averaging across the three items relevant to each construct. In Fig. S6, we plot the effect of our victim manipulation on target moral character for our verbal assault (Panel A) and sexual aggression (Panel B) vignettes, as a function of the relevant specific ideology composite variable (i.e., gun control ideology for our verbal assault vignette and sexual assault ideology for our sexual aggression vignette). To do so, we bin responses to our composite ideology variables (which range in value from 1-7) into six categories (corresponding to each of the six intervals between the integers 1-7).)

In Table S9, we report the results from a series of regressions predicting target moral character (i) as a function of liberal ideology in the neutral condition, (ii) as a function of liberal ideology in the victim condition, and (iii) as a function of liberal ideology, our victim manipulation $(0=$ neutral, $1=$ victim $)$, and their interaction (across both conditions). For our verbal attack and sexual aggression vignettes, we report these results both for the relevant specific ideology composite (gun control for our verbal attack vignette, and sexual harassment for our sexual aggression vignette) and for our general ideology composite. For our iPad theft vignette, we report these results for our general ideology composite only.

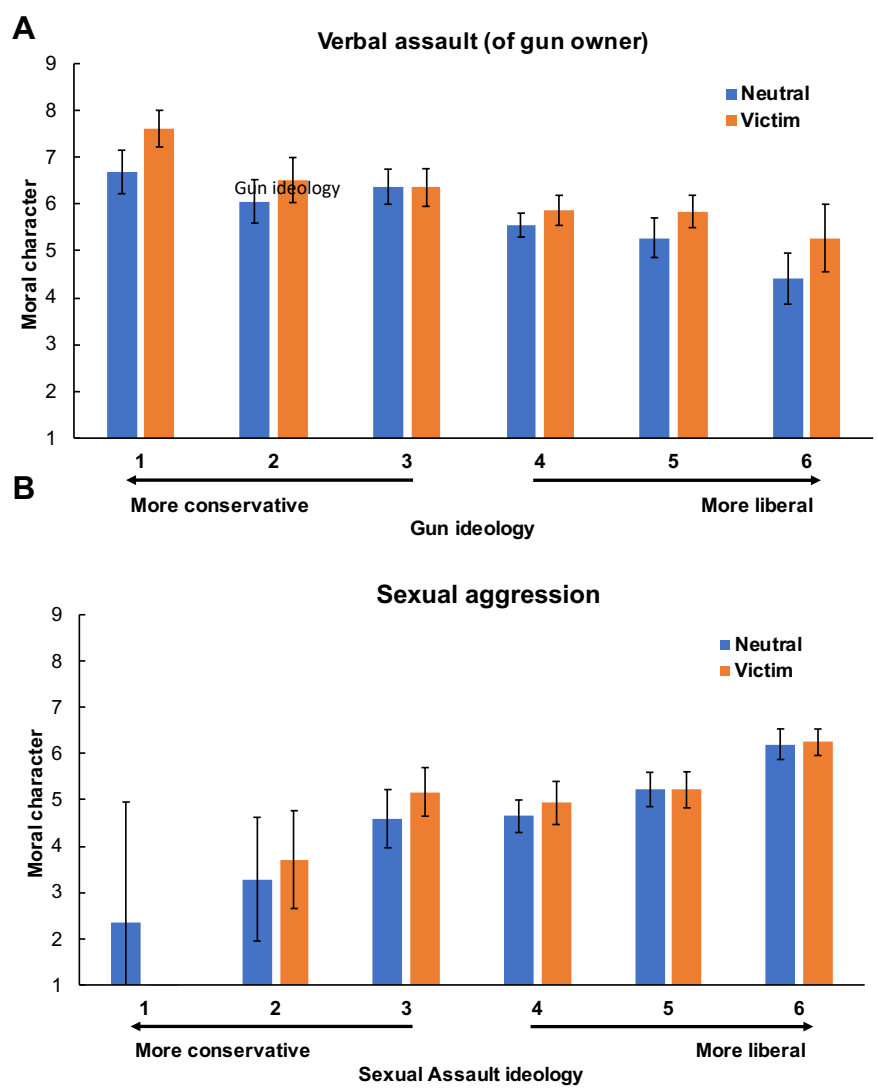

Fig. S6. Effects of our victim manipulation on target moral character as a function of specific ideology, for our verbal assault and sexual aggression vignettes in Experiment 4. 


\begin{tabular}{|c|c|c|c|}
\hline & Verbal attack (on gun owner) & Sexual aggression & iPad theft \\
\hline \multicolumn{4}{|l|}{ Specific ideology } \\
\hline Neutral $(n=255)$ & $\mathrm{b}=-0.43, \mathrm{t}=-7.62, \mathrm{p}<.001$ & $\mathrm{~b}=0.64, \mathrm{t}=8.45, \mathrm{p}<.001$ & \\
\hline Victim $(n=255)$ & $\mathrm{b}=-0.42, \mathrm{t}=-7.51, \mathrm{p}<.001$ & $\mathrm{~b}=0.48, \mathrm{t}=6.19, \mathrm{p}<.001$ & \\
\hline Interaction $(\mathrm{n}=510)$ & $\mathrm{b}=0.01, \mathrm{t}=0.12, \mathrm{p}=.903$ & $\mathrm{~b}=-0.16, \mathrm{t}=-1.46, \mathrm{p}=.145$ & \\
\hline \multicolumn{4}{|l|}{ General ideology } \\
\hline Neutral $(n=255)$ & $\mathrm{b}=-0.20, \mathrm{t}=-3.62, \mathrm{p}<.001$ & $\mathrm{~b}=0.39, \mathrm{t}=6.33, \mathrm{p}<.001$ & $\mathrm{~b}=0.01, \mathrm{t}=0.25, \mathrm{p}=.801$ \\
\hline $\operatorname{Victim}(n=255)$ & $\mathrm{b}=-0.34, \mathrm{t}=-5.77, \mathrm{p}<.001$ & $\mathrm{~b}=0.29, \mathrm{t}=4.38, \mathrm{p}<.001$ & $\mathrm{~b}=-0.06, \mathrm{t}=-1.01, \mathrm{p}=.316$ \\
\hline Interaction $(\mathrm{n}=510)$ & $\mathrm{b}=-0.14, \mathrm{t}=-1.72, \mathrm{p}=.087$ & $\mathrm{~b}=-0.10, \mathrm{t}=-1.09, \mathrm{p}=.277$ & $\mathrm{~b}=-0.08, \mathrm{t}=-0.93, \mathrm{p}=.354$ \\
\hline
\end{tabular}

Table S9. Associations between specific and general liberal ideology and target moral character, as a function of our victim manipulation, across vignettes in Experiment 4.

As discussed above, we originally predicted that the Virtuous Victim effect would be stronger among conservatives for the verbal attack vignette, and stronger among liberals for the sexual aggression vignette. As predicted by this proposal, in the victim condition, conservative ideology is consistently negatively associated with target character ratings for the verbal attack vignette, and consistently positively associated with target character ratings for the sexual aggression vignette. Yet these ideology associations also held in the neutral condition (in which no transgression occurred). And contrary to our original prediction, we found no significant interaction between ideology and victim status for either vignette or ideology measure.

We note that we did find a marginally significant interaction in the predicted direction for the verbal attack vignette and our general ideology variable, reflecting that conservatives showed a somewhat larger Virtuous Victim effect for this vignette. However, looking to this general ideology variable, we see that conservatives showed a directionally larger Virtuous Victim effect for all three of our vignettes, suggesting that this trend should not be interpreted as providing support for our prediction.

These patterns reveal, as noted above, that in the context of our verbal attack and sexual aggression vignettes, ideology is associated with subjects' evaluations of target moral character even in the absence of a transgression. And as argued above, they therefore complicate the interpretation of ideology as an index of incentives to for justice-restorative action (and potential moderator of the Virtuous Victim effect). Thus, we argue that Experiment 4 does not provide a clearly interpretable test of the Justice Restoration Hypothesis.

\subsubsection{Experiment 11a}

Recall that in Experiment 11a, we crossed a manipulation of disincentives for justicerestorative action with our standard victim manipulation in the context of our idea theft vignette, and found that the Virtuous Victim effect was eliminated in the "disincentives" condition. In addition to collecting our primary DVs (moral evaluations of the target), Experiment 11a also measured a set of secondary variables.

Specifically, before measuring our primary DVs, we measured, from subjects in all conditions, moral evaluations of the "other person" (who was a neutral character in the neutral conditions, and the perpetrator of idea theft in the victim conditions). And after collecting our primary DV, we measured, from subjects in all conditions, perceived reputation-based incentives to punish the other person, willingness to punish the other person, perceived reputation-based incentives to help the target, willingness to help the target, and sympathy for the target. (We note that punishment of the other person was described specifically as "giving [the other person] the cold shoulder.") Finally, for subjects in the victim conditions only, we also measured anger 
towards and blame of the other person. Sympathy, anger, and blame were each measured via three-item scales; we report analyses of composite variables computed by averaging these three items.

We show the effects of our manipulations on each of these secondary variables (as well as our primary dependent variables, which measure moral evaluations of the target) in Fig. S7 (which plots each variable by condition) and Table S10 (which reports the effect of an "disincentives" dummy separately for the neutral and victim conditions, as well as the interaction between a "disincentives" dummy and a "victim" dummy).

Our Experiment 11a pre-registration also included several specific analyses of our secondary variables. However, our conceptual framework for our work has shifted since we wrote our pre-registration. Thus, in the following sections we interpret our secondary variable results in light of our current conceptual understanding, and then close by describing our set of pre-registered analyses.
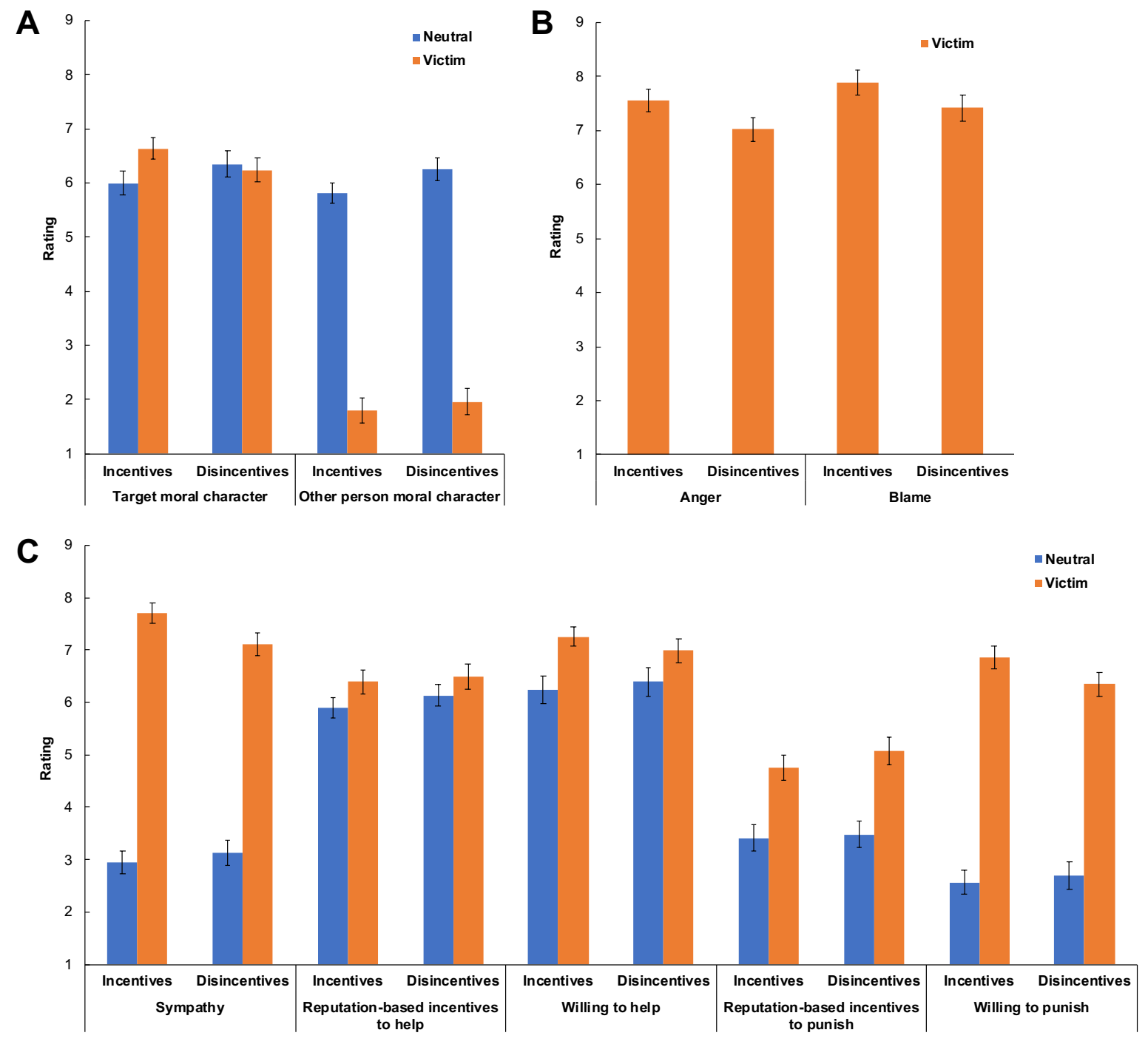

Fig. S7. Dependent variables across conditions in Experiment 11a. 


\begin{tabular}{|c|c|c|c|}
\hline Variable & $\begin{array}{c}\text { Effect of Disncentives } \\
\text { in Neutral }(n=401)\end{array}$ & $\begin{array}{l}\text { Effect of Disincentives } \\
\text { in Victim }(n=400)\end{array}$ & $\begin{array}{c}\text { Disincentives } X \\
\text { Victim interaction }\end{array}$ \\
\hline Anger towards other person & & $\begin{array}{l}\text { Incentives }=7.56, \text { Disincentives }=7.02 \\
\quad b=-0.54, t=-3.38, p=.001\end{array}$ & \\
\hline Blame of other person & & $\begin{array}{l}\text { Incentives }=7.88, \text { Disincentives }=7.41 \\
\qquad \mathrm{~b}=-0.47, \mathrm{t}=-3.28, \mathrm{p}=.001\end{array}$ & \\
\hline Morality of target & $\begin{array}{c}\text { Incentives }=6.00, \text { Disincentives }=6.39 \\
\mathrm{~b}=0.39, \mathrm{t}=2.31, \mathrm{p}=.021\end{array}$ & \multirow{9}{*}{$\begin{array}{c}\text { Incentives }=6.58, \text { Disincentives }=6.23 \\
b=-0.35, t=-2.21, p=.027 \\
\text { Incentives }=6.69, \text { Disincentives }=6.26 \\
b=-0.43, t=-2.73, p=.007 \\
\text { Incentives }=1.85, \text { Disincentives }=2.01 \\
b=0.16, t=0.89, p=.372 \\
\text { Incentives }=1.74, \text { Disincentives }=1.91 \\
\quad b=0.18, t=1.01, p=.315 \\
\text { Incentives }=7.70, \text { Disincentives }=7.10 \\
b=-0.60, t=-4.04, p<.001 \\
\text { Incentives }=6.40, \text { Disincentives }=6.49 \\
\quad b=0.10, t=0.54, p=.591 \\
\text { Incentives }=7.25, \text { Disincentives }=6.99 \\
b=-0.26, t=-1.57, p=.116 \\
\text { Incentives }=4.75, \text { Disincentives }=5.08 \\
b=0.34, t=1.78, p=.075 \\
\text { Incentives }=6.86, \text { Disincentives }=6.34 \\
b=-0.51, t=-2.47, p=.014\end{array}$} & $b=-0.74, t=-3.20, p=.001$ \\
\hline Trustworthiness of target & $\begin{array}{c}\text { Incentives }=6.00, \text { Disincentives }=6.30 \\
\mathrm{~b}=0.30, \mathrm{t}=1.76, \mathrm{p}=.080\end{array}$ & & $b=-0.73, t=-3.15, p=.002$ \\
\hline Morality of other person & $\begin{array}{c}\text { Incentives }=5.83, \text { Disincentives }=6.23 \\
\quad \mathrm{~b}=0.40, \mathrm{t}=2.69, \mathrm{p}=.007\end{array}$ & & $b=-0.24, t=-1.06, p=.290$ \\
\hline Trustworthiness of other person & $\begin{array}{c}\text { Incentives }=5.80, \text { Disincentives }=6.27 \\
\mathrm{~b}=0.47, \mathrm{t}=3.04, \mathrm{p}=.003\end{array}$ & & $b=-0.29, t=-1.25, p=.210$ \\
\hline Sympathy towards target & $\begin{array}{c}\text { Incentives }=2.94, \text { Disincentives }=3.13 \\
\mathrm{~b}=0.19, \mathrm{t}=0.96, \mathrm{p}=.338\end{array}$ & & $b=-0.79, t=-3.20, p=.001$ \\
\hline $\begin{array}{l}\text { Reputaton-based incentives to } \\
\text { help target }\end{array}$ & $\begin{array}{c}\text { Incentives }=5.90, \text { Disincentives }=6.13 \\
\mathrm{~b}=0.23, \mathrm{t}=1.32, \mathrm{p}=.189\end{array}$ & & $b=-0.14, t=-0.54, p=.589$ \\
\hline Willingness to help target & $\begin{array}{c}\text { Incentives }=6.24, \text { Disincentives }=6.39 \\
\mathrm{~b}=0.15, \mathrm{t}=0.86, \mathrm{p}=.391\end{array}$ & & $b=-0.41, t=-1.70, p=.090$ \\
\hline $\begin{array}{c}\text { Reputaton-based incentives to } \\
\text { punish other person }\end{array}$ & $\begin{array}{c}\text { Incentives }=3.42, \text { Disincentives }=3.48 \\
\mathrm{~b}=0.06, \mathrm{t}=0.33, \mathrm{p}=.744\end{array}$ & & $b=0.27, t=1.02, p=.310$ \\
\hline $\begin{array}{l}\text { Willingness to punish other } \\
\text { person }\end{array}$ & $\begin{array}{c}\text { Incentives }=2.57, \text { Disincentives }=2.70 \\
\mathrm{~b}=0.13, \mathrm{t}=0.60, \mathrm{p}=.551\end{array}$ & & $b=-0.64, t=-2.16, p=.031$ \\
\hline
\end{tabular}

Table S10. Condition effects on all dependent variables in Experiment 11a.

Evaluating the success of our disincentives manipulation. As discussed in the main text, we conducted Experiment $11 \mathrm{~b}$ to serve as a post-hoc manipulation check for Experiment 11a. In particular, we used Experiment $11 \mathrm{~b}$ to evaluate the success of our disincentives manipulation in two key ways. First, we sought to confirm that people actually perceive weaker incentives for justice-restorative action in the scenario described by our "disincentives" (vs. "incentives") condition. Second, we sought to confirm that taking on the perspective described by our "disincentives" condition does not prevent people from seeing idea theft as a genuine transgression that creates genuine victims. And indeed, Experiment $11 \mathrm{~b}$ provides clear evidence for both of these claims, suggesting that our disincentives manipulation was successful.

In addition to this evidence, however, the secondary variables collected within Experiment 11a can also shed some light on the success of our disincentives manipulation. Here, we interpret the secondary variables in this light.

To begin, the secondary variables provide further evidence that subjects in the victim version of the "disincentives" condition of Experiment 11 a really did see idea theft as a genuine transgression. These subjects rated the "other person" (who, in the victim conditions, was the idea theft perpetrator) as very immoral and untrustworthy. In fact, their moral evaluations of the perpetrator did not differ significantly from their counterparts in the "incentives" condition. Furthermore, in absolute terms, they also reported substantial anger towards, blame of, and willingness to punish the perpetrator, as well as sympathy towards the victim.

(We also briefly note that within the neutral conditions of our experiment, where no transgression occurred, we see an unexpected positive effect of the "disincentives" condition on moral evaluations of the other person, and also on moral evaluations of the target. One plausible explanation for these unexpected results is that in the "disincentives" condition, subjects were asked to imagine believing that idea theft is less common; for this reason, they may have had higher baseline moral evaluations of people at the advertising agency. Regardless, we see these 
results as unrelated to the question of how our disincentives manipulation influenced moral evaluations of the perpetrator in the victim conditions of our experiment, where theft occurred.)

Thus, our secondary DVs bolster the conclusion that subjects in the "disincentives" condition of Experiment 11a did see idea theft as a genuine transgression. And they consequentially bolster our conclusion that the "disincentives" condition really did eliminate the Virtuous Victim effect by reducing perceived incentives for justice-restorative action - and not simply by preventing subjects from seeing idea theft as morally wrong (and thus seeing the target as a true victim).

Notably, however, the "disincentives" condition did not reduce reported reputation-based incentives to punish or reputation-based incentives to help. Thus, our secondary DVs from Experiment 11a do not provide further evidence that our "disincentives" condition really did reduce perceived incentives for justice-restorative action. Yet we see our secondary DVs as providing a less informative measure of incentives than Experiment $11 \mathrm{~b}$, for three reasons.

First, our secondary DVs in Experiment 11 a asked specifically about reputation-based incentives to help and punish, whereas Experiment $11 \mathrm{~b}$ asked about incentives more generally. And it is plausible that the "disincentives" condition reduced perceived non-reputational incentives for justice-restorative action. In the "incentives" condition, subjects imagined disapproving of the brainstorming system that made idea theft possible. Thus, they may have perceived (non-reputational) incentives to draw attention to idea theft via justice-restorative action, in order to achieve their goal of dismantling the brainstorming system. In contrast, subjects in the "disincentives" condition imagined valuing the brainstorming system, and correspondingly may not have perceived such incentives.

Second, subjects in Experiment 11a were asked to imagine a situation, and then at the end of the study were asked to report the incentives that they would face in that situation. In contrast, subjects in Experiment 11b were asked to evaluate, from an objective third-party perspective, the incentives that subjects in Experiment 11a imagined facing. And we see this objective third-party perspective as providing a "purer" measure of incentives.

Finally, when designing our incentives measures in Experiment 11b, we provided subjects with better definitions of helping and punishment. In particular, our secondary DVs in Experiment 11a simply described helping with the phrase "If you helped Sarah out", and described punishment with the phrase "If you gave Gabrielle the cold shoulder". In contrast, Experiment $11 \mathrm{~b}$ described helping by saying "Imagine that James is considering helping Sarah. For example, James is considering helping Sarah to brainstorm new ideas, being especially warm and friendly towards Sarah when he sees her at work, making sure to praise Sarah for her work in front of others, or taking other similar action" and described punishment by saying "Imagine that James is considering "punishing" Gabrielle for presenting Sarah's idea as her own. For example, James is considering telling other people what Gabrielle did to Sarah and expressing his disapproval of Gabrielle's behavior, giving Gabrielle the cold shoulder when he sees her at work, reporting Gabrielle's behavior formally, or taking some other similar action".

For these reasons, we see Experiment $11 \mathrm{~b}$ as providing better insight into whether our disincentives manipulation actually influenced perceived incentives for justice-restorative action. And thus we believe that there is good reason to believe that our disincentives manipulation was successful in this goal, despite the fact that the "disincentives" condition did not reduce reported reputation-based incentives to punish or help in Experiment 11a. 
Analyses of motivation for justice-restorative action. In the main text, we show that the "disincentives" condition of Experiment 11a caused the Virtuous Victim effect to disappear. Our secondary DVs also show that it reduced motivation for justice-restorative action.

To support this claim, we first considered our set of secondary DVs that can be seen as measures of motivation for punishment: anger towards, blame of, and willingness to punish the other person. We only measured anger and blame in victim conditions (in which a transgression occurred); within these conditions, we find that subjects in the "disincentives" condition reported less anger towards and blame of the other person (i.e., the idea theft perpetrator). We also measured willingness to punish in all conditions, and find that (i) within the victim conditions, subjects in the "disincentives" condition reported less willingness to punish, (ii) this effect is specific to the victim conditions (in which a transgression occurred), as reflected by a significant interaction between incentives and victim status.

Thus, subjects in the "disincentives" version of the victim conditions reported less motivation to punish the perpetrator, as measured by blame, anger, and willingness to punish. We also found some evidence that they felt less motivation to help the victim, as measured by sympathy for and willingness to help the target. Both of these variables were measured in all conditions, and show the same pattern of results as our measure of willingness to punishalthough the results are highly significant for sympathy, but marginal for willingness to help.

Together, then, our set of Experiment 11a results suggest that subjects in the "disincentives" condition saw idea theft as a genuine transgression. Yet they did not morally elevate the victim, and they reported less motivation to engage in justice-restorative action. These results are consistent with the Justice Restoration Hypothesis, and its proposal that introducing disincentives for justice-restorative action should serve to eliminate the Virtuous Victim effect - and consequently prevent people from feel especially motivated to engage in justice-restorative action.

Pre-registered analysis plan. Finally, we describe the specific analyses of our secondary variables that we pre-registered.

In our Experiment 11a pre-registration, we planned to analyze moral evaluations of the other person, blame, and anger as manipulation checks. We predicted that within the victim conditions, we might observe positive effects of the "incentives" (vs. "disincentives") condition on blame and anger, and/or negative effects on moral evaluations of the other person.

Furthermore, we predicted that if we did find negative effects on other person character, that they would not hold or be weaker in the "neutral" condition (leading to a negative interaction between the "incentives" and "victim" conditions on other person character). Above, we discuss the effectiveness of our manipulation; however, with our current conceptual framework, we see a somewhat different set of variables as the most relevant to this discussion.

We also planned to treat the rest of our secondary variables (i.e., perceived reputational incentives to punish, willingness to punish, perceived reputational incentives to help, willingness to help, and sympathy) as additional dependent variables, and planned for each variable to investigate (i) the effects of victim status, our "incentives" condition, and their interaction, as well as (ii) the simple effect of victim status in the "incentives" condition. For all variables, we predicted that there might be positive interactions between our "incentives" and "victim" conditions, and that the simple effect of victim status in the "incentives" condition would be positive. We also planned, as secondary analyses, to conduct exploratory moderated mediation analyses treating these variables, as well as moral evaluations of the other person, as candidate mediators of the interaction between incentives and victim status on moral character. 
Above, we discuss the effects of our manipulation on all of these variables. We do not conduct the planned moderation mediation analyses because, as described above, we generally do not include mediation analyses in our paper (both for reasons of brevity and in order to focus on causal claims that we can support more confidently). However, here we briefly discuss another point, which is specific to these particular mediation analyses: they were designed to test a causal model that differs somewhat from the causal model we focus on in the main text.

When pre-registering these mediation analyses, we imagined a causal model in which, within our victim conditions (i.e., when a transgression occurs), (i) our "incentives" condition increases motivation for justice-restorative action and (ii) this in turn causes people to see victims as having elevated moral character. According to this causal model, it is appropriate to treat motivation for justice-restorative action as a mediator of the interaction between our "incentives" condition and victim status on moral character. Yet our as theorizing developed, we shifted our focus to a different causal model. Specifically, our paper ultimately proposes a causal model in which (i) incentives for justice-restorative action cause people to elevate morality of victims and (ii) this in turn increases motivation for justice-restorative action. According to this causal model, it is not appropriate to treat motivation for justice-restorative action as a mediator of the interaction between our "incentives" condition and victim status on moral character.

In fact, our set of results is actually consistent with either model. In other words, while we propose in our paper that the moral elevation of victims serves to adaptively boost motivation for justice-restorative action, our data are also compatible with the proposal that adaptive motivation for justice-restorative action causes the moral elevation of victims. Critically, both models support our overarching theoretical proposal that incentives for justice-restorative action give rise to the Virtuous Victim effect and motivation for justice-restorative action. Future research should nonetheless attempt to discriminate empirically between the two models; however, our Experiment 11a data do not allow us to do so (or to discriminate them from other models that predict the same correlation structure between variables).

\subsubsection{Experiment 13}

As discussed in the main text, Experiment 13 reveals that subjects report stronger (reputation-based) incentives to help victims of immorality - both as compared to neutral targets and victims of accidental misfortune. In addition to measuring incentives to help the target (as well as target morality and trustworthiness), Experiment 13 measured three other variables that we do not analyze in the main text.

First, we measured willingness to help the target, in order to test the hypothesis that people are particularly motivated to help victims of immorality (in line with the perception that doing so has particularly large reputational benefits). Second, we measured (reputation-based) incentives, and willingness, to affiliate with the target (described to subjects as "hanging out" with the target). We collected these affiliation measures to investigate the possibility that people generally perceive elevated incentives to (and are thus more willing to) interact with victims of immorality, in a way that is not specific to helping. However, in the main text we focus specifically on incentives to help the target (and not willingness to help or either affiliation variable) because we see incentives to help as most relevant to our theoretical claims.

We measured incentives and willingness to help and affiliate with the target all on the same page (and randomized the order of these four variables). In our pre-registration, we planned to use these four variables to create two composite variables: one averaging the two incentives items (i.e., incentives to help and affiliate with the target), and one averaging the two willingness 
items (i.e., willingness to help and affiliate with the target). Yet we found that our victim manipulation had a strong effect on our two helping items, but an inconsistent effect on our two affiliation items. On this basis, we chose to deviate from our plan to create composite variables.

Here, we report analyses of all four individual variables. In Fig. S8, we plot both of our helping and affiliation variables by condition in Experiment 13. And in Table S11, we report results of linear regressions comparing each pair of conditions (victim vs. neutral, accident vs. neutral, and victim vs. accident) for both of our helping and affiliation variables.

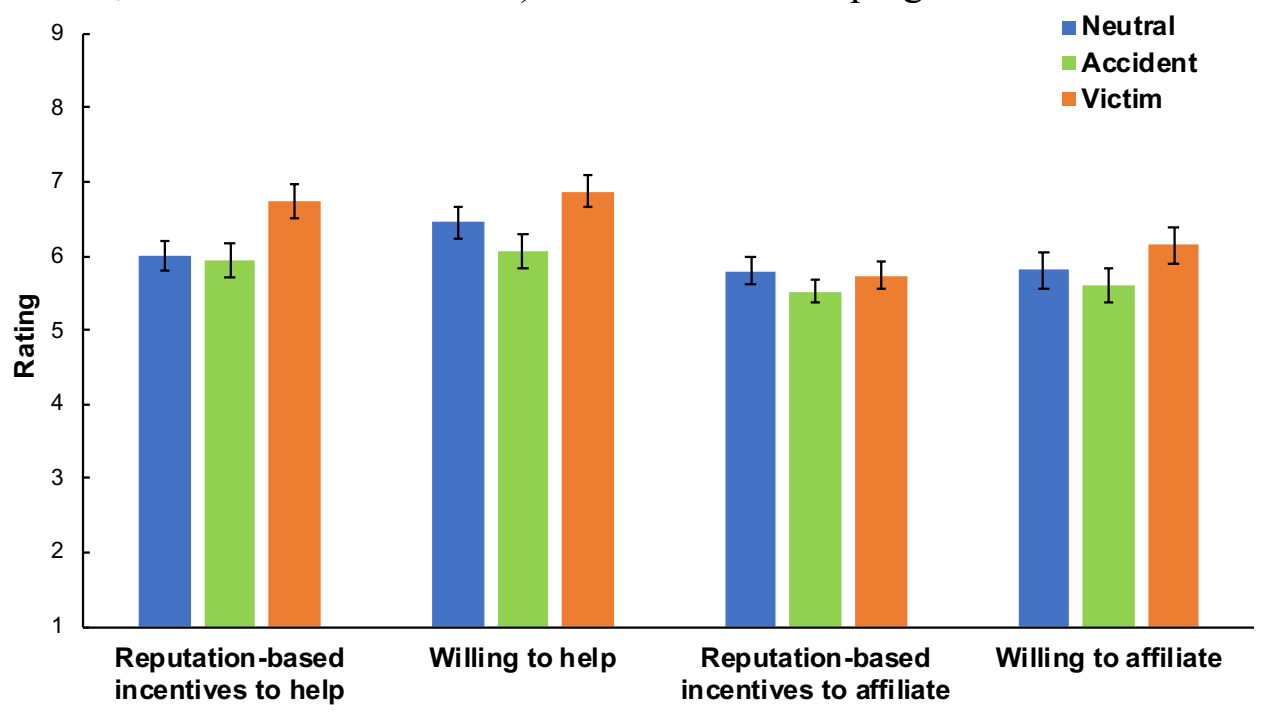

Fig. S8. Helping and affiliation variables across conditions in Experiment 13.

\begin{tabular}{|c|c|c|c|}
\hline Variable & $\begin{array}{l}\text { Victim vs. Neutral } \\
\qquad(\mathrm{n}=\mathbf{4 0 0})\end{array}$ & $\begin{array}{l}\text { Accident vs. Neutral } \\
\qquad(\mathrm{n}=\mathbf{4 0 0})\end{array}$ & $\begin{array}{l}\text { Victim vs. Accident } \\
\qquad(\mathrm{n}=\mathbf{4 0 0})\end{array}$ \\
\hline $\begin{array}{c}\text { Reputation-based incentives } \\
\text { to help }\end{array}$ & $\begin{array}{c}\text { Neutral }=6.00, \text { Victim }=6.74 \\
\mathbf{b}=\mathbf{0 . 7 4}, \mathbf{t}=\mathbf{4 . 7 3}, \mathbf{p}<\mathbf{. 0 0 1}\end{array}$ & $\begin{array}{c}\text { Neutral }=6.00, \text { Accident }=5.94, \\
\mathbf{b}=\mathbf{- 0 . 0 6}, \mathbf{t}=\mathbf{- 0 . 4 2}, \mathbf{p}=\mathbf{. 6 7 7}\end{array}$ & $\begin{array}{c}\text { Accident }=5.94, \text { Victim }=6.74 \\
\mathbf{b}=\mathbf{0 . 8 1}, \mathbf{t}=\mathbf{4 . 9 0}, \mathbf{p}<\mathbf{. 0 0 1}\end{array}$ \\
\hline Willing to help & $\begin{array}{c}\text { Neutral }=6.45, \text { Victim }=6.88 \\
\mathbf{b}=\mathbf{0 . 4 2}, \mathbf{t}=\mathbf{2 . 7 2}, \mathbf{p}=\mathbf{. 0 0 7}\end{array}$ & $\begin{array}{c}\text { Neutral }=6.45, \text { Accident }=6.06 \\
\mathbf{b}=\mathbf{- 0 . 3 9}, \mathbf{t}=\mathbf{- 2 . 5 0}, \mathbf{p}=\mathbf{. 0 1 3}\end{array}$ & $\begin{array}{c}\text { Accident }=6.06, \text { Victim }=6.88 \\
\mathbf{b}=\mathbf{0 . 8 2}, \mathbf{t}=\mathbf{4 . 9 6}, \mathbf{p}<\mathbf{. 0 0 1}\end{array}$ \\
\hline $\begin{array}{c}\text { Reputation-based incentives } \\
\text { to affiliate }\end{array}$ & $\begin{array}{l}\text { Neutral }=5.80, \text { Victim }=5.73 \\
\mathbf{b}=\mathbf{- 0 . 0 7}, \mathbf{t}=\mathbf{- 0 . 5 2}, \mathbf{p}=\mathbf{. 6 0 3}\end{array}$ & $\begin{array}{c}\text { Neutral }=5.80, \text { Accident }=5.52, \\
\mathbf{b}=\mathbf{- 0 . 2 7}, \mathbf{t}=\mathbf{- 2 . 2 5}, \mathbf{p}=\mathbf{. 0 2 5}\end{array}$ & $\begin{array}{c}\text { Accident }=5.52, \text { Victim }=5.73 \\
\mathbf{b}=\mathbf{0 . 2 1}, \mathbf{t}=\mathbf{1 . 6 5}, \mathbf{p}=\mathbf{. 0 9 9}\end{array}$ \\
\hline Willing to affiliate & $\begin{array}{c}\text { Neutral }=5.81, \text { Victim }=6.14 \\
\mathbf{b}=\mathbf{0 . 3 3}, \mathbf{t}=\mathbf{1 . 8 7}, \mathbf{p}=\mathbf{. 0 6 2}\end{array}$ & $\begin{array}{c}\text { Neutral }=5.81 \text {, Accident }=5.60 \\
\mathbf{b}=\mathbf{- 0 . 2 1}, \mathbf{t}=\mathbf{- 1 . 2 3}, \mathbf{p}=\mathbf{. 2 2 0}\end{array}$ & $\begin{array}{c}\text { Accident }=5.60, \text { Victim }=6.14, \\
\mathbf{b}=\mathbf{0 . 5 4}, \mathbf{t}=\mathbf{3 . 1 2}, \mathbf{p}=\mathbf{. 0 0 2}\end{array}$ \\
\hline
\end{tabular}

Table S11. Analyses of helping and affiliation variables in Experiment 13.

We find that our victim manipulation had a positive effect, relative to both other conditions, on both helping variables. In contrast, effects on our affiliation variables were smaller and less consistent. We do observe a positive effect of the victim condition on willingness to affiliate (that is marginally significant in contrast to the neutral condition, and significant in contrast to the accident condition), but it is smaller than the effect of the victim condition on willingness to help. And when looking at incentives to affiliate, we find no significant effect of the victim condition as compared to the neutral condition (with a directionally negative 
coefficient), but a marginally significant positive effect of the victim condition as compared to the accident condition.

Thus, while the effects of our victim manipulation on our affiliation variables mostly go in the same direction as the effects on our helping variables, they are less consistent and weaker. These results suggest that subjects perceive stronger incentives to, and are more willing to, help (as compared to affiliate with) victims. This finding is interesting, and is potentially consistent with the proposal, outlined in the main text, that people perceive elevated incentives to help victims because helping victims is an effective way to signal that one disapproves of the transgression in question (and is thus unlikely to transgress oneself). It makes sense that helping a victim may be a more effective way to signal disapproval of a transgression than generally affiliating with the victim, insofar as helping is perceived as a specific response to the transgression (but general affiliation is not).

Our Experiment 13 pre-registration also included two mediation analyses as primary analyses. Specifically, we planned to test for significant indirect effects of the victim condition on target morality and trustworthiness, using our two helping/affiliation composite variables as mediators. We do not conduct these analyses because, as explained previously, we do not report mediation analyses in our paper. Furthermore, like we noted above in the context of Experiment 11a, the decision to treat willingness to help (a measure of motivation for justice-restorative action) as a mediator of the Virtuous Victim effect assumes a causal model that differs somewhat from the causal model we ultimately propose in our paper. Our paper proposes that the Virtuous Victim effect serves to adaptively boost motivation for justice-restorative action; according to this proposal, motivation for justice-restorative action is a consequence (not a cause) of the Virtuous Victim effect, and thus should not be treated as a mediator.

Finally, we note one last feature of our Experiment 13 pre-registration. It incorrectly states that we measured evaluations of target moral character before measuring our set of helping and affiliation variables; in fact, we measured our set of helping and affiliation variables first.

\subsection{Aggregate analyses of secondary variables}

The previous section concludes our discussion of "primary" deviations from our preregistered analysis plans. However, as mentioned above, our pre-registered analysis plans also involved several secondary and/or exploratory analyses that, for reasons of brevity, we do not discuss individually in this document. Instead, here we report aggregate analyses of two secondary dependent variables that we collected across multiple experiments (ratings of sympathy towards, and exploitability of, the target).

In these aggregate analyses, we focus on the basic effect of our victim manipulation, as compared to our neutral condition. To do so, we analyze our "standard set of neutral vs. victim conditions". As described in Section 2.6 of this document, this label refers to the set of data that we analyze in Fig. S1 and Table S3: the standard victim and neutral conditions of all experiments that included both of these conditions, with the exceptions of (i) the first-person conditions of Experiments 5 and 6, or (ii) the "disincentives" conditions of Experiment 11a. (As described in Section 2.1 of this document, these exceptions reflect that we expected that these conditions might meaningfully change the effects of our standard victim manipulation, and our results supported this expectation.) 


\subsubsection{Sympathy}

We begin by discussing our first secondary dependent measure: sympathy towards the target, which we measured in Experiments 1-7, 11a, and 13-14 (using a three-item scale; we report analyses of composite sympathy ratings computed by averaging these three items).

In the main text, we consider the hypothesis that the Virtuous Victim effect occurs because people feel sympathy for victims, and are thus driven to evaluate them positively. According to this hypothesis, the Virtuous Victim effect should be quite general: it should extend to all sorts of positive traits, and apply to anybody who has suffered. Yet we instead find that the Virtuous Victim effect is specific to victims of moral transgressions (i.e., it does not extend to victims of accidental misfortune) and to moral virtue (i.e., it does not extend equally to positive but nonmoral traits). These results suggest that the effect does not simply reflect that people are generally compelled to positively evaluate those who have suffered (and who thus elicit sympathy).

Importantly, however, these results do not rule out the possibility that sympathy is an important part of the psychology surrounding the Virtuous Victim effect. In fact, as mentioned in the main text, analyses of sympathy ratings are consistent with the possibility that sympathy is a proximate cause, or consequence, of the Virtuous Victim effect. Here, we provide these analyses, which show that ratings of sympathy for the target track with the Virtuous Victim effect.

Specifically, recall that subjects see victims of immorality as more moral than neutral targets or victims of accidental misfortune. When looking to sympathy, we find that (i) subjects reported more sympathy for immorality victims, both relative to neutral targets $(b=4.21$ [4.10, 4.32], $t=74.43, B=.75, p<.001, n=4,949$ observations across 3,929 unique subjects; data from our standard set of neutral vs. victim conditions, among experiments that measured sympathy) and accident victims $(b=1.36[1.13,1.59], t=11.44, B=.34, p<.001, n=1,004$; data from our two experiments including accident conditions, both of which measured sympathy), and (ii) reported sympathy is positively correlated with ratings of target moral character $(B=.30, p<.001, n=4,949$ observations across 3,929 unique subjects; data from our standard set of neutral vs. victim conditions, among experiments that measured sympathy).

Thus, sympathy ratings track with the Virtuous Victim effect-suggesting that sympathy could be an important part of the psychology surrounding the effect. Yet we also find that accident victims receive much more sympathy than neutral targets $(b=3.46[3.23,3.69], t=$ $29.61, B=.69, p<.001, n=1,006)$ despite not being rated as having better moral character than neutral targets $(b=.03[-.13, .19], t=.36, B=.01, p=.722, n=1,006)$ (data from our two experiments including accident conditions, both of which measured sympathy). This pattern bolsters our argument that the Virtuous Victim effect does not simply reflect that people elevate the morality of anybody that they feel sorry for.

Why, then, does sympathy track with the Virtuous Victim effect? One possibility is that seeing immorality victims as virtuous serves to boost our sympathy for them. This proposal is consistent with the Justice Restoration Hypothesis, insofar as feeling elevated sympathy for immorality victims bolsters our motivation to help them and/or punish the perpetrators who have harmed them.

\subsubsection{Exploitability}

Next, we discuss another secondary dependent measure: ratings of the target's "exploitability". 
In the main text, we consider the hypothesis that the Virtuous Victim effect reflects that subjects hold a genuine belief that victims tend to be people who behave morally. If this were true, subjects should rate victims as more likely to behave virtuously (and/or less likely to behave unethically). Yet we instead find that subjects see victims as possessing elevated moral traits (i.e., as being more moral and trustworthy people), but do not expect victims to behave more morally. These results suggest that the effect does not simply reflect that a genuine belief about the typical conduct of victims.

While we see these results as quite decisive, some of our experiments also tested the "genuine belief" account of the Virtuous Victim effect in another way. In particular, they tested the hypothesis that subjects (i) see victims as people who are easy to exploit, and (ii) believe that exploitable individuals tend to be moral actors. To test this hypothesis, Experiments 1-7 and 14 included a three-item exploitability scale measuring the extent to which subjects saw the target as a person who is easily exploited by others. Additionally, in several of these experiments (specifically, Experiments 2,3,5-7, and 14), we added an item to the scale measuring a related construct: the extent to which subjects saw the target as a trusting person.

When we conduct aggregate exploitability analyses, we find that subjects indeed see victims of immorality as relatively exploitable, both as compared to neutral targets $(b=.91[.80$, 1.02], $t=15.96, B=.27, p<.001, n=4,144$ observations across 3,124 unique subjects; data from our standard set of neutral vs. victim conditions, among experiments that measured exploitability) and accident victims $(b=1.49[1.22,1.76], t=10.92, B=.41, p<.001, n=601$; data from Experiment 3, our one accident experiment that measured exploitability). And looking to our trusting item, we see the same pattern: subjects see victims of immorality as more trusting, both as compared to neutral targets $(b=.38[.25, .51], t=5.64, B=.12, p<.001, n=2,211$; data from our standard set of neutral vs. victim conditions, among experiments that included our trusting item) and accident victims $(b=.53[.26, .81], t=3.84, B=.15, p<.001, n=601$; data from Experiment 3, our one accident experiment that included our trusting item).

Thus, subjects do believe that victims of immorality are exploitable and trusting people. Does this explain why they see victims as moral? Interestingly, we do not find a positive correlation between our three-item exploitability scale and ratings of moral character $(B=.01, p$ $=.774, n=4,144$ observations across 3,124 unique subjects; data from our standard set of neutral vs. victim conditions, among experiments that measured exploitability and character). We do, however, find a positive correlation between our trusting item and ratings of moral character $(B=$ $.46, p<.001, n=2,211$; data from our standard set of neutral vs. victim conditions, among experiments that included our trusting item and measured character). Thus, our analyses of our trusting item are thus consistent with the hypothesis that the Virtuous Victim effect reflects that people infer that victims are more trusting, and believe that trusting individuals tend to be morally virtuous.

Yet we argue that this explanation for the Virtuous Victim effect is nonetheless implausible, given that the Virtuous Victim effect does not extend to predictions about moral behavior. And consistent with this intuition, just like we observe a positive correlation between our trusting item and ratings of moral character, we observe a similarly-sized positive correlation between our trusting item and predicted moral behavior, $B=.40, \mathrm{p}<.001, n=804$ (as well as a relatively weaker negative correlation between our trusting item and predicted immoral behavior, $B=-.15, \mathrm{p}<.001, n=804$ ) (data from our standard set of neutral vs. victim conditions, among experiments that included our trusting item and measured behavior predictions). This finding suggests that people expect trusting individuals to have more positive moral character and to 
behave more morally. And it thus bolsters the argument that if the Virtuous Victim effect were caused by the belief that victims tend to be trusting people, the effect should have extended to predicted moral behavior.

\section{Full experimental methods}

Here, we provide detailed design information about each of our experiments, including the pre-test for Experiment 15.

All of our experiments began similarly. In our online experiments, Mturk worker subjects began by entering their Mturk ID, completing a consent form, and learning that they would be reading a story and then answering questions about their impression of characters in the story. In our lab experiment, student subjects began by completing a consent form, entering their participation ID, learning that their session would involve a number of "short, unrelated parts" and then learning that they would begin by reading a story and then answering questions about their impression of characters in the story.

In the subsequent sections, we explain how each experiment continued from this starting point. For each experiment, we provide a design overview, include the full texts of all versions of our vignettes, and report all measures collected. Many of our experiments randomized the gender of the target character (along with all other characters in the vignette); for these experiments, we (i) illustrate our stimuli in the context of the female version of the vignette and (ii) specify the alternative names provided in the male version of the vignette.

\subsection{Experiment 1}

\section{Design overview}

Experiment 1 employed a four-condition, between-subject design in which subjects were assigned one of the following conditions: neutral (in which the target was a neutral character), standard victim (in which the target behaved identically, but was victimized by a perpetrator), other victim (in which the target behaved identically and was not victimized, but another character was victimized), or minimal narrative victim (in which the target behaved identically and was victimized, but less detail was provided about the perpetrator). We also randomized between-subjects whether the target character (and all other characters in the vignette) was male or female. Experiment 1 used our iPad vignette, in which the relevant transgression is the theft of an iPad.

\section{Vignette text}

In all conditions, the vignette began as follows: Sarah is a politically moderate college student. Last Wednesday, she and a few of her classmates were studying for a big upcoming exam in the common room of Sarah's dorm suite. At one point, one of Sarah's classmates, Gabrielle, asked to use Sarah's iPad to look something up. Later that day, Sarah relaxed by watching a TV show on her iPad, and then went out for the evening. This was the entire vignette in the neutral condition.

In the standard victim condition, the vignette continued: That evening, while Sarah was out, Gabrielle figured out how to enter her suite. After entering, Gabrielle stole Sarah's iPad from her room. When Sarah noticed that it was missing, she was very upset.

In the other victim condition, the vignette continued: That evening, Gabrielle figured out how to enter the suite of another classmate, Rachel, who Gabrielle knew also owned an iPad. 
After entering, Gabrielle stole Rachel's iPad from her room. When Rachel noticed that it was missing, she was very upset.

In the minimal narrative victim condition, the vignette continued: That evening, while Sarah was out, Sarah's iPad was stolen from her room. When Sarah noticed that it was missing, she was very upset.

In the male version of the vignette, the names "Sarah", "Gabrielle", and "Rachel" were replaced with "Sam", "Gordon", and "Rob" (and male pronouns were used).

\section{Measures}

Subjects then answered a series of questions about characters in the vignette, spread out across several pages. All questions were answered on 1-9 Likert scales (Anchors: 1 - Not at all, 2, 3 - A little bit, 4, 5- Moderately, 6, 7 - Quite a lot, 8, 9 - Extremely). On all pages, the (identical) vignette was presented before the questions. The first presentation of the vignette was paired with the first set of questions.

Key dependent measures. We began by measuring our key dependent measures: (i) ratings of moral character (morality and trustworthiness), and (ii) a set of behavior predictions (predicted past/future, specific/general, moral/immoral behavior).

Moral character. On the first evaluation page, subjects rated the moral character of the target character, Sarah, across two questions. First, they rated Sarah's morality ("How moral of a person is Sarah?") and second, they rated Sarah's trustworthiness ("How trustworthy of a person is Sarah?").

Behavior predictions. On the next two evaluation pages, subjects made a set of eight predictions about the target's moral behavior. One page elicited four predictions about past behavior, and one page elicited four predictions about future behavior; the order of these pages was randomized between-subjects. Within each page, subjects always first made two predictions about general behavior (both moral and immoral), and then made two predictions about specific moral behavior (both moral and immoral); we randomized between-subjects whether the questions about moral vs. immoral behavior were presented first.

The questions about past behavior asked subjects: "How frequently do you think Sarah engaged in moral behaviors that benefited others over the past year?" (Past, general, moral), "How frequently do you think Sarah engaged in immoral behaviors that benefited others over the past year?" (Past, general, immoral), "How frequently do you think Sarah volunteered to help others in her life over the past year?" (Past, specific, moral), and "How frequently do you think Sarah lied to others to get she wanted over the past year?" (Past, specific, immoral). The questions about future behavior were identical, except that they were directed towards the next year (e.g., "How frequently do you think Sarah will engage in moral behaviors that benefit others over the next year?" (Future, general, moral)).

Secondary dependent measures. Next, we collected our secondary dependent measures: (i) sympathy towards the target, (ii) exploitability of the target, and (iii) (in all conditions besides neutral) blame of the perpetrator. Specifically, across three pages, we collected these three measures; the order of these pages was randomized between-subjects.

Sympathy. The set of sympathy question asked subjects in random order: "How sympathetic do you feel towards Sarah?", "How bad do you feel for Sarah?", and "How sorry for Sarah are you?".

Exploitability. The set of exploitability question asked subjects in random order: "How easy do you think that it would be to exploit Sarah for one's personal gain?", "How naïve of a 
person do you think Sarah is?", and "How likely do you think that people are to try to harm Sarah in the future?".

Blame. In the standard victim condition, the set of blame question asked subjects in random order: "How bad of a person is Gabrielle for stealing Sarah's iPad?", "How immoral was Gabrielle's choice to steal Sarah's iPad?", and "How blameworthy is Gabrielle for stealing Sarah's iPad?". In the other victim condition, these questions were identical, except that instead of referring to Sarah's iPad, they referred to Rachel's iPad. In the minimal narrative victim condition, these questions were identical, except that we specified upfront in the instructions that subjects would be answering questions "about the person who stole Sarah's iPad", and then instead of referring to Gabrielle, our questions referred to "this person".

\section{Post-experimental survey}

Finally, subjects completed a post-experimental survey in which they (i) answered a simple analogy question and wrote three sentences about their activities and plans for their day (questions that were designed to test English comprehension), and then (ii) answered a set of demographic and survey questions. In particular, we measured age, gender, level of education, income, country of residence, generalized trust in others, belief in a just world, political party affiliation, and social and fiscal conservativism. To measure belief in a just world, we asked subjects to rate their agreement, on 1-7 Likert scales, with two statements: "I feel that people get what they deserve" and "In general, I find society to be fair".

\subsection{Experiment 2}

\section{Design overview}

Experiment 2 employed a two-condition, between-subject design in which subjects were assigned one of the following conditions: neutral (in which the target was a neutral character) and standard victim (in which the target behaved identically, but was victimized by a perpetrator). We also randomized between-subjects whether the target character (and all other characters in the vignette) was male or female. Experiment 2 used our iPad vignette, in which the relevant transgression is the theft of an $\mathrm{Pad}$.

\section{Vignette text}

In all conditions, the vignette began as follows: Sarah is a politically moderate college student. Last Wednesday, she and a few of her classmates were studying for a big upcoming exam in the common room of Sarah's dorm suite. At one point, one of Sarah's classmates, Gabrielle, asked to use Sarah's iPad to look something up. Later that day, Sarah relaxed by watching a TV show on her iPad, and then went out for the evening. This was the entire vignette in the neutral condition.

In the standard victim condition, the vignette continued: That evening, while Sarah was out, Gabrielle figured out how to enter her suite. After entering, Gabrielle stole Sarah's iPad from her room. When Sarah noticed that it was missing, she was very upset.

In the male version of the vignette, the names "Sarah" and "Gabrielle" were replaced with "Sam" and "Gordon" (and male pronouns were used). 


\section{Measures}

Subjects then answered a series of questions about characters in the vignette, spread out across several pages. All questions were answered on 1-9 Likert scales (Anchors: 1 - Not at all, 2, 3 - A little bit, 4, 5- Moderately, 6, 7 - Quite a lot, 8, 9 - Extremely). On all pages, the (identical) vignette was presented before the questions. The first presentation of the vignette was paired with the first set of questions.

Key dependent measures. We began by measuring our key dependent measures: ratings of moral character (morality and trustworthiness).

Moral character. On the first evaluation page, subjects rated the moral character of the target character, Sarah, across two questions. First, they rated Sarah's morality ("How moral of a person is Sarah?") and second, they rated Sarah's trustworthiness ("How trustworthy of a person is Sarah?").

Secondary dependent measures. Next, we collected our secondary dependent measures: (i) sympathy towards the target and (ii) exploitability of the target. Specifically, across two pages, we collected these two measures; the order of these pages was randomized betweensubjects.

Sympathy. The set of sympathy question asked subjects in random order: "How sympathetic do you feel towards Sarah?", "How bad do you feel for Sarah?", and "How sorry for Sarah are you?".

Exploitability. The set of exploitability question asked subjects in random order: "How trusting do you think Sarah is of others?", "How easy do you think that it would be to exploit Sarah for one's personal gain?", "How naïve of a person do you think Sarah is?", and "How likely do you think that people are to try to harm Sarah in the future?".

\section{Post-experimental survey}

After completing these measures, subjects completed a survey in which they answered a set of demographic and survey questions. In particular, subjects reported their age, gender, student status, income, two items measuring their belief in a just world, political party affiliation, the extent to which they are socially, and fiscally, liberal vs. conservative, and if English is their native language. To measure belief in a just world, we asked subjects to rate their agreement, on 1-7 Likert scales, with two statements: "I feel that people get what they deserve" and "In general, I find society to be fair". After completing this set of questions, subjects were directed to complete other parts of the lab experiments (that were used for other research purposes, and are not relevant to or discussed in this paper).

\subsection{Experiment 3}

\section{Design overview}

Experiment 3 employed a four-condition, between-subject design in which subjects were assigned one of the following conditions: neutral (in which the target was a neutral character), standard victim (in which the target behaved identically, but was victimized by a perpetrator), accident victim: earthquake (in which the target behaved identically, but suffered accidental misfortune due to an earthquake), or accident victim: cat (in which the target behaved identically, but suffered accidental misfortune due to a stray cat). We also randomized betweensubjects whether the target character (and all other characters in the vignette) was male or 
female. Experiment 3 used our iPad vignette, in which the relevant transgression is the theft of an iPad.

\section{Vignette text}

In all conditions, the vignette began as follows: Sarah is a politically moderate college student. Last Wednesday, she and a few of her classmates were studying for a big upcoming exam in the common room of Sarah's dorm suite. Two of these classmates were named Rachel and Gabrielle. At one point, Gabrielle asked to use Sarah's iPad to look something up. Later that day, Sarah relaxed by watching a TV show on her iPad, and then went out for the evening. This was the entire vignette in the neutral condition.

In the standard victim condition, the vignette continued: That evening, while Sarah was out, Gabrielle figured out how to enter her suite. After entering, Gabrielle stole Sarah's iPad from her room. When Sarah noticed that it was missing, she was very upset.

In the accident victim: earthquake condition, the vignette continued: That evening, while Sarah was out, there was a major and unexpected earthquake. The earthquake knocked Sarah's iPad off the shelf, damaging it irreparably. When Sarah noticed that it was broken, she was very upset.

In the accident victim: cat condition, the vignette continued: That evening, while Sarah was out, a stray cat managed to find its way into her suite. The cat jumped up on the shelf and knocked Sarah's iPad off, damaging it irreparably. When Sarah noticed that it was broken, she was very upset.

In the male version of the vignette, the names "Sarah", "Gabrielle", and "Rachel" were replaced with "Sam", "Gordon", and "Rob" (and male pronouns were used).

\section{Measures}

Subjects then answered a series of questions about characters in the vignette, spread out across several pages. All questions were answered on 1-9 Likert scales (Anchors: 1 - Not at all, 2, 3-A little bit, 4, 5- Moderately, 6, 7 - Quite a lot, 8, 9-Extremely). On all pages, the (identical) vignette was presented before the questions. The first presentation of the vignette was paired with the first set of questions.

Key dependent measures. We began by measuring our key dependent measures: ratings of moral character (morality and trustworthiness) as well as four nonmoral traits (sociability, intelligence, funniness, and athleticism).

Moral character and nonmoral traits. On the first evaluation page, subjects evaluated the target character, Sarah, on six traits in random order. Subjects rated Sarah's morality ("How moral of a person is Sarah?"), trustworthiness ("How trustworthy of a person is Sarah?"), sociability ("How social of a person is Sarah?"), intelligence ("How intelligent of a person is Sarah?"), funniness ("How funny of a person is Sarah?"), and athleticism ("How athletic of a person is Sarah?").

Secondary dependent measures. Next, we collected our secondary dependent measures: (i) sympathy towards the target and (ii) exploitability of the target. Specifically, across two pages, we collected these two measures; the order of these pages was randomized betweensubjects.

Sympathy. The set of sympathy question asked subjects in random order: "How sympathetic do you feel towards Sarah?", "How bad do you feel for Sarah?", and "How sorry for Sarah are you?". 
Exploitability. The set of exploitability question asked subjects in random order: "How trusting do you think Sarah is of others?", "How easy do you think that it would be to exploit Sarah for one's personal gain?", "How naïve of a person do you think Sarah is?", and "How likely do you think that people are to try to harm Sarah in the future?".

\section{Post-experimental survey}

Finally, subjects completed a post-experimental survey in which they (i) answered a simple analogy question and wrote three sentences about their activities and plans for their day (questions that were designed to test English comprehension), and then (ii) answered a set of demographic and survey questions. In particular, subjects reported their age, gender, level of education, income, and country of residence.

\subsection{Experiment 4}

\section{Design overview}

Experiment 4 employed a two-condition, between-subject design in which subjects were assigned one of the following conditions: neutral (in which the target was a neutral character), standard victim (in which the target behaved identically, but was victimized by a perpetrator).

Experiment 4 differed from all other experiments in that it employed more than one vignette. In Experiment 4, all subjects were assigned to evaluate three different vignettes: specifically, our iPad vignette (in which the relevant transgression is the theft of an iPad), our verbal attack vignette (in which the relevant transgression is the verbal attack of a gun owner), and our sexual aggression vignette (in which the relevant transgression is aggression during a sexual encounter). Subjects were assigned to just one experimental condition (i.e., neutral or standard victim) and thus all three vignettes matched this single condition. We randomized between-subjects the order in which the three vignettes were presented. Furthermore, for our iPad vignette only, we also randomized between-subjects whether the target character (and all other characters in the vignette) was male or female.

Before any vignettes were presented, subjects completed (i) a demographic questionnaire and (ii) a set of survey questions assessing their ideology with respect to various social issues.

\section{Demographic questionnaire}

In the demographic questionnaire, we measured subjects' age, gender, level of education, income, country of residence, political party affiliation, social and fiscal conservativism, and belief in a just world. To measure belief in a just world, we asked subjects to rate their agreement, on 1-7 Likert scales, with two statements: "I feel that people get what they deserve" and "In general, I find society to be fair".

\section{Ideology Assessment}

In the ideology assessment, we measured subjects' agreement with four sets of statements. These four sets of statements were designed to assess ideology with respect to four social issues: gun control, sexual harassment, climate change, and racism by police officers. Each set involved three statements.

For each statement, we categorized whether agreement reflected a liberal or conservative ideology with respect to the relevant issue. We then reverse-coded statements reflecting liberal ideology to compute a composite measure of conservative ideology for each set of statements. 
Below, we list each set of statements, and for each statement indicate whether we categorized agreement as liberal or conservative.

Gun control: "We need increased gun regulation in America" (liberal), "It is morally wrong to own guns" (liberal), and "The right to bear arms is extremely important and must be fiercely protected" (conservative).

Sexual harassment: "All else equal, I usually believe women who say that they've been sexually assaulted" (liberal), "I strongly support the \#MeToo movement against sexual harassment and sexual assault" (liberal), and "Alleged acts of sexual assault and harassment are not always the man's fault, if the woman sent mixed signals" (conservative).

Climate change: "Global warming is an enormous threat to our society that is caused by human behavior" (liberal), "It is morally wrong to drive a gas-guzzling SUV, given the threat of global warming" (liberal), and "The scientific evidence for climate change has serious limitations" (conservative).

Racism by police officers: "Racism among police officers is a huge problem in society" (liberal), "All else equal, when a police officer is violent towards an unarmed black person, I blame the police officer" (liberal), and "If police officers are more violent towards black people, it is simply because they engage in more criminal activity" (conservative).

All twelve statements were presented on one page in random order. For each statement, subjects rated their level of agreement on the following scale: (i) strongly disagree, (ii) disagree, (iii) somewhat disagree, (iv) neither agree nor disagree, (v) somewhat agree, (vi) agree, or (vii) strongly agree.

\section{Vignette texts}

iPad vignette. In all conditions, the vignette began as follows: Sarah is a politically moderate college student. Last Wednesday, she and a few of her classmates were studying for a big upcoming exam in the common room of Sarah's dorm suite. At one point, one of Sarah's classmates, Gabrielle, asked to use Sarah's iPad to look something up. Later that day, Sarah relaxed by watching a TV show on her iPad, and then went out for the evening. This was the entire vignette in the neutral condition.

In the standard victim condition, the vignette continued: While she was out, Gabrielle figured out how to enter her suite and stole her iPad. When Sarah noticed that it was missing, she was very upset.

In the male version of the moderate vignette, the names "Sarah" and "Gabrielle" were replaced with "Sam" and "Gordon" (and male pronouns were used).

Verbal attack vignette. In all conditions, the vignette began as follows: Josh is a politically moderate college student. Growing up, his family kept guns in the home for protection and recreational shooting, and Josh owns a few guns. He doesn't bring them to campus with him, but some of his classmates know about his guns because Josh often talks about them, and has told stories about using them when he goes home for school vacations. Last Wednesday, one of Josh's classmates, Chelsea, saw him at a party.

In the neutral condition, the vignette continued: She started talking with Josh and brought up his and his family's gun ownership.

In the standard victim condition, the vignette continued: Unprovoked, Chelsea started aggressively criticizing Josh for his and his family's gun ownership, calling him harsh names in front of everyone and saying that gun ownership is a horrible force in society. Josh was very upset. 
Sexual aggression vignette. In all conditions, the vignette began as follows: Elizabeth is a politically moderate college student. Last Saturday night, she and a few of her close friends went out to a party at a campus fraternity. While she was there, Elizabeth had a few drinks, and chatted with several guys she knew at the frat. Towards the end of the night, she flirted a bunch with a guy named Chris. Later that night, Chris hooked up with Elizabeth in his room.

In the neutral condition, the vignette continued: Part way through their encounter, Elizabeth told Chris she wanted to stop hooking up, so they stopped.

In the standard victim condition, the vignette continued: Part way through their encounter, Elizabeth told Chris she wanted to stop hooking up, but he repeatedly kept trying things. Elizabeth was very upset.

\section{Measures}

Subjects answered a series of questions after each of the three vignettes. All questions were answered on 1-9 Likert scales (Anchors: 1 - Not at all, 2, 3 - A little bit, 4, 5 - Moderately, 6, 7-Quite a lot, 8, 9-Extremely). On all pages, the (identical) vignette was presented before the questions. The first presentation of the vignette was paired with the first set of questions.

Below, we print the text of all questions. Several questions that were identical across vignettes, with the exception that the target character's name varied across vignettes; for those questions, in the below text we use "[target]" to stand in for the target character's actual name.

Key dependent measures. We began by measuring our key dependent measures: ratings of moral character (morality and trustworthiness).

Moral character. On the first evaluation page, subjects rated the moral character of the target character across two questions. First, they rated the target character's morality ("How moral of a person is [target]?") and second, they rated target character's trustworthiness ("How trustworthy of a person is [target]?").

Secondary dependent measures. Next, we collected our secondary dependent measures: (i) sympathy towards the target, (ii) exploitability of the target, and (iii) blame towards the perpetrator (in the standard victim condition). Specifically, across three pages, we collected these three measures; the order of these pages was randomized between-subjects.

Sympathy. The set of sympathy question asked subjects in random order: "How sympathetic do you feel towards [target]?", "How bad do you feel for [target]?", and "How sorry for [target] are you?".

Exploitability. The set of exploitability question asked subjects in random order: "How easy do you think that it would be to exploit [target] for one's personal gain?", "How naïve of a person do you think [target] is?", and "How likely do you think that people are to try to harm [target] in the future?".

Blame. In the $i P a d$ vignette, the set of blame question asked subjects in random order: "How bad of a person is Gabrielle for stealing Sarah's iPad?", "How immoral was Gabrielle's choice to steal Sarah's iPad?", and "How blameworthy is Gabrielle for stealing Sarah's iPad?".

In the verbal attack vignette, the set of blame question asked subjects in random order: "How bad of a person is Chelsea for aggressively criticizing Josh?", "How immoral was Chelsea's choice to aggressively criticize Josh?", and "How blameworthy is Chelsea for aggressively criticizing Josh?".

In the sexual aggression vignette, the set of blame question asked subjects in random order: "How bad of a person is Chris for repeatedly trying things after Elizabeth said that she wanted to stop?", "How immoral was Chris choice to repeatedly try things after Elizabeth said 
that she wanted to stop?", and "How blameworthy is Chris for repeatedly trying things after Elizabeth said that she wanted to stop?".

\section{Post-experimental survey}

Finally, subjects completed a post-experimental survey in which they (i) answered a simple analogy question and wrote three sentences about their activities and plans for their day (questions that were designed to test English comprehension), and then (ii) answered a set of survey questions. In particular, subjects answered the following questions: "Do you consider gun control to be a moral issue?", "Do you consider sexual assault and harassment to be a moral issue?", and "Do you consider stealing to be a moral issue?". For each of these questions, subjects responded on the following scale: (i) Not at all, (ii) Slightly, (iii) Moderately, (iv) Much, or (v) Very much.

\subsection{Experiment 5}

\section{Design overview}

Experiment 5 employed a two-by-two, between-subject design. As our first factor, we manipulated whether subjects were assigned to the neutral condition (in which the target was a neutral character) or the standard victim condition (in which the target behaved identically, but was victimized by a perpetrator). As our second factor, we manipulated whether subjects were assigned to the first-person condition (in which the vignette was presented in first-person) or the third-person condition (in which the vignette was presented in third-person). Subjects were randomly assigned to one of the four possible conditions that resulted from crossing these manipulations. We also randomized between-subjects whether the target character (and all other characters in the vignette) was male or female. Experiment 5 used our iPad vignette, in which the relevant transgression is the theft of an $\mathrm{iPad}$.

\section{Vignette text}

In all conditions, the vignette began with some third-person background information, as follows: Sarah is a politically moderate college student.

In both of the third-person conditions, the vignette continued: Last Wednesday, she and a few of her classmates were studying for a big upcoming exam in the common room of Sarah's dorm suite. At one point, one of Sarah's classmates, Gabrielle, asked to use Sarah's iPad to look something up. Later that day, Sarah relaxed by watching a TV show on her iPad, and then went out for the evening. This was the entire vignette in the neutral, third-person condition.

In the standard victim, third-person condition, the vignette additionally continued: That evening, while Sarah was out, Gabrielle figured out how to enter her suite. After entering, Gabrielle stole Sarah's iPad from her room. When Sarah noticed that it was missing, she was very upset.

In both of the first-person conditions, the vignette continued: Recently, Sarah told the following story to a friend: "Last Wednesday, a few of my classmates and I were studying for a big upcoming exam in the common room of my dorm suite. At one point, one of my classmates, Gabrielle, asked to use my iPad to look something up. Later that day, I relaxed by watching a TV show on my iPad, and then went out for the evening." This was the entire vignette in the neutral, first-person condition. 
In the standard victim, first-person condition, the vignette additionally continued: "That evening, while I was out, Gabrielle figured out how to enter my suite. After entering, Gabrielle stole my iPad from my room. When I noticed that it was missing, I was very upset."

In the male version of the vignette, the names "Sarah" and "Gabrielle" were replaced with "Sam" and "Gordon" (and male pronouns were used).

\section{Measures}

Subjects then answered a series of questions about characters in the vignette, spread out across several pages. All questions were answered on 1-9 Likert scales (Anchors: 1 - Not at all, 2, 3 - A little bit, 4, 5- Moderately, 6, 7 - Quite a lot, 8, 9 - Extremely). On all pages, the (identical) vignette was presented before the questions. The first presentation of the vignette was paired with the first set of questions.

Key dependent measures. We began by measuring our key dependent measures: ratings of moral character (morality and trustworthiness) as well as two nonmoral traits (intelligence and athleticism).

Moral character and nonmoral traits. On the first evaluation page, subjects evaluated the target character, Sarah, on four traits in random order. Subjects rated Sarah's morality ("How moral of a person is Sarah?"), trustworthiness ("How trustworthy of a person is Sarah?"), intelligence ("How intelligent of a person is Sarah?"), and athleticism ("How athletic of a person is Sarah?").

Secondary dependent measures. Next, we collected our secondary dependent measures: (i) sympathy towards the target and (ii) exploitability of the target. Specifically, across two pages, we collected these two measures; the order of these pages was randomized betweensubjects.

Sympathy. The set of sympathy question asked subjects in random order: "How sympathetic do you feel towards Sarah?", "How bad do you feel for Sarah?", and "How sorry for Sarah are you?".

Exploitability. The set of exploitability question asked subjects in random order: "How trusting do you think Sarah is of others?", "How easy do you think that it would be to exploit Sarah for one's personal gain?", "How naïve of a person do you think Sarah is?", and "How likely do you think that people are to try to harm Sarah in the future?".

\section{Post-experimental survey}

Finally, subjects completed a post-experimental survey in which they (i) answered a simple analogy question and wrote three sentences about their activities and plans for their day (questions that were designed to test English comprehension), and then (ii) answered a set of demographic and survey questions. In particular, subjects reported their age, gender, level of education, income, and country of residence.

\subsection{Experiment 6}

\section{Design overview}

Experiment 6 employed a two-by-two, between-subject design. As our first factor, we manipulated whether subjects were assigned to the neutral condition (in which the target was a neutral character) or the standard victim condition (in which the target behaved identically, but was victimized by a perpetrator). As our second factor, we manipulated whether subjects were 
assigned to the first-person condition (in which the vignette was presented in first-person) or the third-person condition (in which the vignette was presented in third-person). Subjects were randomly assigned to one of the four possible conditions that resulted from crossing these manipulations. We also randomized between-subjects whether the target character (and all other characters in the vignette) was male or female. Experiment 6 used our idea theft vignette, in which the relevant transgression is the theft of an idea by a co-worker.

\section{Vignette text}

In all conditions, the vignette began with some third-person background information, as follows: Sarah is a 26-year-old woman who works at an advertising agency. Her job involves working with co-workers to come up with clever advertising slogans. While she and her coworkers often brainstorm in teams, they get individual credit for their ideas and are promoted or fired based on the quality of their individual work. Last week, Sarah was brainstorming slogans for a product with her manager, Gabrielle. Previous advertisements for this product had not been very effective, so it was important to come up with something substantially better. During their brainstorming session, Sarah came up with an idea that she was very excited about, and shared it with Gabrielle, who agreed that it was very promising.

In both of the third-person conditions, the vignette continued: The day after Sarah came up with her idea, Gabrielle and Sarah both met with the director of their advertising agency, who asked if they had come up with anything. Sarah was about to describe her idea when another co-worker came in to the room to return Sarah's iPhone charger to her. This was the entire vignette in the neutral, third-person condition.

In the standard victim, third-person condition, the vignette additionally continued: When Sarah briefly stood up to grab the charger, Gabrielle jumped in to tell the director that she had come up with an idea she was really proud of, and then presented Sarah's idea as her own. Sarah was very upset.

In both of the first-person conditions, the vignette continued: Recently, Sarah told the following story to a friend: "The day after I came up with my idea, Gabrielle and I both met with the director of our advertising agency, who asked if we had come up with anything. I was about to describe my idea when another co-worker came in to the room to return my iPhone charger to me." This was the entire vignette in the neutral, first-person condition.

In the standard victim, first-person condition, the vignette additionally continued: "When I briefly stood up to grab the charger, Gabrielle jumped in to tell the director that she had come up with an idea she was really proud of, and then presented my idea as her own. I was very upset."

In the male version of the vignette, the names "Sarah" and "Gabrielle" were replaced with "Sam" and "Gordon" (and male pronouns were used).

\section{Measures}

Subjects then answered a series of questions about characters in the vignette, spread out across several pages. All questions were answered on 1-9 Likert scales (Anchors: 1 - Not at all, 2, 3-A little bit, 4, 5- Moderately, 6, 7 - Quite a lot, 8, 9 - Extremely). On all pages, the (identical) vignette was presented before the questions. The first presentation of the vignette was paired with the first set of questions. 
Key dependent measures. We began by measuring our key dependent measures: ratings of moral character (morality and trustworthiness) as well as two nonmoral traits (intelligence and athleticism).

Moral character and nonmoral traits. On the first evaluation page, subjects evaluated the target character, Sarah, on four traits in random order. Subjects rated Sarah's morality ("How moral of a person is Sarah?"), trustworthiness ("How trustworthy of a person is Sarah?"), intelligence ("How intelligent of a person is Sarah?"), and athleticism ("How athletic of a person is Sarah?").

Secondary dependent measures. Next, we collected our secondary dependent measures: (i) sympathy towards the target, (ii) exploitability of the target, (iii) evaluation of target as angry, unforgiving, negative, and entitled, and (iv) subjects' self-reported belief that events described in vignette were true. Specifically, across four pages, we collected these four measures. On the first two pages, we collected measures (i) and (ii) in a random order, and then on the last two pages we collected measures (iii) and (iv) in a random order.

Sympathy. The set of sympathy questions asked subjects in random order: "How sympathetic do you feel towards Sarah?", "How bad do you feel for Sarah?", and "How sorry for Sarah are you?".

Exploitability. The set of exploitability questions asked subjects in random order: "How trusting do you think Sarah is of others?", "How easy do you think that it would be to exploit Sarah for one's personal gain?", "How naïve of a person do you think Sarah is?", and "How likely do you think that people are to try to harm Sarah in the future?".

Evaluation of target as angry, unforgiving, negative, and entitled. This set of questions asked subjects in random order: "How angry of a person do you think that Sarah is?", "To what extent do you think Sarah is a negative person who likes to complain?", "To what extent do you think Sarah tends to feel entitled to a lot from others?", "How unforgiving of a person do you think Sarah is?".

Belief. We asked subjects one question about their belief that the events described in the vignette were true: "When you read the story about Sarah's meeting with the director, how much did you believe that the events described were true?"

\section{Post-experimental survey}

Finally, subjects completed a post-experimental survey in which they (i) answered a simple analogy question and wrote three sentences about their activities and plans for their day (questions that were designed to test English comprehension), and then (ii) answered a set of demographic and survey questions. In particular, subjects reported their age, gender, level of education, income, and country of residence.

\subsection{Experiment 7}

\section{Design overview}

Experiment 7 employed a two-condition, between-subject design in which subjects were assigned one of the following conditions: neutral (in which the target was a neutral character) and standard victim (in which the target behaved identically, but was victimized by a perpetrator). We also randomized between-subjects whether the target character (and all other characters in the vignette) was male or female. Experiment 7 used our corrupt doctor vignette, in 
which (i) the relevant transgression is a doctor harming a patient through corruption, and (ii) the vignette provides morally relevant background information about the target character.

\section{Vignette text}

In all conditions, the vignette began as follows: Sarah is a 34-year-old who works for United Airlines and lives in the Chicago area. She has been married to her husband, Chris, for a few years, and the two of them are thinking about having their first child soon. Sarah is politically moderate and somewhat religious. In her free time, Sarah likes to run, watch movies, drink wine, and attend social events in her church community. She also enjoys traveling, especially because she gets great flight benefits through United.

Sarah is described her friends as generally being fun to be around, and having a good sense of humor. On the other hand, they think that she can be a bit self-focused when having a conversation, and can get defensive when criticized, but they do say that she usually comes through when you need her to do a favor.

Sarah was recently diagnosed with Crohn's disease. Last week, she went to the doctor to discuss treatment strategies with Dr. Wilson, who has been her doctor for about three years. She and Dr. Wilson discussed a few potential drug options, and the likelihood of each of the working and causing different side effects, given Sarah's medical history and risk profile. This was the entire vignette in the neutral condition.

In the standard victim condition, the vignette continued: One of these drugs is called Prednisone, and Dr. Wilson has a longstanding relationship with the drug company that sells it. Given her medical history, Dr. Wilson suspected that Prednisone would be unlikely to work for Sarah, and also likely to cause her some substantial side effects (such as nausea, vomiting, increased sweating or acne, or trouble sleeping).

However, because of his history with the drug company, Dr. Wilson lied to Sarah and said that he thought Prednisone would be the best treatment option. Sarah decided to take Prednisone as a result, and ended up finding that the drug did not work, and caused considerable side effects. These side effects were very distressing to Sarah.

In the male version of the vignette, the names "Sarah" and "Chris" were replaced with "Sam" and "Christina" respectively.

\section{Measures}

Subjects then answered a series of questions about characters in the vignette, spread out across several pages. All questions were answered on 1-9 Likert scales (Anchors: 1 - Not at all, 2,3-A little bit, 4, 5-Moderately, 6, 7 - Quite a lot, 8, 9-Extremely). On all pages, the (identical) vignette was presented before the questions. The first presentation of the vignette was paired with the first set of questions.

Key dependent measures. We began by measuring our key dependent measures: (i) ratings of moral character (morality and trustworthiness) as well as two nonmoral traits (intelligence and athleticism), and (ii) a set of behavior predictions (for four moral and four immoral behaviors).

Moral character and nonmoral traits. On the first evaluation page, subjects evaluated the target character, Sarah, on four traits in random order. Subjects rated Sarah's morality ("How moral of a person is Sarah?"), trustworthiness ("How trustworthy of a person is Sarah?"), intelligence ("How intelligent of a person is Sarah?"), and athleticism ("How athletic of a person is Sarah?"). 
Behavior predictions. On the next evaluation page, subjects made a set of eight predictions about the target's behavior: four predictions about moral behavior and four predictions about immoral behavior; the order of these predictions was randomized betweensubjects.

The questions about moral behavior asked subjects: "How likely do you think Sarah is to donate to charity at her church?", "How likely do you think Sarah is to volunteer to help a new coworker out at United?", "How likely do you think Sarah is to put a lot of effort into planning a birthday surprise for her husband?", and "How likely do you think Sarah is to pay for dinner when a friend from out of town comes to visit her?".

The questions about immoral behavior asked subjects: "How likely do you think Sarah is to flirt with other men at the gym, despite being married?", "How likely do you think Sarah is to intentionally 'forget' to pay a friend back?", "How likely do you think Sarah is to harshly scold her United coworkers when they make honest mistakes?", and "How likely do you think Sarah is to spread mean gossip about members of her church community?".

Secondary dependent measures. Next, we collected our secondary dependent measures: (i) sympathy towards the target and (ii) exploitability of the target. The order of these two pages was randomized between-subjects.

Sympathy. The set of sympathy question asked subjects in random order: "How sympathetic do you feel towards Sarah?", "How bad do you feel for Sarah?", and "How sorry for Sarah are you?".

Exploitability. The set of exploitability question asked subjects in random order: "How trusting do you think Sarah is of others?", "How easy do you think that it would be to exploit Sarah for one's personal gain?", "How naïve of a person do you think Sarah is?", and "How likely do you think that people are to try to harm Sarah in the future?".

\section{Post-experimental survey}

Finally, subjects completed a post-experimental survey in which they (i) answered a simple analogy question and wrote three sentences about their activities and plans for their day (questions that were designed to test English comprehension), and then (ii) answered a set of demographic and survey questions. In particular, subjects reported their age, gender, level of education, income, and country of residence.

\subsection{Experiment 8}

\section{Design overview}

Experiment 8 employed a two-condition, between-subject design in which subjects were assigned one of the following conditions: neutral (in which the target was a neutral character) and standard victim (in which the target behaved identically, but was victimized by a perpetrator). Experiment 8 used our rape vignette, in which the relevant transgression is a sexual assault. The victim condition of this vignette was sourced from Niemi \& Young, 2016, and we adapted the vignette to create a neutral condition.

\section{Vignette text}

In all conditions, the vignette began as follows: Kelly was walking home from the grocery store one night when she ran into her cousin's friend from college, Dave, who was home for the summer and lived in the neighborhood. Kelly was carrying many grocery bags and was right 
outside her apartment. Although they didn't know each other well, Dave recognized Kelly and since she was struggling to carry her many grocery bags, he offered to help her carry them up to the apartment. One of the bags was about to tear, and she gladly allowed him to help.

In standard victim condition, the vignette continued: Once in the apartment, however, Dave closed and locked the door behind him and pushed Kelly against a wall forcefully. She tried pushing him off her but wasn't strong enough. When she tried to scream Dave covered her mouth and threatened her, and shortly after he forced sexual intercourse with her.

\section{Measures}

On the same page as the vignette was presented, subjects rated the moral character of the target character, Kelly, across two questions. First, they rated Kelly's morality ("How moral of a person is Kelly?") and second, they rated Kelly's trustworthiness ("How trustworthy of a person is Kelly?"). Both questions were answered on 1-9 Likert scales (Anchors: 1 - Not at all, 2, 3 - A little bit, 4, 5- Moderately, 6, 7 - Quite a lot, 8, 9- Extremely).

\section{Attention checks}

After completing these measures and advancing the page, subjects completed two short attention checks. In the first, subjects read a short vignette about a grocery store employee (Olivia works at a local grocery store. At the store, Olivia's job is to serve as the cashier. Normally, Olivia works Monday-Friday but does not work weekends. However, last week Olivia's coworker Ben asked her to cover his Saturday shift. So this Saturday, Olivia has to work a 7-hour shift.). Then, on the next page, we asked subjects to identify, via a multiple-choice question, the employee's job at the grocery store (answer choices: manager, cashier, stocker, customer service, it was not specified in the story; correct answer: cashier).

In the second attention check, subjects were shown a photograph of a meal. Then, on the same page, we asked subjects to identify, via a multiple-choice question, a food item that is probably not included in the meal (answer choices: olives, onion, mustard, relish, ketchup, bread, hotdog; correct answer: olives).

Finally, subjects completed a third attention check at the end of the post-experimental survey described below. This attention check involved completing a simple analogy question (Kitten is to cat as puppy is to ___ ; correct answer: dog). We note that while Experiments 8 and 9 were the only experiments to include these first two attention checks, many other experiments employed a similar analogy question. However, only in Experiments 8 and 9 did our pre-registered plans for our primary analyses involve excluding subjects who answered this question incorrectly.

\section{Post-experimental survey}

After completing the attention checks, subjects completed a brief post-experimental survey, in which they (i) reported their age, gender, race, level of education, income, political party affiliation, and social and fiscal conservativism, and then (ii) answered the aforementioned simple analogy question. 


\subsection{Experiment 9}

\section{Design overview}

Experiment 9 employed a two-by-two-by-two, between-subject design. As our first factor, we manipulated whether subjects were assigned to the neutral condition (in which the target was a neutral character) or the standard victim condition (in which the target behaved identically, but was victimized by a perpetrator). To this end, we used a lightly modified version our iPad theft vignette, in which the relevant transgression is the theft of an iPad.

As our second and third factors, we manipulated the target's race (White vs. Black) and gender (female vs. male) via a photograph of the target's face that we paired with the vignette in all conditions. More specifically, each subject was assigned to one race/gender condition (i.e., White male, White female, Black male, or Black female) and then was randomly presented with one of three potential target photographs corresponding to their condition. The photograph was presented at the top of the screen, with the vignette underneath.

All photographs were selected from the Chicago Face Database (Ma et al., 2015). We selected photographs depicting a closed mouth smile, and of models who were roughly collegeaged (given that the iPad theft vignette is about college students). We also selected photographs that were reasonably well-matched across race/gender conditions on perceived age, attractiveness, and trustworthiness (using norming data from the Chicago Face Database); see Fig. S2 and Table S4 for the photographs and corresponding norming data.

As noted above, we lightly modified our iPad theft vignette for use in Experiment 9. In particular, we attempted to select names for the vignette characters that would sound racially neutral (both in the male and female versions of the vignette). Additionally, because Experiment 9 was conducted during the COVID-19 pandemic, we modified the scenario to avoid any reference to indoor gathering.

We also note also that Experiment 9 included three attention checks and, per our preregistration, our primary analyses restrict to subjects who passed all three checks.

\section{Vignette text}

In all conditions, the vignette began as follows: Maya is a politically moderate college student, and her photo is shown above. Last Wednesday, Maya and a few of her classmates met up outside to study for a big upcoming exam. At one point, one of Maya's classmates, Jackie, asked to use Maya's iPad to look something up. Later that day, Maya relaxed by watching a TV show on her iPad, and then went out for the evening. This was the entire vignette in the neutral condition.

In standard victim condition, the vignette continued: That evening, while Maya was out, Jackie figured out how to enter her dorm suite. After entering, Jackie stole Maya's iPad from her room. When Maya noticed that it was missing, she was very upset.

In the male version of the vignette, the names "Maya" and "Jackie" were replaced with "Kevin" and "Michael" (and male pronouns were used).

\section{Measures}

On the same page as the vignette was presented, subjects rated the moral character of the target character, Maya, across two questions. First, they rated Maya's morality ("How moral of a person is Maya?") and second, they rated Maya's trustworthiness ("How trustworthy of a person 
is Maya?"). Both questions were answered on 1-9 Likert scales (Anchors: 1 - Not at all, 2, 3 - A little bit, 4, 5- Moderately, 6, 7 - Quite a lot, 8, 9 - Extremely).

\section{Attention checks}

After completing these measures and advancing the page, subjects completed two short attention checks. In the first, subjects read a short vignette about a grocery store employee (Olivia works at a local grocery store. At the store, Olivia's job is to serve as the cashier. Normally, Olivia works Monday-Friday but does not work weekends. However, last week Olivia's coworker Ben asked her to cover his Saturday shift. So this Saturday, Olivia has to work a 7-hour shift.). Then, on the next page, we asked subjects to identify, via a multiple-choice question, the employee's job at the grocery store (answer choices: manager, cashier, stocker, customer service, it was not specified in the story; correct answer: cashier).

In the second attention check, subjects were shown a photograph of a meal. Then, on the same page, we asked subjects to identify, via a multiple-choice question, a food item that is probably not included in the meal (answer choices: olives, onion, mustard, relish, ketchup, bread, hotdog; correct answer: olives).

Finally, subjects completed a third attention check at the end of the post-experimental survey described below. This attention check involved completing a simple analogy question (Kitten is to cat as puppy is to ; correct answer: dog). We note that while Experiments 8 and 9 were the only experiments to include these first two attention checks, many other experiments employed a similar analogy question; however, only in Experiments 8 and 9 did our pre-registered plans for our primary analyses involve excluding subjects who answered this question incorrectly.

\section{Post-experimental survey}

After completing the attention checks, subjects completed a brief post-experimental survey, in which they (i) reported their age, gender, race, level of education, income, political party affiliation, and social and fiscal conservativism, and then (ii) answered the aforementioned simple analogy question.

\subsection{Experiment 10}

\section{Design overview}

Experiment 10 employed a three-condition, between-subjects design in which subjects were assigned to one of the following conditions: Control (in which the target was described as relatively less moral and relatively less competent), moral (in which the target was described as relatively more moral and relatively less competent), and competent (in which the target was described as relatively less moral and relatively more competent). After subjects read about the target's morality and competence, they were always assigned to the victim condition of our idea theft vignette, in which the relevant transgression is the theft of an idea.

\section{Vignette text}

In all conditions, the vignette began by describing the target as follows: Sarah is a 26year-old woman who works at an advertising agency.

In the control and competent conditions (in which the target is described as relatively less moral), the vignette continued: Sarah is a fun-loving person who enjoys spending time with 
friends and family, although people around her sometimes find her to be self-centered and arrogant. For example, Sarah pretty much never volunteers her time or donates any money to charity, and she tends to talk about herself more than she listens to others. Recently, when Sarah's friend was laid off, Sarah offered to help him with his job search, bragging about her relevant expertise. But when he followed up with a few specific requests, Sarah decided not to respond, reasoning that helping would take up time that she'd rather spend doing something more fun. That said, Sarah's friends and family do still often enjoy her company.

In the moral condition (in which the target is described as relatively more moral), the second paragraph of the vignette instead read: Sarah is a good listener, frequently volunteers to help others out, and often plans thoughtful surprises for friends and family. Recently, when Sarah's friend was laid off, Sarah offered to help him with his job search and spent hours providing him with emotional support. She also surprised him by taking him out to an outdoor dinner at his favorite restaurant and paying for appetizers, dinner, drinks, and dessert. Sarah also regularly donates money to several different charitable organizations and finds way to volunteer her time. For example, she has recently been quite involved in her church group's efforts to fundraise for people in her community who have been negatively affected by coronavirus.

In the control and moral conditions (in which the target is described as relatively less competent), the third paragraph of the vignette read: In her free time, two of Sarah's hobbies are cooking and running, although she is not great at either activity. Even after several attempts making the same dish, the dishes that Sarah cooks often wind up bland or over-cooked. Additionally, Sarah runs fairly slowly and is unable to complete long distance runs.

In the competent condition (in which the target is described as relatively more competent), the third paragraph of the vignette instead read: In her free time, two of Sarah's hobbies are cooking and running. Sarah is exceptionally skilled at both of these activities. Sarah frequently cooks very complex dishes and pretty much everything that she makes turns out delicious. Despite the fact that Sarah has zero professional training, many of her dishes are easily restaurant-quality. Additionally, Sarah is a very fast runner who regularly runs in halfmarathons, and has actually placed in some major races in the past.

After reading this description of the target, subjects advanced to a new page. Then, all subjects read the victim version of our idea theft vignette, spread across two pages.

On the first page, subjects read: At work, Sarah's job involves working with co-workers to come up with clever advertising slogans. While she and her co-workers often brainstorm in teams, they get individual credit for their ideas and are promoted or fired based on the quality of their individual work. Last week, Sarah was brainstorming slogans for a product with her manager, Gabrielle. Previous advertisements for this product had not been very effective, so it was important to come up with something substantially better. During their brainstorming session, Sarah came up with an idea that she was very excited about, and shared it with Gabrielle, who agreed that it was very promising.

On the second page, subjects read: The day after Sarah came up with her idea, Gabrielle and Sarah both met with the director of their advertising agency, who asked if they had come up with anything. Sarah was about to describe her idea when another co-worker came in to the room to return Sarah's iPhone charger to her. When Sarah briefly stood up to grab the charger, Gabrielle jumped in to tell the director that she had come up with an idea she was really proud of, and then presented Sarah's idea as her own. Sarah was very upset. 


\section{Measures}

Next, subjects again advanced to a new page and began answering a series of questions about the vignette, spread out across several pages. All questions were answered on 1-9 Likert scales (Anchors: 1 - Not at all, 2, 3 - A little bit, 4, 5- Moderately, 6, 7 - Quite a lot, 8, 9Extremely). On all pages, the full (identical) vignette was presented before the questions (including the background information about the target's morality and competence).

Morality and competence. On the first evaluation page, subjects evaluated the victim character, Sarah, on two traits in random order; these measures served as manipulation checks. Subjects rated Sarah's morality ("How moral of a person is Sarah?") and Sarah's competence ("How competent of a person is Sarah?").

Willingness to punish. On the second evaluation page, we measured our first key dependent variable: willingness to punish. Subjects were presented with the following question: "Imagine that you work at the advertising agency with Sarah and Gabrielle. How inclined would you be to "punish" Gabrielle (e.g., by expressing your disapproval of Gabrielle's behavior to others, giving Gabrielle the cold shoulder at work, reporting Gabrielle's behavior formally, or taking some other similar action)?"

Willingness to help. On the third evaluation page, we measured our second key dependent variable: willingness to help. Subjects were presented with the following question: "Imagine that you work at the advertising agency with Sarah and Gabrielle. How willing would you be to help Sarah (e.g., by helping Sarah to brainstorm new ideas, being especially warm and friendly towards Sarah at work, making sure to praise Sarah to others for her work, or taking other similar action)?"

\section{Post-experimental survey}

Finally, subjects completed a post-experimental survey in which they (i) answered a simple analogy question (that was designed to test English comprehension), and then (ii) answered a set of demographic and survey questions (in which they reported their age, gender, level of education, income, and political party affiliation).

\subsection{Experiment 11a}

\section{Design overview}

Experiment 11a employed a two-by-two, between-subject design. As our first factor, we manipulated whether subjects were assigned to the neutral condition (in which the target was a neutral character) or the standard victim condition (in which the target behaved identically, but was victimized by a perpetrator). Experiment 11 a used our idea theft vignette, in which the relevant transgression is the theft of an idea by a co-worker.

As our second factor, we manipulated whether subjects were assigned to the incentives condition (in which, before reading the vignette, subjects were asked to imagine being in a situation that created incentives for justice-restorative action) or the disincentives condition (in which subjects were asked to imagine being in a situation that created disincentives for justicerestorative action). Subjects were randomly assigned to one of the four possible conditions that resulted from crossing these manipulations. 


\section{Imagination exercise}

We began the experiment by asking subjects to engage in an imagination exercise, which we used to manipulate the presence of incentives versus disincentives for justice-restorative action.

In all conditions, subjects were given the following instructions: Imagine that you work at an advertising agency. At the agency, you and your co-workers work to come up with clever advertising slogans. While you and your co-workers often brainstorm in teams, everyone gets individual credit for their ideas and are promoted or fired based on the quality of their individual work.

In the incentives conditions, the instructions continued: In your experience, one problem with this system is that it creates the potential for people to steal each other's ideas. When this happens, the wrong person gets credit for an idea, which you think is really unfair and wrong. While some people at work agree with you that this is a major issue, other colleagues of yours tend to dismiss it as not being a big concern. They acknowledge that people do sometimes steal ideas, leading to an unjust outcome. However, they argue that idea stealing is extremely rare. They also argue that the rest of the time, the system works really well for creating productive brainstorming sessions and generating excellent ideas. You, however, strongly disagree. You think that ideas are frequently stolen, and that the system needs major reform. At work, you've been very vocal about your views on this issue, and have publicly argued for your position to colleagues on several occasions.

In the disincentives conditions, the instructions continued: One problem that some people at work have with this system is that it creates the potential for people to steal each other's ideas. When this happens, the wrong person gets credit for an idea, which they think is really unfair and wrong. While some people at work think this is a major issue, you (and some other colleagues of yours) strongly disagree. You acknowledge that people do sometimes steal ideas, leading to an unjust outcome. However, in your experience, idea stealing is extremely rare. And the rest of the time, the system works really well for creating productive brainstorming sessions and generating excellent ideas. Since you don't think that ideas are frequently stolen, you don't think that the system needs reform. At work, you've been very vocal about your views on this issue, and have publicly argued for your position to colleagues on several occasions.

Next, subjects in both conditions were presented with the following prompt: Imagine that a co-worker asked you whether you think that idea stealing is a big concern with the current system at work. In your own words, what would you tell him or her? Subjects were asked to write two sentences explaining their position, and were provided with a free text box to do so.

\section{Vignette text}

After subjects completed this writing exercise, they advanced to a new page. On this page, we presented subjects with the vignette.

In all conditions, the vignette began as follows: One of your co-workers is a 26-year-old woman named Sarah. Last week, Sarah was brainstorming slogans for a product with her manager, Gabrielle. Previous advertisements for this product had not been very effective, so it was important to come up with something substantially better. During their brainstorming session, Sarah came up with an idea that she was very excited about, and shared it with Gabrielle, who agreed that it was very promising. 
In the neutral conditions, the vignette continued: Right after Sarah came up with her idea, Sarah ran into the director of the advertising agency, who asked if she and Gabrielle had come up with anything. Sarah told her director about her idea.

In the standard victim conditions, the vignette continued: Right after Sarah came up with her idea, Gabrielle and Sarah both ran into the director of the advertising agency, who asked if they had come up with anything. Before Sarah could say anything, Gabrielle jumped in to tell the director that she had come up with an idea she was really proud of, and then presented Sarah's idea as her own. Sarah was very upset.

\section{Measures}

Next, subjects again advanced to a new page and began answering a series of questions about characters in the vignette, spread out across several pages. With one exception (noted below), all questions were answered on 1-9 Likert scales (Anchors: 1 - Not at all, 2, 3 - A little bit, 4, 5-Moderately, 6, 7 - Quite a lot, 8, 9-Extremely). On all pages, the (identical) vignette was presented before the questions (not including the imagination exercise).

Initial secondary dependent measure. We began by measuring one of our secondary dependent measures: ratings of moral character (morality and trustworthiness) of the "other person", Gabrielle (who was a neutral other character in the neutral condition, and the perpetrator in the standard victim condition).

“Other person" moral character. On the first evaluation page, subjects rated Gabrielle's character across two questions in random order. They rated Gabrielle's morality ("How moral of a person is Gabrielle?") and trustworthiness ("How trustworthy of a person is Gabrielle?").

Key dependent measures. Next, we measured measuring our key dependent measures: ratings of moral character (morality and trustworthiness) of the target, Sarah.

Target moral character. On the second evaluation page, subjects rated Sarah's character across two questions in random order. They rated Sarah's morality ("How moral of a person is Sarah?") and trustworthiness ("How trustworthy of a person is Sarah?").

Other secondary dependent measures. Next, we collected the rest of our secondary dependent measures, which involved questions concerning: (i) sympathy towards the target, (ii) helping the target, (iii) punishing the other person, (iv) blame of the other person, and (v) anger towards the other person. Each measure was assessed on a separate page. We first presented measures (i), (ii), and (iii) in a random order to all subjects. Then, we presented measures (iv) and (v) in a random order to subjects in the standard victim conditions only.

Sympathy. The set of sympathy questions asked subjects in random order: "How sympathetic do you feel towards Sarah?", "How bad do you feel for Sarah?", and "How sorry for Sarah are you?".

Helping the target. The set of "helping the target" questions asked subjects in random order: "If Sarah needed help at work, how willing would you be to help her out?" and "If you helped Sarah out, how positively would this be seen by your co-workers?".

Punishing the other person. The set of "punishing the other person" questions asked subjects in random order: "How inclined would you be to give Gabrielle the cold shoulder?" and "If you gave Gabrielle the cold shoulder, how would this influence your reputation in the eyes of your co-workers?". For this second question, the anchors on the 1-9 Likert scale differed from the anchors for all other questions. Specifically, they read: 1 - It would HURT your reputation a lot, 2, 3-It would HURT your reputation a little, 4, 5 - It would have no effect on your 
reputation, 6, 7 - It would HELP your reputation a little, 8, 9- It would HELP your reputation a lot.

Blame of the other person. The set of "blame of the other person" questions asked subjects in random order: "How bad of a person is Gabrielle for her behavior towards Sarah?", "How bad was Gabrielle's behavior towards Sarah?", and "How blameworthy is Gabrielle for her behavior towards Sarah?".

Anger towards the other person. The set of "anger towards the other person" questions asked subjects in random order: "How angry do you feel towards Gabrielle for her behavior towards Sarah?", "How much of an outrage is Gabrielle's behavior?", and "How upset are you with Gabrielle?".

\section{Post-experimental survey}

Finally, subjects completed a post-experimental survey in which they (i) answered a set of demographic and survey questions (in which they reported their age, gender, level of education, income, political party affiliation, and social and fiscal conservativism), and then (ii) answered a simple analogy question (that was designed to test English comprehension).

\subsection{Experiment 11b}

\section{Design overview}

Experiment $11 \mathrm{~b}$ employed a two-condition, between-subject design in which subjects were assigned to one of the following conditions: incentives (in which subjects read about the situation described in the "incentives" condition of Experiment 11a) and disincentives (in which subjects read about the situation described in the "disincentives" condition of Experiment 11a). After subjects read about the relevant scenario, they were always assigned to the victim condition of our idea theft vignette, in which the relevant transgression is the theft of an idea.

\section{Imagination exercise}

Like in Experiment 11a, we began by asking subjects to engage in an imagination exercise. However, in contrast to Experiment 11a, the focal actor in the imagined situation was not the subject, but rather a person named James.

In all conditions, subjects were given the following instructions: Imagine that a man named James works at an advertising agency. At the agency, James and his co-workers work to come up with clever advertising slogans. While James and his co-workers often brainstorm in teams, everyone gets individual credit for their ideas and are promoted or fired based on the quality of their individual work.

In the incentives condition, the instructions continued: In James's experience, one problem with this system is that it creates the potential for people to steal each other's ideas. When this happens, the wrong person gets credit for an idea, which James thinks is really unfair and wrong. While some people at work agree with James that this is a major issue, other colleagues of his tend to dismiss it as not being a big concern. They acknowledge that people do sometimes steal ideas, leading to an unjust outcome. However, they argue that idea stealing is extremely rare. They also argue that the rest of the time, the system works really well for creating productive brainstorming sessions and generating excellent ideas. James, however, strongly disagrees. He thinks that ideas are frequently stolen, and that the system needs major 
reform. At work, James has been very vocal about his views on this issue, and has publicly argued for his position to colleagues on several occasions.

In the disincentives condition, the instructions continued: One problem that some people at work have with this system is that it creates the potential for people to steal each other's ideas. When this happens, the wrong person gets credit for an idea, which they think is really unfair and wrong. While some people at work think this is a major issue, James (and some other colleagues of his) strongly disagree. James acknowledges that people do sometimes steal ideas, leading to an unjust outcome. However, in his experience, idea stealing is extremely rare. And the rest of the time, the system works really well for creating productive brainstorming sessions and generating excellent ideas. Since James doesn't think that ideas are frequently stolen, he doesn't think that the system needs reform. At work, James has been very vocal about his views on this issue, and has publicly argued for his position to colleagues on several occasions.

Next, subjects in both conditions were presented with the following prompt: Imagine that a co-worker asks James whether he thinks that idea stealing is a big concern with the current system at work. What do you think James would you tell this co-worker? Subjects were asked to write two sentences explaining their position, and were provided with a free text box to do so.

\section{Vignette text}

After subjects completed this writing exercise, they advanced to a new page. On this page, we presented subjects with the victim version of the idea theft vignette.

The vignette read: One of James's co-workers is a 26-year-old woman named Sarah. Last week, Sarah was brainstorming slogans for a product with her manager, Gabrielle. Previous advertisements for this product had not been very effective, so it was important to come up with something substantially better. During their brainstorming session, Sarah came up with an idea that she was very excited about, and shared it with Gabrielle, who agreed that it was very promising. Right after Sarah came up with her idea, Gabrielle and Sarah both ran into the director of the advertising agency, who asked if they had come up with anything. Before Sarah could say anything, Gabrielle jumped in to tell the director that she had come up with an idea she was really proud of, and then presented Sarah's idea as her own. Sarah was very upset.

\section{Measures}

Next, subjects again advanced to a new page and began answering a series of questions about characters in the vignette. Across three different pages, we collected three key dependent variables: (i) incentives to punish, (i) incentives to help, and (iii) victim ratings. We both randomized (i) whether victim ratings were measured first or last, and (ii) whether incentives to punish were measured before or after incentives to help. On all pages, the full (identical) vignette was presented before the questions (including the imagination exercise). All questions were answered on 1-9 Likert scales.

Incentives to punish. To measure subjects' evaluations of James' incentives to punish the perpetrator, we presented subjects with the following preamble: "Now, imagine that James is considering "punishing" Gabrielle for presenting Sarah's idea as her own. For example, James is considering telling other people what Gabrielle did to Sarah and expressing his disapproval of Gabrielle's behavior, giving Gabrielle the cold shoulder when he sees her at work, reporting Gabrielle's behavior formally, or taking some other similar action. To what extent would punishing Gabrielle..." 
This preamble was followed by two questions, in the following fixed order: (i) “...help James to achieve his goals?" (1 - It would strongly hurt his goals, 2, 3, 4, 5 - It would be neutral, $6,7,8,9$ - It would strongly help his goals); (ii) “...be in James's self interest?” (1 - It would strongly be against his interests, 2, 3, 4, 5 - It would be neutral, 6, 7, 8, 9- It would strongly be in his interests).

Incentives to help. To measure subjects' evaluations of James' incentives to help the victim, we presented subjects with the following preamble: "Now, imagine that James is considering helping Sarah. For example, James is considering helping Sarah to brainstorm new ideas, being especially warm and friendly towards Sarah when he sees her at work, making sure to praise Sarah for her work in front of others, or taking other similar action. To what extent would helping Sarah..." This preamble was followed by the same two questions used to measure incentives to punish.

Victim rating. To measure the extent to which subjects, taking James' perspective, saw the target of idea theft as a victim, we presented subjects with the one question. In the incentives condition, it read: "Imagine that James is correct in his assessment that idea theft occurs frequently, such that the brainstorming system needs major reform. To what extent do you think Sarah is a victim of wrongdoing?" (1 - Sarah is not at all a victim, 2, 3, 4, 5 - Sarah is somewhat a victim, 6, 7, 8, 9 - Sarah is very much a victim).

In the disincentives condition, the question used identical anchors but instead read: "Imagine that James is correct in his assessment that idea theft is extremely rare, and the brainstorming system otherwise works really well. To what extent do you think Sarah is a victim of wrongdoing?"

\section{Post-experimental survey}

Finally, subjects completed a post-experimental survey in which they (i) answered a set of demographic and survey questions (in which they reported their age, gender, level of education, income, political party affiliation, and social and fiscal conservativism), and then (ii) answered a simple analogy question (that was designed to test English comprehension).

\subsection{Experiment 12}

\section{Design overview}

Experiment 12 employed a three-condition, between-subject design in which subjects were assigned one of the following conditions: neutral (in which the target was a neutral character), standard victim (in which the target behaved identically, but was victimized by a perpetrator), or other victim (in which the target behaved identically and was not victimized, but another character was victimized). Experiment 12 used our iPad vignette, in which the relevant transgression is the theft of an iPad.

Experiment 12 differed from all other experiments in that it took place in the context of a hypothetical economic "Trust Game". Specifically, we began the experiment by asking subjects to imagine participating in a Trust Game with another Mturk worker, in the role of the firstmover (who must decide how much money to entrust the second-mover with). We then presented our iPad vignette (in the relevant condition), and framed it as an opportunity for the subject to learn more about the Trust Game second-mover. Specifically, we told subjects that the target character from the vignette was the Trust Game second-mover. And then in addition to asking subjects to rate the moral character of (and answer other questions about) the target 
character (like in other experiments), in Experiment 12 we also asked subjects to decide how much to send the target, and to predict how much the target would return, in the Trust Game.

\section{Trust Game}

We began Experiment 12 by informing subjects that they would be playing a hypothetical interactive game with another Mturk worker. We asked subjects to imagine that the game was real and was being played for real money, and informed subjects that on subsequent screens we would describe the game as such (despite the game actually being hypothetical).

Next, we described an economic Trust Game to subjects. We told subjects that they would receive an endowment of money and decide how much (if anything) to send to another Mturk worker. Any money sent would be tripled before being delivered to this other Mturk worker, who would then decide how much (if anything) to return to the subject. Specifically, we provided the following instructions to subjects:

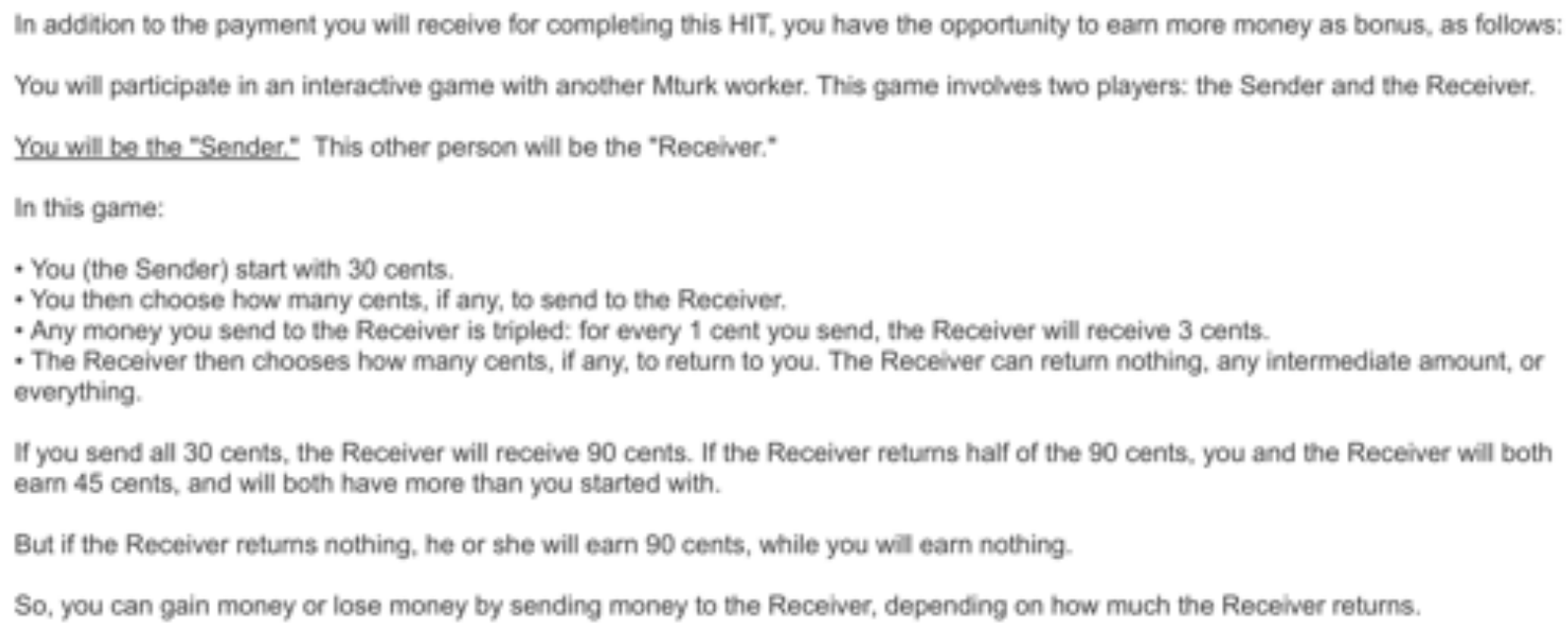

Next, we asked subjects to answer a set of comprehension questions about the payoff structure of the economic Trust Game: 


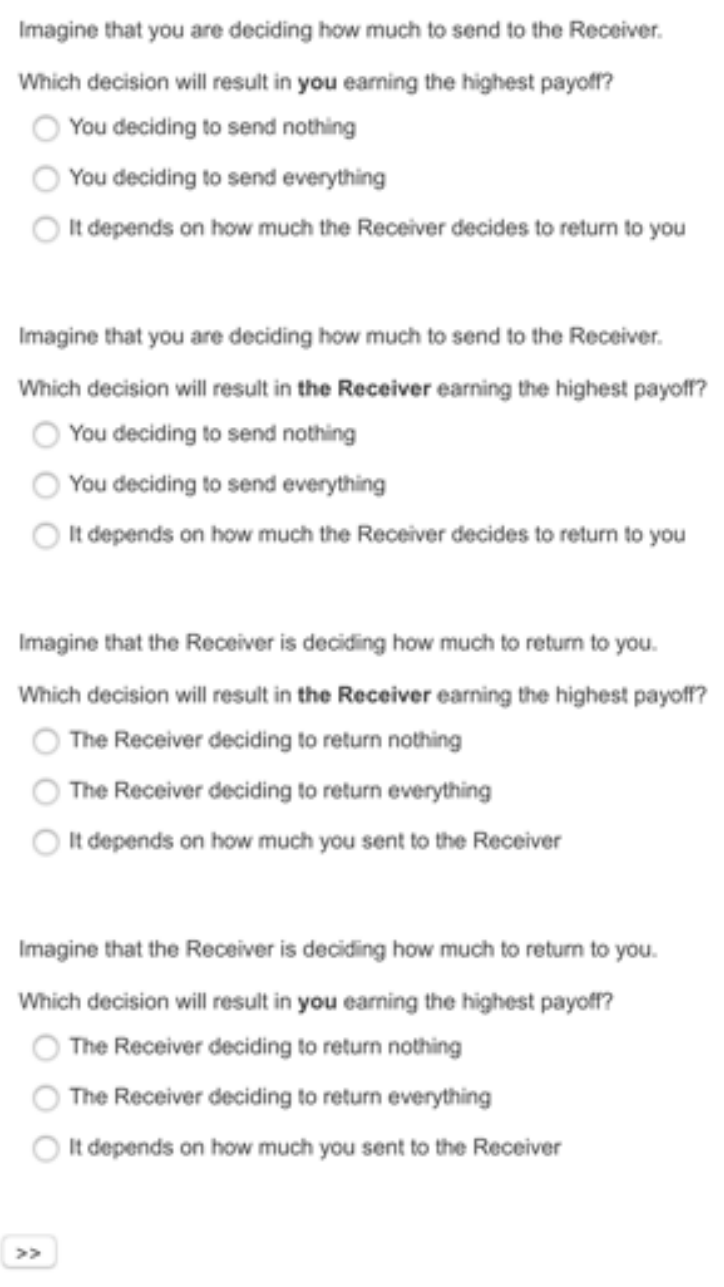

Correct answers: It depends on how much the Receiver decides to return to you; You deciding to send everything; The Receiver deciding to return nothing; The Receiver deciding to return everything.

\section{Vignette text}

Next, we informed subjects that before deciding how much money to send the Receiver in the Trust Game, they would have the opportunity to learn more about them. We informed subjects that Receiver is another Mturk worker named Sarah, and then presented our vignette.

In the neutral and standard victim conditions, the vignette began as follows: Sarah is a politically moderate college student. A few weeks ago, she and a few of her classmates were studying for a big upcoming exam in the common room of Sarah's dorm suite. Two of these classmates were named Rachel and Gabrielle.

In the neutral condition, the vignette continued: At one point, Gabrielle asked to use Sarah's iPad to look something up. Later that day, Sarah relaxed by watching a TV show on her iPad, and then went out for the evening.

In the standard victim condition, the vignette continued: At one point, Gabrielle asked to use Sarah's iPad to look something up. Later that day, Sarah relaxed by watching a TV show on her iPad, and then went out for the evening. That evening, while Sarah was out, Gabrielle 
figured out how to enter her suite. After entering, Gabrielle stole Sarah's iPad from her room. When Sarah noticed that it was missing, she was very upset.

In the other victim condition, the vignette continued: At one point, Gabrielle asked to look at Rachel's wristwatch to check the time. Later that day, Sarah relaxed by watching a TV show on her iPad, and then went out for the evening. That evening, Gabrielle figured out how to enter Rachel's suite. After entering, Gabrielle stole Rachel's jewelry box, filled with many expensive items, from her room. When Rachel noticed that it was missing, she was very upset.

\section{Measures}

Key dependent measures. We began by measuring our three key dependent measures, in the following order: (i) money sent to the target in the Trust Game, (ii) predicted money returned by the target in the Trust Game, and (iii) ratings of moral character (morality and trustworthiness). We collected these three measures across three pages. The (identical) vignette was presented on each page before the measure. The first presentation of the vignette was paired with the first measure.

Money sent to the target. First, we asked subjects to decide how much to send to Sarah in the Trust Game. We briefly reminded subjects of their game decision (reiterating that they had received 30 cents, and that for every 1 cent they sent, Sarah would receive 3 cents) and then asked subjects how many cents they would like to send. We provided subjects with choices ranging from 0 to 30 cents in 5 -cent increments.

Predicted money returned by the target. Second, we asked subjects to predict how much Sarah would return to them in the Trust Game. We informed subjects that we would ask Sarah to decide what percentage to return of whatever money she receives, and that we would require Sarah to decide on this percentage before learning how much she had been sent. We then asked subjects what percentage they expected Sarah to choose to return. We provided choices ranging from $0 \%$ to $100 \%$ in 10 -point increments.

Moral character. Third, we asked subjects to rate Sarah's moral character, across two questions. First, they rated Sarah's morality ("How moral of a person is Sarah?") and second, they rated Sarah's trustworthiness ("How trustworthy of a person is Sarah?"). These questions were answered on 1-9 Likert scales (Anchors: 1 - Not at all, 2, 3 - A little bit, 4, 5 - Moderately, 6, 7 - Quite a lot, 8, 9 - Extremely)

\section{Post-experimental survey}

Finally, subjects completed a post-experimental survey in which they (i) answered a simple analogy question and wrote three sentences about their activities and plans for their day (questions that were designed to test English comprehension), and then (ii) answered a set of demographic and survey questions. In particular, subjects reported their age, gender, level of education, income, and country of residence.

\subsection{Experiment 13}

\section{Design overview}

Experiment 13 employed a three-condition, between-subject design in which subjects were assigned one of the following conditions: neutral (in which the target was a neutral character), standard victim (in which the target behaved identically, but was victimized by a perpetrator), or accident victim: earthquake (in which the target behaved identically, but suffered 
accidental misfortune due to an earthquake). We also randomized between-subjects whether the target character (and all other characters in the vignette) was male or female. Experiment 13 used our iPad vignette, in which the relevant transgression is the theft of an iPad.

\section{Vignette text}

In all conditions, the vignette began as follows: Sarah is a politically moderate college student. Last Wednesday, she and a few of her classmates were studying for a big upcoming exam in the common room of Sarah's dorm suite. Two of these classmates were named Rachel and Gabrielle. At one point, Gabrielle asked to use Sarah's iPad to look something up. Later that day, Sarah relaxed by watching a TV show on her iPad, and then went out for the evening. This was the entire vignette in the neutral condition.

In the standard victim condition, the vignette continued: That evening, while Sarah was out, Gabrielle figured out how to enter her suite. After entering, Gabrielle stole Sarah's iPad from her room. When Sarah noticed that it was missing, she was very upset.

In the accident victim: earthquake condition, the vignette continued: That evening, while Sarah was out, there was a major and unexpected earthquake. The earthquake knocked Sarah's iPad off the shelf, damaging it irreparably. When Sarah noticed that it was broken, she was very upset.

In the male version of the vignette, the names "Sarah" and "Gabrielle" were replaced with "Sam" and "Gordon" (and male pronouns were used).

\section{Measures}

Subjects then answered a series of questions about characters in the vignette, spread out across several pages. All questions were answered on 1-9 Likert scales (Anchors: 1 - Not at all, 2, 3 - A little bit, 4, 5- Moderately, 6, 7 - Quite a lot, 8, 9 - Extremely). On all pages, the (identical) vignette was presented before the questions. The first presentation of the vignette was paired with the first set of questions.

Key dependent measures and first secondary dependent measure. We began by measuring our key dependent measures: (i) a set of questions about helping the target and (ii) ratings of target moral character (morality and trustworthiness). And while presenting our set of questions about helping the target, we also presented a set of questions about affiliating with the target. This set of questions constituted our first secondary dependent measure.

Helping and affiliation questions. On the first evaluation page, subjects answered a set of questions about helping and affiliating with the target. Specifically, we asked the following four questions in random order: "If Sarah needed help, how willing would you be to help her out?", "If you helped Sarah out, how positively would this be seen by others?", "How inclined would you be to hang out with Sarah?", and "How would hanging out with Sarah influence your reputation in the eyes of others?".

Moral character. On the next evaluation page, subjects rated the moral character of the target character, Sarah, across two questions in random order. They rated Sarah's morality ("How moral of a person is Sarah?") and Sarah's trustworthiness ("How trustworthy of a person is Sarah?").

Other secondary dependent measure. Next, we collected our other secondary dependent measure: sympathy towards the target. 
Sympathy. The set of sympathy question asked subjects in random order: "How sympathetic do you feel towards Sarah?", "How bad do you feel for Sarah?", and "How sorry for Sarah are you?".

\section{Post-experimental survey}

Finally, subjects completed a post-experimental survey in which they (i) answered a simple analogy question and wrote three sentences about their activities and plans for their day (questions that were designed to test English comprehension), and then (ii) answered a set of demographic and survey questions. In particular, subjects reported their age, gender, level of education, income, and country of residence.

\subsection{Experiment 14}

\section{Design overview}

Experiment 14 employed a two-condition, between-subject design in which subjects were assigned one of the following conditions: neutral (in which the target was a neutral character) and standard victim (in which the target behaved identically, but was victimized by a perpetrator). We also randomized between-subjects whether the target character (and all other characters in the vignette) was male or female. Experiment 14 used our iPad vignette, in which the relevant transgression is the theft of an iPad, but modified the "victim" condition of the vignette to avoid stating that the target was upset following their victimization.

\section{Vignette text}

In all conditions, the vignette began as follows: Sarah is a politically moderate college student. Last Wednesday, she and a few of her classmates were studying for a big upcoming exam in the common room of Sarah's dorm suite. At one point, one of Sarah's classmates, Gabrielle, asked to use Sarah's iPad to look something up. Later that day, Sarah relaxed by watching a TV show on her iPad, and then went out for the evening.

This was the entire vignette in the neutral condition. In the standard victim condition, the vignette continued: While Sarah was out, Gabrielle figured out how to enter her suite, and stole her iPad.

In the male version of the vignette, the names "Sarah" and "Gabrielle" were replaced with "Sam" and "Gordon" respectively.

\section{Measures}

Subjects then answered a series of questions about characters in the vignette, spread out across several pages. All questions were answered on 1-9 Likert scales (Anchors: 1 - Not at all, 2,3-A little bit, 4, 5- Moderately, 6, 7 - Quite a lot, 8, 9 - Extremely). On all pages, the (identical) vignette was presented before the questions. The first presentation of the vignette was paired with the first set of questions.

Key dependent measures. We began by measuring our key dependent measures: (i) a set of behavior predictions (for four moral and four immoral behaviors) and (ii) ratings of moral character (morality and trustworthiness) as well as two nonmoral traits (intelligence and athleticism).

Behavior predictions. Across the first two evaluation pages, subjects made a set of eight predictions about the target's moral behavior: four predictions about moral behavior (on one 
page) and four predictions about immoral behavior (on another page). The order of these pages was randomized between-subjects, as was the order of predictions within each page.

The questions about moral behavior asked subjects: "How likely do you think Sarah is to donate to charity?", "How likely do you think Sarah is to volunteer to tutor low-income middle school students for free?", "How likely do you think Sarah is to help a friend move to an offcampus apartment?", and "How likely do you think Sarah is to give leftover food to a homeless person?".

The questions about immoral behavior asked subjects: "How likely do you think Sarah is to flirt with others while in a committed relationship?", "How likely do you think Sarah is to intentionally 'forget' to pay a friend back?", "How likely do you think Sarah is to exclude or betray a friend in order to fit in with popular peers?", and "How likely do you think Sarah is to spread private or mean gossip about others?". The order of the questions was randomized between-subjects.

Moral character and nonmoral traits. On the next evaluation page, subjects evaluated the target character, Sarah, on four traits in random order. Subjects rated Sarah's morality ("How moral of a person is Sarah?"), trustworthiness ("How trustworthy of a person is Sarah?"), intelligence ("How intelligent of a person is Sarah?"), and athleticism ("How athletic of a person is Sarah?").

Secondary dependent measures. Next, we collected our secondary dependent measures: (i) sympathy towards the target and (ii) exploitability of the target. The order of these two pages was randomized between-subjects.

Sympathy. The set of sympathy question asked subjects in random order: "How sympathetic do you feel towards Sarah?", "How bad do you feel for Sarah?", and "How sorry for Sarah are you?".

Exploitability. The set of exploitability question asked subjects in random order: "How trusting do you think Sarah is of others?", "How easy do you think that it would be to exploit Sarah for one's personal gain?", "How naïve of a person do you think Sarah is?", and "How likely do you think that people are to try to harm Sarah in the future?".

\section{Post-experimental survey}

Finally, subjects completed a post-experimental survey in which they (i) answered a simple analogy question and wrote three sentences about their activities and plans for their day (questions that were designed to test English comprehension), and then (ii) answered a set of demographic and survey questions. In particular, subjects reported their age, gender, level of education, income, and country of residence.

\subsection{Experiment 15 Pre-test}

\section{Design overview}

Our Experiment 15 pre-test employed a two-by-two, between-subject design. As our first factor, we manipulated whether subjects were assigned to the immoral condition (in which the target was described as immoral) or the moral condition (in which the target was described as moral). As our second factor, we manipulated whether subjects were assigned to the not upset condition (in which no information was provided about whether the target was upset) or the upset condition (in which the target was described as being upset). We then randomly assigned subjects to one of the four possible conditions that resulted from crossing these manipulations, 
and asked subjects to rate the likelihood that the target would engage in a set of candidate behaviors. We also randomized between-subjects whether the target character was male or female. Our Experiment 15 pre-test did not employ one of our standard vignettes, and in no conditions involved any kind of transgression; instead, we created a very brief and novel vignette for our Experiment 15 pre-test, reported below.

\section{Vignette text}

In the moral, not upset condition, the vignette read as follows: Sarah is a politically moderate college student. In general, she is a pretty moral and trustworthy person.

In the moral, upset condition, the vignette read as follows: Sarah is a politically moderate college student. In general, she is a pretty moral and trustworthy person. Recently, something quite bad happened to her in her life that made her very upset.

In the immoral, not upset condition, the vignette read as follows: Sarah is a politically moderate college student. In general, she is not a very moral and trustworthy person.

In the immoral, upset condition, the vignette read as follows: Sarah is a politically moderate college student. In general, she is not a very moral and trustworthy person. Recently, something quite bad happened to her in her life that made her very upset.

In the male version of the vignette, the name "Sarah" was replaced with "Sam" (and male pronouns were used).

\section{Key dependent measures}

On the page presenting this vignette, subjects made a series of behavior predictions about Sarah. Specifically, we presented each subject with a random set of six behavioral prediction questions (in random order) from the complete set of twelve questions listed below. All questions were answered on 1-9 Likert scales (Anchors: 1 - Not at all, 2, 3-A little bit, 4, 5 Moderately, 6, 7 - Quite a lot, 8, 9-Extremely).

1. Sarah wants to buy a cup of coffee, and she could go to Starbucks. Alternatively, she could go to a local shop with similar prices and similar quality coffee, that donates a portion of its proceeds to charity. How likely is she to go to the local shop?

2. Sarah doesn't finish a meal she ordered at a restaurant, and doesn't intend to take the leftovers home with her. The waitress asks for her consent to give them to a homeless man who often comes by the restaurant. How likely is Sarah to say yes?

3. How likely is it that Sarah makes a habit of donating old clothes to goodwill instead of throwing them out?

4. How likely is it that Sarah makes a habit of always tipping $20 \%$ at restaurants?

5. How likely is it that Sarah makes a habit of always recycling?

6. How likely is it that Sarah always thanks the driver before getting off a bus or out of an uber?

7. How likely is that Sarah is always polite and gracious to people working in service (e.g., bartenders and waitstaff, salespeople, etc)?

8. Sarah's best friend Alicia's birthday is coming up soon. How likely is Sarah to put a ton of effort into planning a surprise party for Alicia?

9. Sarah reads in a newsletter that a local chapter of habitat for humanity was just founded, and they are looking for volunteers to help get things organized. How likely is Sarah to call them to sign up as a volunteer? 
10. Sarah and her group of friends are chatting about their upcoming plans for spring break, and one girl complains that she can't afford a plane ticket home. How likely is Sarah to pull her aside later and offer to loan her money for a plane ticket?

11. Sarah is on the phone with her mom, who complains to her that her cooking thermometer recently broke. How likely is Sarah to surprise her mom by shipping her a new one from Amazon?

12. Sarah recently read an article about how the owner of her favorite sandwich shop is racist and discriminates when hiring. How likely is Sarah to stop going there for lunch?

\section{Post-experimental survey}

Finally, subjects completed a post-experimental survey in which they (i) answered a simple analogy question and wrote three sentences about their activities and plans for their day (questions that were designed to test English comprehension), and then (ii) answered a set of demographic and survey questions. In particular, subjects reported their age, gender, level of education, income, and country of residence.

\subsection{Experiment 15}

\section{Design overview}

Experiment 15 employed a two-condition, between-subject design in which subjects were assigned one of the following conditions: neutral (in which the target was a neutral character) and standard victim (in which the target behaved identically, but was victimized by a perpetrator). We also randomized between-subjects whether the target character (and all other characters in the vignette) was male or female. Experiment 15 used our iPad vignette, in which the relevant transgression is the theft of an iPad.

\section{Vignette text}

In all conditions, the vignette began as follows: Sarah is a politically moderate college student. Last Wednesday, she and a few of her classmates were studying for a big upcoming exam in the common room of Sarah's dorm suite. At one point, one of Sarah's classmates, Gabrielle, asked to use Sarah's iPad to look something up. Later that day, Sarah relaxed by watching a TV show on her iPad, and then went out for the evening.

This was the entire vignette in the neutral condition. In the standard victim condition, the vignette continued: While Sarah was out, Gabrielle figured out how to enter her suite, and stole her iPad. When Sarah noticed that it was missing, she was very upset.

In the male version of the vignette, the names "Sarah" and "Gabrielle" were replaced with "Sam" and "Gordon" respectively.

\section{Measures}

Subjects then answered a series of questions about characters in the vignette, spread out across several pages. All questions were answered on 1-9 Likert scales (Anchors: 1 - Not at all, 2,3-A little bit, 4, 5-Moderately, 6, 7 - Quite a lot, 8, 9-Extremely). On all pages, the (identical) vignette was presented before the questions. The first presentation of the vignette was paired with the first set of questions. 
First key dependent measures. We began by measuring our first set of key dependent measures: a set of behavior predictions (four moral behaviors, two of which were pre-tested to be, and two of which were pre-tested not to be, less likely among upset actors).

Behavior predictions. Across the first two evaluation pages, subjects made a set of four predictions about the target's moral behavior. On the first page, subjects made two predictions about moral behaviors that were pre-tested not to be less likely among upset actors. On the second page, subjects made two predictions about moral behaviors that were pre-tested to be less likely among upset actors (on a second page page). We randomized the order of questions within pages.

The questions about moral behaviors that were pre-tested not to be less likely among upset actors asked subjects: "How likely is it that Sarah makes a habit of always recycling?" and "Sarah doesn't finish a meal she ordered at a restaurant, and doesn't intend to take the leftovers home with her. The waitress asks for her consent to give them to a homeless man who often comes by the restaurant. How likely is Sarah to say yes?".

The questions about moral behaviors that were pre-tested to be less likely among upset actors asked subjects: "Sarah is on the phone with her mom, who complains to her that her cooking thermometer recently broke. How likely is Sarah to surprise her mom by shipping her a new one from Amazon?" and "Sarah and her group of friends are chatting about their upcoming plans for spring break, and one girl complains that she can't afford a plane ticket home. How likely is Sarah to pull her aside later and offer to loan her money for a plane ticket?".

Other key dependent measure, and secondary dependent measure. Next, we collected our other key dependent measure (ratings of moral character), as well as our secondary dependent measure (ratings of the extent to which the target was upset). The order of these two pages was randomized between-subjects.

Moral character. On the page measuring moral character, subjects rated the target on two traits in random order. Subjects rated Sarah's morality ("How moral of a person is Sarah?") and trustworthiness ("How trustworthy of a person is Sarah?").

Upsetness. On the page measuring upsetness, subjects evaluated the extent to which the target was upset. Subjects answered two questions in random order: "To what extent do you think Sarah is currently feeling down about life, as if things aren't going her way?" and "How upset do you think Sarah is?".

\section{Post-experimental survey}

Finally, subjects completed a post-experimental survey in which they (i) answered a simple analogy question and wrote three sentences about their activities and plans for their day (questions that were designed to test English comprehension), and then (ii) answered a set of demographic and survey questions. In particular, subjects reported their age, gender, level of education, income, and country of residence.

\subsection{Experiment 16}

\section{Design overview}

Experiment 16 employed a two-condition, between-subject design in which subjects were assigned to one of the following conditions: positively-valanced control (in which the target was a neutral character, but was described as having positive nonmoral traits) and standard victim (in which the target was a neutral character, and was both described as having positive nonmoral 
traits and as being morally good). We also randomized between-subjects whether the target character (and all other characters in the vignette) was male or female. Experiment 16 drew from the neutral condition of our iPad vignette, but in no conditions involved any kind of transgression.

\section{Vignette text}

In the positively-valanced condition, the vignette began as follows: Sarah is a politically moderate college student. Her friends generally say that she is fun to be around, and has a good sense of humor.

In the direct morality condition, the vignette instead began: Sarah is a politically moderate college student. Her friends generally say that she is a moral and trustworthy person. They also say that she is fun to be around, and has a good sense of humor.

In both conditions, the vignette then continued: Last Wednesday, she and a few of her classmates were studying for a big upcoming exam in the common room of Sarah's dorm suite. At one point, one of Sarah's classmates, Gabrielle, asked to use Sarah's iPad to look something up. Later that day, Sarah relaxed by watching a TV show on her iPad, and then went out for the evening.

\section{Measures}

Subjects then answered a series of questions about characters in the vignette, spread out across several pages. All questions were answered on 1-9 Likert scales (Anchors: 1 - Not at all, 2, 3 - A little bit, 4, 5- Moderately, 6, 7 - Quite a lot, 8, 9 - Extremely). On all pages, the (identical) vignette was presented before the questions. The first presentation of the vignette was paired with the first set of questions.

Key dependent measures. We measured our key dependent measures: (i) ratings of moral character (morality and trustworthiness) as well as two nonmoral traits (intelligence and athleticism), and (ii) a set of behavior predictions (for four moral and four immoral behaviors).

Moral character and nonmoral traits. On the first evaluation page, subjects evaluated the target character, Sarah, on four traits in random order. Subjects rated Sarah's morality ("How moral of a person is Sarah?"), trustworthiness ("How trustworthy of a person is Sarah?"), intelligence ("How intelligent of a person is Sarah?"), and athleticism ("How athletic of a person is Sarah?").

Behavior predictions. Across the next two evaluation pages, subjects made a set of eight predictions about the target's moral behavior: four predictions about moral behavior (on one page) and four predictions about immoral behavior (on another page). The order of these pages was randomized between-subjects, as was the order of predictions within each page.

The questions about moral behavior asked subjects: "How likely do you think Sarah is to donate to charity?", "How likely do you think Sarah is to volunteer to tutor low-income middle school students for free?", "How likely do you think Sarah is to help a friend move to an offcampus apartment?", and "How likely do you think Sarah is to give leftover food to a homeless person?".

The questions about immoral behavior asked subjects: "How likely do you think Sarah is to flirt with others while in a committed relationship?", "How likely do you think Sarah is to intentionally 'forget' to pay a friend back?", "How likely do you think Sarah is to exclude or betray a friend in order to fit in with popular peers?", and "How likely do you think Sarah is to 
spread private or mean gossip about others?". The order of the questions was randomized between-subjects.

\section{Post-experimental survey}

Finally, subjects completed a post-experimental survey in which they (i) answered a simple analogy question and wrote three sentences about their activities and plans for their day (questions that were designed to test English comprehension), and then (ii) answered a set of demographic and survey questions. In particular, subjects reported their age, gender, level of education, income, and country of residence. 